\title{
Characterization and investigation of molybdenum carbides on activated carbon as hydrogenation catalysts
}

Christopher H. Clark

West Virginia University

Follow this and additional works at: https://researchrepository.wvu.edu/etd

\section{Recommended Citation}

Clark, Christopher H., "Characterization and investigation of molybdenum carbides on activated carbon as hydrogenation catalysts" (2005). Graduate Theses, Dissertations, and Problem Reports. 1659.

https://researchrepository.wvu.edu/etd/1659

This Thesis is protected by copyright and/or related rights. It has been brought to you by the The Research Repository @ WVU with permission from the rights-holder(s). You are free to use this Thesis in any way that is permitted by the copyright and related rights legislation that applies to your use. For other uses you must obtain permission from the rights-holder(s) directly, unless additional rights are indicated by a Creative Commons license in the record and/ or on the work itself. This Thesis has been accepted for inclusion in WVU Graduate Theses, Dissertations, and Problem Reports collection by an authorized administrator of The Research Repository @ WVU. For more information, please contact researchrepository@mail.wvu.edu. 
Characterization and Investigation of Molybdenum Carbides on Activated Carbon as Hydrogenation Catalysts

By

Christopher H. Clark

\begin{abstract}
A THESIS
Submitted to the College of Engineering and Mineral Resources at West Virginia University in partial fulfillment of the requirements for the degree of

\author{
Master of Science \\ in \\ Chemical Engineering
}

Edwin L. Kugler, Chair

Dady B. Dadyburjor

Joseph A. Shaeiwitz

Department of Chemical Engineering

Morgantown, West Virginia

2005

Keywords: molybdenum carbide, benzene hydrogenation, x-ray diffraction, temperature-programmed-reaction, carbon-monoxide chemisorption 


\title{
Abstract \\ Characterization and Investigation of Molybdenum Carbides on Activated Charcoal as a Hydrogenation Catalysts
}

\author{
Christopher H. Clark
}

The formation of $\mathrm{Mo}_{2} \mathrm{C}$ and $\mathrm{MoC}$ supported on activated carbon was investigated in three different flowing reaction gas environments: $\mathrm{H}_{2}, \mathrm{He}$, and $\mathrm{CO}$. Additionally, benzene hydrogenation activity was studied for the catalysts reduced in each of these three different gas environments.

It was found through in-situ x-ray diffraction (XRD) that reducing in $\mathrm{H}_{2}$, ammonium heptamolybdate impregnated on activated carbon yielded 1-3 $\mathrm{nm} \mathrm{Mo}_{2} \mathrm{C}$ particles. When the same material was calcinced in inert, $9 \mathrm{~nm} \mathrm{Mo}_{2} \mathrm{C}$ particles were formed. If the reduction gas were $\mathrm{CO}, \mathrm{MoC}$ particles having size less than $3 \mathrm{~nm}$ were formed. In all three reduction environments, the in-situ XRD revealed that $\mathrm{MoO}_{2}$ reduced to molybdenum carbide, without the appearance of $\mathrm{Mo}^{0}$. Data from temperature programmed reaction (TPR) spectra compared to the in-situ XRD patterns indicates that the carbon support is the source for carburization.

Only the catalyst reduced in $\mathrm{H}_{2}$ has significant activity for benzene hydrogenation. Furthermore, these $\mathrm{Mo}_{2} \mathrm{C}$-on-carbon catalysts have only a small range of reduction temperatures, $675-825^{\circ} \mathrm{C}$, for which they are active. Additionally, as soak time at reduction temperature increases, the catalyst's initial activity decreases. Activity seems to be correlated to the appearance of graphitic carbon in the XRD patterns of the spent catalyst. 
Dedicated to my grandfather, Paul Franklin 


\section{Acknowledgements}

To my advisors Dr. Edwin Kugler and Dr. Dady Dadyburjor I am extremely thankful for the help, knowledge, advice, solace, and praise they gave me in the good times and the bad. For all his help not only as the third member of my committee, but for his "sage-like" wisdom in all things involving chemical engineering I would like to thank Dr. Joseph Shaeiwitz.

I am grateful for ever helpful conversations and assistance by Dr. Tapan Das that would lead to experimental success and fundamental understanding of experimental systems. To the current members of the West Virginia University reactions engineering group, Dr. Wenping Ma, Huifang Shao, and James Wright, for all their help in both formulating ideas and running experiments. The financial support from US Department of Energy under cooperative agreement contract DE-FC26-99FT40540 with Consortium for Fossil Fuel Liquefaction Science is gratefully acknowledged and my personal financial support from the generous donations to WVU by George and Carolyn Berry.

I would like to thank Dr. Jonathan Hanson at Brookhaven National Laboratory in Upton, NY for all his help and advice with x-ray diffraction run at the National Synchrotron Light Source. Additionally, I would like to thank Todd Gardner at the National Energy and Technology Laboratory in Morgantown, WV for performing temperature programmed reaction coupled with mass spectroscopy on my samples.

I would like to thank Jim Hall, Bonita Helmick, and Linda Rogers for their patience in helping me with all the crucial non-academic issues that no graduate student can avoid. Finally, I would like to thank my fellow graduate students and the faculty for making the last two years at WVU productive and enjoyable. 


\title{
Table of Contents
}

\begin{abstract}
ii
Dedication iii

Acknowledgements iv

Table of Figures vi

Table of Tables viii

1. Introduction 1

2. Literature Review 2
\end{abstract}

2.1 Molybdenum Carbide Preparation Methods 2

2.2 Molybdenum Carbide as a Catalyst 6

2.3 Characterization Techniques 8

3. Materials and Methods 10

3.1 Catalyst Preparation 10

3.2 Benzene Hydrogenation Reaction Setup 11

3.3 Reduction and Calcination of Benzene Hydrogenation Catalysts 11

3.4 Benzene Hydrogenation Procedure 13

3.5 X-ray Diffraction (XRD) 13

3.6 Temperature Programmed Reaction (TPR) 15

3.7 CO Chemisorption 17

3.8 Safety 19

4. Results and Discussions 20

4.1 Benzene Hydrogenation 20

4.2 XRD of Spent Benzene Hydrogenation Catalysts 24

4.3 In-situ XRD 30

4.4 Temperature Programmed Reaction-Mass Spectrometry (TPR-MS) 39

4.5 CO Chemisorption 45

4.6 Active Site Determination 45

5. Conclusions 50

6. Recommendations 52

References 54

Appendix A: Mass Flow Controller Calibration 58

Appendix B: GC Separations 59

Appendix C: XRD Calibrations 60

Appendix D: Benzene Hydrogenation and CO Chemisorption Data and Calculations 61 Appendix E: XRD Analysis of Spent Benzene Hydrogenation Catalysts 67

Appendix F: Reaction Equilibrium Calculations 76 


\section{Table of Figures}

Figure 1: Plot of Equilibrium Conditions for Equation 1 and Equation 2. Plot constructed by Lee et al. (4)

Figure 2: Schematic of Powder Diffraction Measurment at NSLS Beamline X7B (figure provided by Jonathan Hanson at NSLS) 9

Figure 3: Flow diagram of catalyst test unit constructed for use in testing benzene hydrogenation activity

Figure 4: Labeled pictorial diagram of in-situ XRD flow cell (35) 14

Figure 5: Flow diagram of TPR-MS apparatus at the National Energy and Technology Laboratory in Morgantown, WV. 16

Figure 6: Flow diagram of chemisorption and TPR apparatus constructed in the West Virginia University reactions engineering laboratory

Figure 7: Effect of time on stream and final reduction temperature on the rate of disappearance of benzene for molybdenum-on-carbon Samples reduced in UHP $\mathrm{H}_{2}$ and held at final temperature for 15 minutes (for data comparison for commercial $5 \% \quad \mathrm{Pt} / \mathrm{Al}_{2} \mathrm{O}_{3}$ is also shown)

Figure 8: Effect of time on stream and final reduction temperature on the rate of disappearance of benzene for molybdenum-on-carbon Samples reduced in UHP $\mathrm{H}_{2}$ and held at final temperature for 15 minutes 22

Figure 9: Effect of time on stream and soak time at final reduction temperature $\left(825^{\circ} \mathrm{C}\right)$ on the rate of disappearance of benzene for molybdenum-on-carbon catalysts 23

Figure 10: XRD pattern of molybdenum-on-carbon catalyst tested for benzene hydrogenation, catalyst was reduced at $825^{\circ} \mathrm{C}$ and held at $825^{\circ} \mathrm{C}$ for 60 minutes

Figure 11: XRD pattern of molybdenum-on-carbon catalyst tested for benzene hydrogenation, catalyst was reduced at $825^{\circ} \mathrm{C}$ and held at $825^{\circ} \mathrm{C}$ for 15 minutes

Figure 12: Plot illustrating growth of graphite XRD peak at $26.2^{\circ} 2 \theta$ with increasing time at maximum reduction temperature $\left(825^{\circ} \mathrm{C}\right) \quad 28$

Figure 13: XRD Pattern of molybdenum-on-carbon catalyst tested for benzene hydrogenation, catalyst was reduced at $775^{\circ} \mathrm{C}$ and held at $775^{\circ} \mathrm{C}$ for 15 minutes 29

Figure 14: In-situ XRD scans of the reduction of $18 \% \mathrm{Mo} / \mathrm{C}$ to $825^{\circ}$ at $5^{\circ} \mathrm{C}$ per minute in $5 \% \mathrm{H}_{2}$ (balance $\mathrm{He}$ ). Each scan represents $25^{\circ} \mathrm{C}$ of heating 31

Figure 15: XRD Profile, with peak fitting, of final product of in-Situ reduction of $18 \% \mathrm{Mo} / \mathrm{C}$ in $5 \% \mathrm{H}_{2}$ (balance $\mathrm{He}$ )

Figure 16: In-situ XRD scans of the reduction of $24 \% \mathrm{Mo} / \mathrm{C}$ to $825^{\circ}$ at $5^{\circ} \mathrm{C}$ per minute in $\mathrm{He}$. Each scan represents $25^{\circ} \mathrm{C}$ of heating up to $825^{\circ} \mathrm{C}$ then held at $825^{\circ}$ for 30 minutes 34

Figure 17: XRD profile, with peak fitting, of final product of in-Situ calcination $24 \% \mathrm{Mo} / \mathrm{C}$ in $\mathrm{He}$

Figure 18: Plot of in-situ XRD scans of the reduction of $21 \% \mathrm{Mo} / \mathrm{C}$ to $825^{\circ}$ at $5^{\circ} \mathrm{C}$ per minute in $5 \% \mathrm{CO}$ (balance $\mathrm{He}$ ). Each scan represents $25^{\circ} \mathrm{C}$ of Heating 37

Figure 19: Profile, with peak fitting, of final product of in-Situ calcination $21 \% \mathrm{Mo} / \mathrm{C}$ in $5 \% \mathrm{CO}$ (balance $\mathrm{He}$ )

Figure 20: TPR-MS Spectra of Mo/C Reduced in $5 \% \mathrm{H}_{2}$ (balance Ar) from $25^{\circ} \mathrm{C}$ to $900^{\circ} \mathrm{C}$ at $10^{\circ} \mathrm{C}$ per minute 
Figure 21: TPR-MS Spectra of $\mathrm{Mo} / \mathrm{C}$ calcined in $\mathrm{Ar}$ from $25^{\circ} \mathrm{C}$ to $900^{\circ} \mathrm{C}$ at $10^{\circ} \mathrm{C}$ per minute, then held at $900^{\circ} \mathrm{C}$ for 130 minutes (plot of only 40 minutes of 130 -minute temperature soak at $900^{\circ} \mathrm{C}$ )

Figure 22: TPR-MS spectra of Mo/C calcined in $10 \% \mathrm{CO}$ (balance $\mathrm{Ar}$ ) from $25^{\circ} \mathrm{C}$ to $900^{\circ} \mathrm{C}$ at $10^{\circ} \mathrm{C}$ per minute, then held at $900^{\circ} \mathrm{C}$ for 130 minutes (plot of only 20 minutes of 130 -minute temperature soak at $900^{\circ} \mathrm{C}$ )

Figure 23: Pulse CO chemisorption over 0.1078g Pressure Chemical 5\% $\mathrm{Pt} / \mathrm{Al}_{2} \mathrm{O}_{3}$ reduced in $\mathrm{H}_{2}$ to $425^{\circ} \mathrm{C}$

Figure 24: Pulse CO chemisorption over $0.1074 \mathrm{~g}$ molybdenum-on-carbon calcined in flowing Ar to $615^{\circ} \mathrm{C}$

Figure 25: Pulse CO chemisorption over $0.1258 \mathrm{~g}$ molybdenum-on-carbon, prepared through reduction in flowing $\mathrm{UHP} \mathrm{H}_{2}$ to $825^{\circ} \mathrm{C}$ at $10^{\circ}$ per minute and held at $825^{\circ} \mathrm{C}$ for 15 minutes

Figure 26: Calibration of MFC for UHP $\mathrm{H}_{2}$ Flow

Figure 27: Calibration of MFC for $5 \% \mathrm{CO} /$ balance $\mathrm{He} \quad 58$

Figure 28: Chromatograph of $1 \mu \mathrm{L}$ injection of a $1 / 1$ mixture of benzene and cyclohexane, where the $\mathrm{GC}$ oven was kept isothermal at $120^{\circ} \mathrm{C}$ and data was collected for $5 \mathrm{~min}$. 59

Figure 29: Effect of time-on-stream on the rate of disappearance of benzene for $\mathrm{Mo} / \mathrm{C}$ catalysts with varying final reduction temperature with exponential curve fitting to find initial rate of benzene disappearance

Figure 30: Effect of time on stream on rate of disappearance of benzene for $\mathrm{Mo} / \mathrm{C}$ catalysts with varying soak time at final reduction temperature $\left(825^{\circ} \mathrm{C}\right)$ with exponential curve fitting to find in rate of benzene disappearance

Figure 31: XRD pattern of $\mathrm{Mo} / \mathrm{C}$ catalyst tested for benzene hydrogenation, catalyst was reduced at $675^{\circ} \mathrm{C}$ and held at $675^{\circ} \mathrm{C}$ for 15 minutes

Figure 32: XRD pattern of $\mathrm{Mo} / \mathrm{C}$ catalyst tested for benzene hydrogenation, catalyst was reduced at $725^{\circ} \mathrm{C}$ and held at $725^{\circ} \mathrm{C}$ for 15 minutes

Figure 33: XRD pattern of $\mathrm{Mo} / \mathrm{C}$ catalyst tested for benzene hydrogenation, catalyst was Reduced at $775^{\circ} \mathrm{C}$ and held at $775^{\circ} \mathrm{C}$ for 15 minutes

Figure 34: XRD pattern of $\mathrm{Mo} / \mathrm{C}$ catalyst tested for benzene hydrogenation, catalyst was reduced at $825^{\circ} \mathrm{C}$ and held at $825^{\circ} \mathrm{C}$ for 0 minutes

Figure 35: XRD pattern of $\mathrm{Mo} / \mathrm{C}$ catalyst tested for benzene hydrogenation, catalyst was reduced at $825^{\circ} \mathrm{C}$ and held at $825^{\circ} \mathrm{C}$ for 15 minutes

Figure 36: $\mathrm{XRD}$ pattern of $\mathrm{Mo} / \mathrm{C}$ catalyst tested for benzene hydrogenation, catalyst was reduced at $825^{\circ} \mathrm{C}$ and held at $825^{\circ} \mathrm{C}$ for 30 minutes

Figure 37: XRD pattern of $\mathrm{Mo} / \mathrm{C}$ catalyst tested for benzene hydrogenation, catalyst was reduced at $825^{\circ} \mathrm{C}$ and held at $825^{\circ} \mathrm{C}$ for 60 minutes

Figure 38: XRD Pattern of $\mathrm{Mo} / \mathrm{C}$ catalyst tested for benzene hydrogenation, catalyst was reduced at $875^{\circ} \mathrm{C}$ and held at $875^{\circ} \mathrm{C}$ for 15 minutes 


\section{Table of Tables}

Table 1: Surface Site Concentrations as Either Measured by CO Chemisorption or Benzene Hydrogenation

Table 2: Data Collected through the Analysis of a $\mathrm{LaBa}_{6}$ Standard to Calibrate Experimental Conditions for XRD data Collected at NSLS.

Table 3: Raw Gas Chromatograph Data for Benzene Hydrogenation tested on $\mathrm{Mo} / \mathrm{C}$ reduced in UHP $\mathrm{H}_{2}$ to $675^{\circ} \mathrm{C}$ at $10^{\circ} \mathrm{C} / \mathrm{min}$, then held at $675^{\circ} \mathrm{C}$ for 15 minutes

Table 4: Raw Gas Chromatograph Data for Benzene Hydrogenation tested on $\mathrm{Mo} / \mathrm{C}$ reduced in $\mathrm{UHP} \mathrm{H}_{2}$ to $725^{\circ} \mathrm{C}$ at $10^{\circ} \mathrm{C} / \mathrm{min}$, then held at $725^{\circ} \mathrm{C}$ for 15 minutes

Table 5: Raw Gas Chromatograph Data for Benzene Hydrogenation tested on $\mathrm{Mo} / \mathrm{C}$ reduced in $\mathrm{UHP} \mathrm{H}_{2}$ to $775^{\circ} \mathrm{C}$ at $10^{\circ} \mathrm{C} / \mathrm{min}$, then held at $775^{\circ} \mathrm{C}$ for 15 minutes

Table 6: Raw Gas Chromatograph Data for Benzene Hydrogenation tested on $\mathrm{Mo} / \mathrm{C}$ reduced in UHP $\mathrm{H}_{2}$ to $825^{\circ} \mathrm{C}$ at $10^{\circ} \mathrm{C} / \mathrm{min}$, then held at $825^{\circ} \mathrm{C}$ for 0 minutes

Table 7: Raw Gas Chromatograph Data for Benzene Hydrogenation tested on $\mathrm{Mo} / \mathrm{C}$ reduced in $\mathrm{UHP} \mathrm{H}_{2}$ to $825^{\circ} \mathrm{C}$ at $10^{\circ} \mathrm{C} / \mathrm{min}$, then held at $825^{\circ} \mathrm{C}$ for 15 minutes

Table 8: Raw Gas Chromatograph Data for Benzene Hydrogenation tested on $\mathrm{Mo} / \mathrm{C}$ reduced in UHP $\mathrm{H}_{2}$ to $825^{\circ} \mathrm{C}$ at $10^{\circ} \mathrm{C} / \mathrm{min}$, then held at $825^{\circ} \mathrm{C}$ for 30 minutes

Table 9: Raw Gas Chromatograph Data for Benzene Hydrogenation Data tested on Mo/C reduced in $\mathrm{UHP} \mathrm{H}_{2}$ to $825^{\circ} \mathrm{C}$ at $10^{\circ} \mathrm{C} / \mathrm{min}$, then held at $825^{\circ} \mathrm{C}$ for 60 minutes

Table 10: Raw Gas Chromatograph Data for Benzene Hydrogenation Data tested on Mo/C reduced in $\mathrm{UHP} \mathrm{H}_{2}$ to $875^{\circ} \mathrm{C}$ at $10^{\circ} \mathrm{C} / \mathrm{min}$, then held at $875^{\circ} \mathrm{C}$ for 15 minutes

Table 11: Raw Benzene Hydrogenation Data for $\mathrm{Pt} / \mathrm{Al}_{2} \mathrm{O}_{3}$ reduced in $\mathrm{UHP} \mathrm{H}_{2}$ to $425^{\circ} \mathrm{C}$ at $10^{\circ} \mathrm{C} / \mathrm{min}$, then held at $875^{\circ} \mathrm{C}$ for 0 minutes

Table 12: Gibbs' Energy of Formation and Reaction from Yaws' Handbook for $\mathrm{CO}$ and $\mathrm{CO}_{2}$ 


\section{Introduction}

In recent years, West Virginia University, along with many schools across the country and around the world, have sought to investigate the synthesis, characteristics, and potential reaction niches of molybdenum-based catalysts. One such reaction is the platinum-like behavior of molybdenum carbide for hydrogenation reactions (1). Due to its low cost, in comparison to platinum, molybdenum carbide is worthy of further investigation.

There are currently several proposed methods for preparing molybdenum carbides. The specific method of interest involves the reduction of ammonium heptamolybdate impregnated on activated carbon $(2,3)$. Using $\mathrm{H}_{2}$ as a reduction gas, this method has been shown to form small particles of $\mathrm{Mo}_{2} \mathrm{C}$ between $700-800^{\circ} \mathrm{C}$. Through Debye-Scherrer peak-broadening analysis of the $\mathrm{x}$-ray diffraction pattern, the $\mathrm{Mo}_{2} \mathrm{C}$ formed has been shown to have average particle sizes of 3 nm (2). Further studies done at the Université of Pierre et Marie Curie and West Virginia University show that larger-particle $\mathrm{Mo}_{2} \mathrm{C}$ can be formed between $750-850^{\circ} \mathrm{C}$ by using the same impregnation method for catalyst preparation, but the catalyst pretreatment environment is changed from $\mathrm{H}_{2}$ to $\mathrm{Ar}(2)$. Work done to date at West Virginia University has revealed that $\mathrm{MoC}$, a cubic crystal-structure form of molybdenum carbide referenced less often than $\mathrm{Mo}_{2} \mathrm{C}$, can also be formed. This MoC on activated carbon catalyst is prepared using the same impregnation method, but the pretreatment gas is changed to $\mathrm{CO}$ and the $\mathrm{MoC}$ is formed between $550-650^{\circ} \mathrm{C}$

It is the purpose of this research to characterize these molybdenum-on-carbon catalysts prepared under three different flowing gas environments: $\mathrm{H}_{2}$, inert, and $\mathrm{CO}$. Methods of characterization include $\mathrm{x}$-ray diffraction for identification of bulk phases, $\mathrm{CO}$ chemisorption for 
titration of the surface reaction sites, and kinetic studies of the benzene hydrogenation reaction to provide evidence of noble-metal-like activity.

\section{Literature Review}

\subsection{Molybdenum Carbide Preparation Methods}

Investigation of Group VI B transition metal carbides was pioneered by Boudart's group at Stanford University. This group proposed that these carbides could be made through the direct caburization and reduction of unsupported $\mathrm{MoO}_{3}$ by flowing a gas mix of $20 \% \mathrm{CH}_{4}\left(\right.$ balance $\mathrm{H}_{2}$ ) over the sample at high temperature (4). This reduction method yields hexagonal $\mathrm{Mo}_{2} \mathrm{C}$ at a temperature of approximately $700^{\circ} \mathrm{C}$. This reduction was first observed through a temperatureprogrammed reaction (TPR) in $20 \% \mathrm{CH}_{4}\left(\right.$ balance $\mathrm{H}_{2}$ ) performed from room temperature to $825^{\circ} \mathrm{C}$ at $60^{\circ} \mathrm{C}$ per hour (4). The Stanford group later reported that this process yields $\mathrm{Mo}_{2} \mathrm{C}$ particles of $11.5 \mathrm{~nm}$, as found from XRD peak broadening (5). In this work done at Stanford, there is much care taken to keep graphitic carbon from occluding the molybdenum carbide surface. Equation 1 is the mechanism for the carburization of $\mathrm{MoO}_{3}$ to $\mathrm{Mo}_{2} \mathrm{C}$, as proposed by Boudart's group (4). Equation 2 gives a possible side reaction thought to cause catalyst deactivation by graphitic carbon formation. Figure 1 shows the equilibrium relationship between Equation 1 and Equation 2 at atmospheric pressure as shown by Lee et al. (4). In Figure 1, curve (a) represents equilibrium data for Equation 1 and curve (b) represents equilibrium data for Equation 2. Where the $\mathrm{x}$-axis is temperature in $\mathrm{K}$ and the $\mathrm{y}$-axis is $\% \mathrm{CH}_{4}$ (balance $\left.\mathrm{H}_{2}\right)$. For carburization conditions on the left of curve (a) only Mo and $\mathrm{CH}_{4}$ should be observed. If temperature is increased, and carburization conditions move beyond curve (a), but below curve 
(b) only $\mathrm{Mo}_{2} \mathrm{C}$ and $\mathrm{CH}_{4}$ should be observed. Finally, if temperature is high, where carburization conditions are above line (b), $\mathrm{Mo}_{2} \mathrm{C}$ and graphite should be observed.

$\mathrm{CH}_{4} \Leftrightarrow \mathrm{C}($ graphite $)+2 \mathrm{H}_{2}$

$2 \mathrm{Mo}+\mathrm{CH}_{4} \Leftrightarrow 2 \mathrm{Mo}+\mathrm{Mo}_{2} \mathrm{C}+2 \mathrm{H}_{2}$

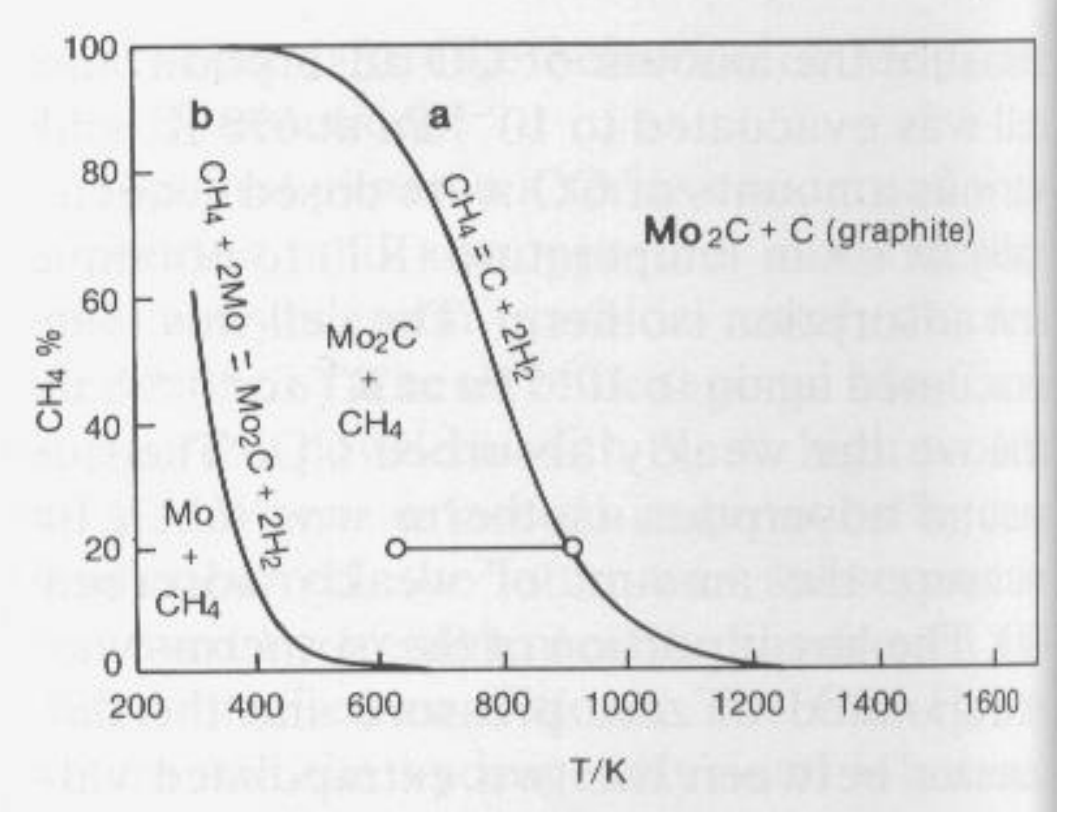

Figure 1: Plot of Equilibrium Conditions for Equation 1 and Equation 2. Plot constructed by Lee et al. (4)

From Figure 1, it was reported that the optimum balance between molybdenum carbide formation from $\mathrm{Mo}^{0}$ and prevention of graphite formation on the $\mathrm{Mo}_{2} \mathrm{C}$ occurred at a $20 \% \mathrm{CH}_{4}$ (balance $\mathrm{H}_{2}$ ). Conditions were chosen for carburization to stay in the phase regime of $\mathrm{Mo}_{2} \mathrm{C}$ and $\mathrm{CH}_{4}$.

Other methods of molybdenum carbide formation proposed by the Stanford Group include the preparation of cubic $\mathrm{MoC}$ through doping $\mathrm{MoO}_{3}$ with a low concentration of Pt and performing the same TPR in $20 \% \mathrm{CH}_{4}$ (balance $\mathrm{H}_{2}$ ) (5). This method formed MoC at 
approximately $700^{\circ} \mathrm{C}$. The particles formed in this method are very small, $3.4 \mathrm{~nm}$ as measured by x-ray line broadening.

Yet another method proposed by the Stanford Group for forming cubic MoC, is first to form $\mathrm{Mo}_{2} \mathrm{~N}$ with flowing $20 \% \mathrm{NH}_{3}$ (balance $\mathrm{H}_{2}$ ) up to $700^{\circ} \mathrm{C}$. After initially forming $\mathrm{Mo}_{2} \mathrm{~N}$, one can form MoC using TPR in $20 \% \mathrm{CH}_{4}$ (balance $\mathrm{H}_{2}$ ). This method forms $\mathrm{MoC}$ at approximately $700^{\circ} \mathrm{C}(5)$. As these particles are $6 \mathrm{~nm}$, as measured by $\mathrm{x}$-ray line broadening, it is postulated that small $\mathrm{MoC}$ particles are formed from small $\mathrm{Mo}_{2} \mathrm{~N}$ precursors (5).

Similar TPR methods with $20 \% \mathrm{CH}_{4}$ (balance $\mathrm{H}_{2}$ ) have been used to form $\mathrm{Al}_{2} \mathrm{O}_{3}$ supported $\mathrm{Mo}_{2} \mathrm{C}$ (6). This involves first impregnating $\gamma-\mathrm{Al}_{2} \mathrm{O}_{3}$ with ammonium heptamolybdate (AHM), then calcining in air at $500^{\circ} \mathrm{C}$ for $5 \mathrm{~h}$. The catalyst is then carburized using TPR in $20 \%$ $\mathrm{CH}_{4} /$ balance $\mathrm{H}_{2}$ up to $900^{\circ} \mathrm{C}$. This method yields $7.8 \mathrm{~nm} \mathrm{Mo}_{2} \mathrm{C}$ particles, as measured by $\mathrm{x}$-ray line broadening. These supported $\mathrm{Mo}_{2} \mathrm{C}$ nanoparticles are formed at approximately $700^{\circ} \mathrm{C}(6)$.

More recently, another method of $\mathrm{Mo}_{2} \mathrm{C}$ preparation was discovered by a group at Université of Pierre et Marie Curie(2). This method does not utilize methane or $\mathrm{MoO}_{3}$. Instead the $\mathrm{Mo}_{2} \mathrm{C}$ is prepared by impregnating activated carbon with AHM and then heating the sample to $700^{\circ} \mathrm{C}$ in flowing $\mathrm{H}_{2}(2,3)$. In yet unpublished work, $\mathrm{x}$-ray diffraction peak broadening predicts that the $\mathrm{Mo}_{2} \mathrm{C}$ particles formed by the West Virginia University group are $3 \mathrm{~nm}$ in size. Furthermore, larger particles of $\mathrm{Mo}_{2} \mathrm{C}$ can be formed by simply pretreating the molybdenum impregnated carbon catalyst in flowing inert gas.

Mordent et al. propose the following mechanism for the reduction of $\mathrm{MoO}_{2}$ on activated carbon to $\mathrm{Mo}_{2} \mathrm{C}$ in inert gas (2):

$$
\begin{aligned}
& \mathrm{H}_{2} \mathrm{O}+\mathrm{C}_{n} \Leftrightarrow \mathrm{CO}+\mathrm{H}_{2}+\mathrm{C}_{n-1} \\
& \mathrm{CO}+\mathrm{H}_{2} \mathrm{O} \Leftrightarrow \mathrm{CO}_{2}+\mathrm{H}_{2}
\end{aligned}
$$


$\mathrm{C}+\mathrm{CO}_{2} \Leftrightarrow 2 \mathrm{CO}$

$\mathrm{C}+2 \mathrm{H}_{2} \Leftrightarrow \mathrm{CH}_{4}$

$\mathrm{CO}+3 \mathrm{H}_{2} \Leftrightarrow \mathrm{CH}_{4}+\mathrm{H}_{2} \mathrm{O}$

$2 \mathrm{MoO}_{2}+\mathrm{CH}_{4}+\mathrm{H}_{2} \Leftrightarrow \mathrm{Mo}_{2} \mathrm{C}+4 \mathrm{H}_{2} \mathrm{O}$

It is proposed that water is present in the carbon support material reacts with carbon to form carbon monoxide. The water then reacts with carbon monoxide, in Equation 4, to produce the hydrogen needed for reduction. Methane can then be formed by the hydrogenation of carbon (Equation 6) or the hydrogenation of CO (Equation 7). Finally, the methane and hydrogen react with the molybdenum dioxide (Equation 8) to form $\mathrm{Mo}_{2} \mathrm{C}$. The reaction in Equation 8 is similar to that proposed for unsupported $\mathrm{MoO}_{3}$ particles (4).

The reaction scheme proposed by Mordenti et al. (Paris Group), Equations 3-8, is significantly different than that proposed by the Stanford Group. The Paris Group's mechanism has $\mathrm{Mo}_{2} \mathrm{C}$ formed from $\mathrm{MoO}_{2}$. However, the Stanford Group has $\mathrm{Mo}_{2} \mathrm{C}$ formed from $\mathrm{Mo}^{0}$.

A recent unpublished investigation by the West Virginia University group has revealed that cubic MoC can be formed by a new synthesis method. MoC is formed through the reduction of a molybdenum-on-carbon catalyst in 5\% CO (balance inert). The molybdenum -on-carbon precursor material is prepared by impregnating AHM on activated carbon. Preliminary estimates of particle size by x-ray peak broadening have shown that these particles are $3 \mathrm{~nm}$ or less (7).

The review of the literature shows that the study of molybdenum carbide catalysts has focused on unsupported $\mathrm{Mo}_{2} \mathrm{C}$ having particle sizes ranging from 3.4-to-11.5 $\mathrm{nm}(5,6)$. It is then interesting that the carbon-supported molybdenum-carbide catalysts of West Virginia University have a smaller particle size, 1-3 nm size evident by scanning tunneling micrographs, on a support that can offer high pore volume and surface area. 


\subsection{Molybdenum Carbide as a Catalyst}

Boudart's group at Stanford concluded that molybdenum carbide behaved in many ways like a Group VIII metal (1), but noted that the activity of the catalyst was limited by the surface area (4). They advocated that a synthesis method should be developed that yields high-surfacearea carbides (4).

Since this initial investigation, a myriad of reactions have been tested for activity over molybdenum carbide. The most prominent reactions reported in the literature are: FischerTropsch synthesis (1), alkene hydrogenation (7-10), aromatic hydrogenation (6,11-14), hydrodenitrogenation (15-19), hydrodesulfurization (8,20-21), hydrocarbon reforming (22-26), isomerization (27-28), aromatization (29-31), and ammonia synthesis (32). To insure only pertinent background is provided, only Fischer-Tropsch synthesis, alkene and aromatic hydrogenation, hydrodenitrogenation, and hydrodesulfurzation will be surveyed.

Like most noble metals, molybdenum carbides have been shown to be active hydrogenation catalysts (1). As mentioned previously, this was initially studied on CO hydrogenation reactions, generally termed Fischer-Tropsch synthesis (1). Lee et al. (6) report that molybdenum and tungsten carbides have better initial activities for this reaction than ruthenium-on- $\mathrm{Al}_{2} \mathrm{O}_{3}$. However, all molybdenum carbide catalysts tested for hydrocarbon and aromatic hydrogenations deactivated very quickly $(6,9,11-13)$. Unsupported $\mathrm{Mo}_{2} \mathrm{C}$ catalysts, prepared by the $\mathrm{CH}_{4} / \mathrm{H}_{2}$ TPR method, are active for aromatic hydrogenation and can be regenerated $(9,12)$. Further, the degree of carburization has a significant effect on activity (13). The effect of degree-of-carburization on aromatic hydrogenation was performed by varying $\mathrm{CH}_{4} / \mathrm{H}_{2}$ ratio and temperature (13). This study showed, that for the unsupported $\mathrm{Mo}_{2} \mathrm{C}$, there is an optimum temperature and $\mathrm{CH}_{4} / \mathrm{H}_{2}$ ratio that leads to the highest aromatic hydrogenation 
activity and density of $\mathrm{CO}$ chemisorption sites (13). Unsupported and $\mathrm{Al}_{2} \mathrm{O}_{3}$-supported $\mathrm{Mo}_{2} \mathrm{C}$ catalysts were comparable to an $\mathrm{Al}_{2} \mathrm{O}_{3}$-supported $\mathrm{Ru}$ catalyst for benzene hydrogenating activity at room temperature $(6,13)$. Other research groups have studied molybdenum carbide activity for alkene hydrogenation. One such group at Université Henri Poincaré concluded that $\mathrm{Mo}_{2} \mathrm{C}$ was very active for propene hydrogenation and could be regenerated with no significant change in activity (6).

Another reaction that $\mathrm{Mo}_{2} \mathrm{C}$ has been reported to catalyze is the hydrodenitrogenation of nitrogen containing aromatics, such as indole and quinoline (15-16). Schlatter et al. report that unsupported $\mathrm{Mo}_{2} \mathrm{C}$, prepared by the method proposed by the Stanford group, uses less $\mathrm{H}_{2}$ than the commercial Ni-Mo/ $\mathrm{Al}_{2} \mathrm{O}_{3}(15)$. Additionally, the unsupported $\mathrm{Mo}_{2} \mathrm{C}$ catalyst retains its activity longer in the presence of sulfur. Although this is a promising result, on an equal mass of metal basis, the unsupported $\mathrm{Mo}_{2} \mathrm{C}$ is about half as active as the commercial $\mathrm{Ni}-\mathrm{Mo} / \mathrm{Al}_{2} \mathrm{O}_{3}$ catalyst at the desired selectivity of propylbenzene to propylcyclohexane, the two major products of the quinoline hydrodenitrogenation (15).

MoC has been tested with limited success for the hydrodesulfurization of thiophene. It was determined (through differences in chemisorbed $\mathrm{CO}$ concentration before and after the reaction) that the surface was being sulfided, even though XRD shows the bulk is unchanged. Although the reaction rate is high in the initial hours of the reaction, once the catalyst surface is sulfided, the reactivity is comparable to $\mathrm{Mo} / \mathrm{Al}_{2} \mathrm{O}_{3}(21)$.

The reactions cited above give a wealth of information about reaction conditions and catalytic behavior. The literature proposes that molybdenum carbides are excellent hydrogenation catalysts, with activity comparable to supported Group VIII metals. Further studies on hydrodenitrogenation and hydrodesulfurization reactions show that molybdenum 
carbide is marginally susceptible to sulfide poisoning. Review of the literature further suggests that few studies have been performed on carbon-supported molybdenum carbide catalysts.

\subsection{Characterization Techniques}

For this study, four different catalyst characterization techniques were used. The goal of this study was to characterize the catalyst bulk, to characterize the catalyst surface, and correlate the two characterizations to catalytic performance for benzene hydrogenation. The characterization techniques proposed are: temperature programmed reaction (TPR), CO chemisorption, $\mathrm{H}_{2}$ chemisorption, and XRD. Basic theory and usage will be provided for each. Powder x-ray diffraction seeks to probe the major crystalline phases in the bulk of a material, in this case the catalyst. X-ray diffraction is the uniform interaction of $\mathrm{x}$-rays with crystalline materials. Strong X-ray diffraction is observed when the x-ray wavelength approaches the interatomic distances in a molecule (33). When this material is a single crystal, the diffraction has less secondary diffraction, leading to little or no interference. This gives a noiseless diffraction of spots on an x-ray image plate. The more amorphous a material is, the more interference there is in the diffraction.

A powder diffraction pattern is normally a plot of the scanning angle $2 \theta$ on the ordinate vs. intensity on the abscissa. When analyzed using theoretical calculations for simple crystalline material and measured values for more complex crystal structures, one can match the peaks and determine the major crystalline components of the bulk phase (33). One example of a powder diffraction apparatus used for in-situ experiments at the National Synchrotron Light Source (NSLS) is given in Figure 2. 


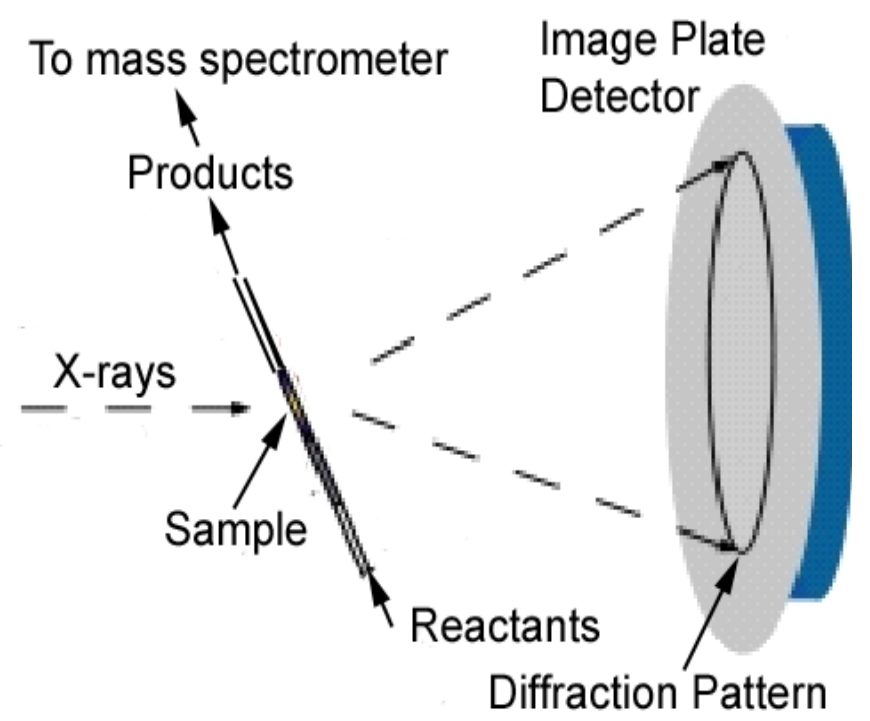

\section{Figure 2: Schematic of Powder Diffraction Measurment at NSLS Beamline X7B (figure provided by Jonathan Hanson at NSLS)}

In Figure 2, the sample is in a single-crystal sapphire tube. The synchrotron x-rays then bombard the sample and are scattered to the image-plate detector. Since sapphire is a single crystal, it diffracts x-rays as spots through Bragg diffraction while the powder diffracts as rings. The spots are subtracted as background and the rings averaged and analyzed (34). The setup, shown in Figure 2, allows the use high temperature, high pressure, and gas flow in experimentation, making it useful for in-situ material science and catalysis studies (35).

Temperature-programmed reaction (TPR) is the heating of a material at a specific rate in an environment with a reactant gas, usually $\mathrm{CO}, \mathrm{CH}_{4}$, or $\mathrm{H}_{2}$, to observe when the reactant gas is consumed. The temperature at which a reducing agent is consumed usually corresponds to a reduction in oxidation state in a metal. Through proper use of this method, multiple reduction steps can be characterized. TPR is an excellent starting point when exploring the proper preparation method for a test system or a preliminary probe into oxidation state transitions (2-4). It should be noted that analysis of simple systems is fairly easy, as metallic oxide reduction temperatures are prominent in catalysis and metallurgy literature, but more complex systems 
require either a TPR apparatus attached to a mass spectrometer or a way of modeling the underlying peak structure $(2,3)$.

The characterization methods discussed thus far can be used to characterize the bulk of the material. However, catalyzed reactions occur on the surface or in the pores of the catalyst. The proposed method of characterizing the surface seeks to measure the amount of a chemisorbing species, either $\mathrm{CO}$ or $\mathrm{H}_{2}$, taken up by the catalyst.

In the pulse chemisorption method, an activated catalyst sample is placed in inert flow at a fixed temperature. Usually, the exit gas is analyzed by a gas chromatograph or mass spectrometer and set as a background. Then, a known-volume pulse of absorbing gas is injected into the flow system and allowed to adsorb on the catalyst. This pulse procedure is repeated until the measured pulse-peak areas become constant. This occurs when surface sites are saturated. The amount of adsorbate gas taken up by the catalyst is calculated as the difference between the measured peak areas and the peak areas expected if no gas is adsorbed (36).

\section{Materials and Methods}

\subsection{Catalyst Preparation}

Samples were prepared by first impregnating activated carbon (from Sigma-Aldrich) with a $0.100 \mathrm{~g} / \mathrm{L}$ aqueous solution of ammonium heptamolybdate (Sigma-Aldrich, P.A. grade), followed by drying in air at $100^{\circ} \mathrm{C}$. Multiple impregnations were used in achieving the desired loading (37). All temperature-programmed-reaction studies and benzene hydrogenation studies were performed on catalyst having an approximate Mo metal loading of 13\%. In-situ XRD studies were carried out on molybdenum-on-carbon samples in which the AHM was 
predecomposed in $\mathrm{N}_{2}$ at $500^{\circ} \mathrm{C}$. The Mo loadings for the catalysts used for in-situ XRD were between $18 \%$ and $24 \%$ (37). This high metal loading allowed for clearer XRD patterns.

\subsection{Benzene Hydrogenation Reaction Setup}

A simple gas-phase, down-flow tubular reactor was constructed in which to carry out low-temperature benzene hydrogenation experiments. Figure 3 is a flow diagram of the constructed unit. The reaction was carried out in an 11.5" long stainless-steel tube with an outside diameter of $1 / 4$ ". A quartz wool plug was placed 7" down the reactor and the catalyst bed was directly above. An Omega 1/16" type K thermocouple, placed at the top of the catalyst bed, was used for temperature control. The reactor bed was heated by an Applied Test Systems clamshell-style tube furnace controlled by an 8 segment Yokogawa 351A temperature controller. Gas flow through the reactor was controlled using three Brooks 5890 mass flow controllers (MFC). The MFC used to control $\mathrm{H}_{2}$ flow was calibrated for $0-50 \mathrm{sccm}$ of He flow. This controller was tested and a correction factor applied for ultra high purity (UHP) $\mathrm{H}_{2}$. The MFC's used for He and $10 \% \mathrm{CO}$ (balance He) were calibrated for 0-100 sccm of He. These controllers were also calibrated and a correction factor applied. The calibrations for these controllers can be found in Appendix A.

\subsection{Reduction and Calcination of Benzene Hydrogenation Catalysts}

Molybdenum-on-carbon samples were reduced in the reactor where the sample was not exposed to air between reduction and benzene hydrogenation. During either reduction or inertgas calcination, gas flow was $34 \mathrm{sccm}$, as measured by a "bubble" type flow meter and a stop watch. The catalyst sample was purged for approximately 5 minutes with the gas flow prior to 


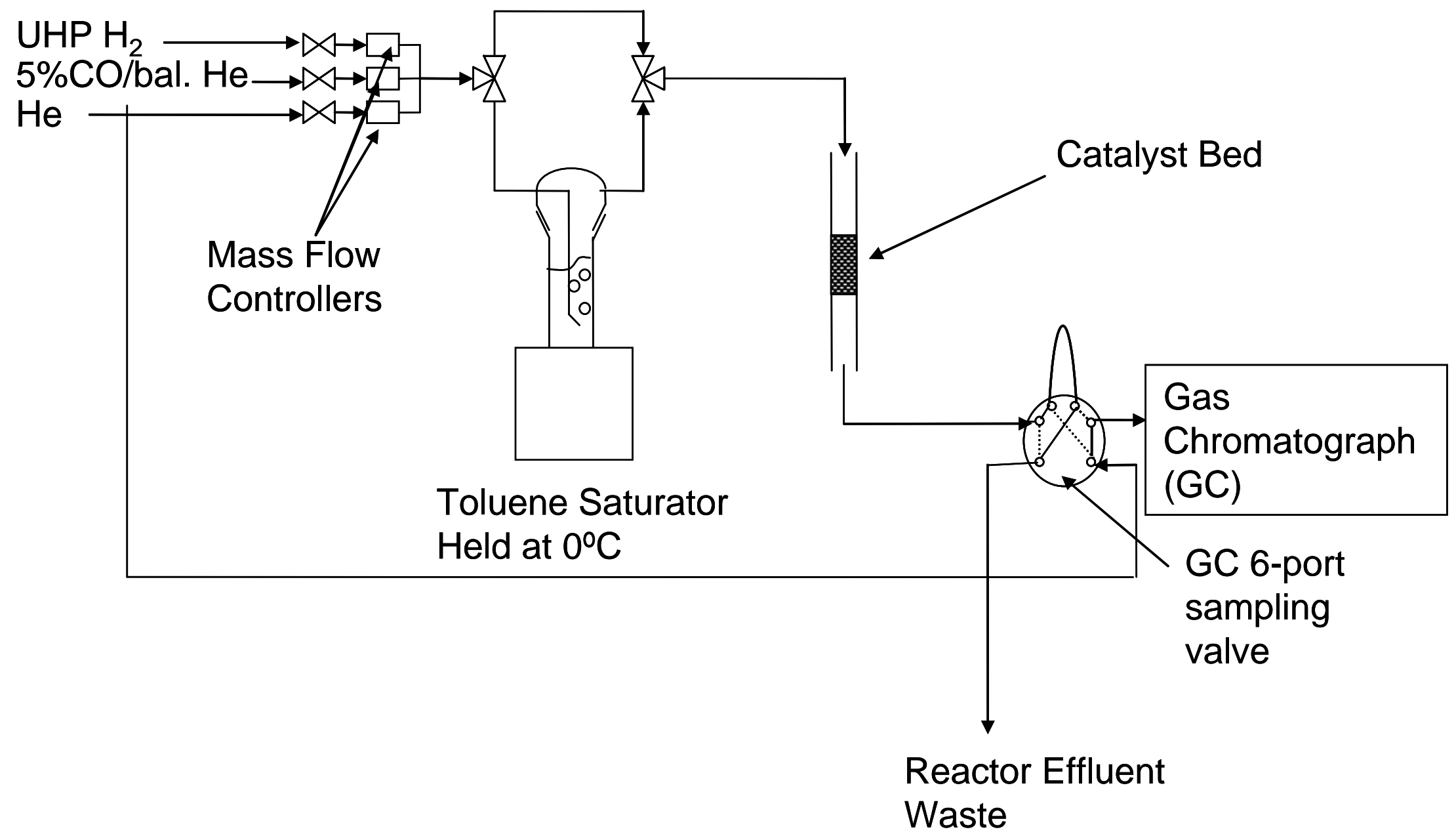

Figure 3: Flow diagram of catalyst test unit constructed for use in testing benzene hydrogenation activity 
heating. The sample was then heated to desired reduction temperature, always at $10^{\circ} \mathrm{C}$ per minute.

\subsection{Benzene Hydrogenation Procedure}

Sigma-Aldrich (99.9\%) benzene was introduced into the system using a $25 \mathrm{~mL}$ glass saturator, hand blown by Sherman Adams in the WVU chemistry department, and held at $1^{\circ} \mathrm{C}$. This saturator allowed the reaction gas to bubble through the liquid benzene. The saturator was connected to the system through the use of $1 / 4$ " Cajon compression fittings with viton o-rings to prevent gas leaks. The saturator was purged for no less than $36 \mathrm{~h}$ with $\mathrm{UHP} \mathrm{H}_{2}$ before a series of reaction studies. This long purge was an attempt to remove all dissolved air from the benzene. During benzene hydrogenation reactions, the saturator was kept at $1^{\circ} \mathrm{C}$.

The effluent gas was sampled using a Valco six-port valve and a Valco 2-mL sample loop. The sample was analyzed by the thermal conductivity detector (TCD) of a Hewlett Packard 5890 Series II gas chromatograph. A 6’ 35\% BC-150 on 100/120 Chromosorb P AW 1/8" stainless steel packed column was used to separate the analytes (cyclohexane and benzene); this column is designed for aromatic analysis of gasoline. The results of a test separation of cyclohexane and benzene are provided in Appendix B. The GC oven was kept isothermal at $120^{\circ} \mathrm{C}$ with a typical analysis time being 5 minutes.

For all benzene hydrogenation tests, benzene conversions were kept below $12 \%$, in most cases below $5 \%$, to use the differential reactor model for calculating reaction rate.

\subsection{X-ray Diffraction (XRD)}

Time resolved (in-situ) x-ray diffraction and powder x-ray diffraction of molybdenumon-carbon samples were carried out at beamline X7B at the National Synchrotron Light Source 


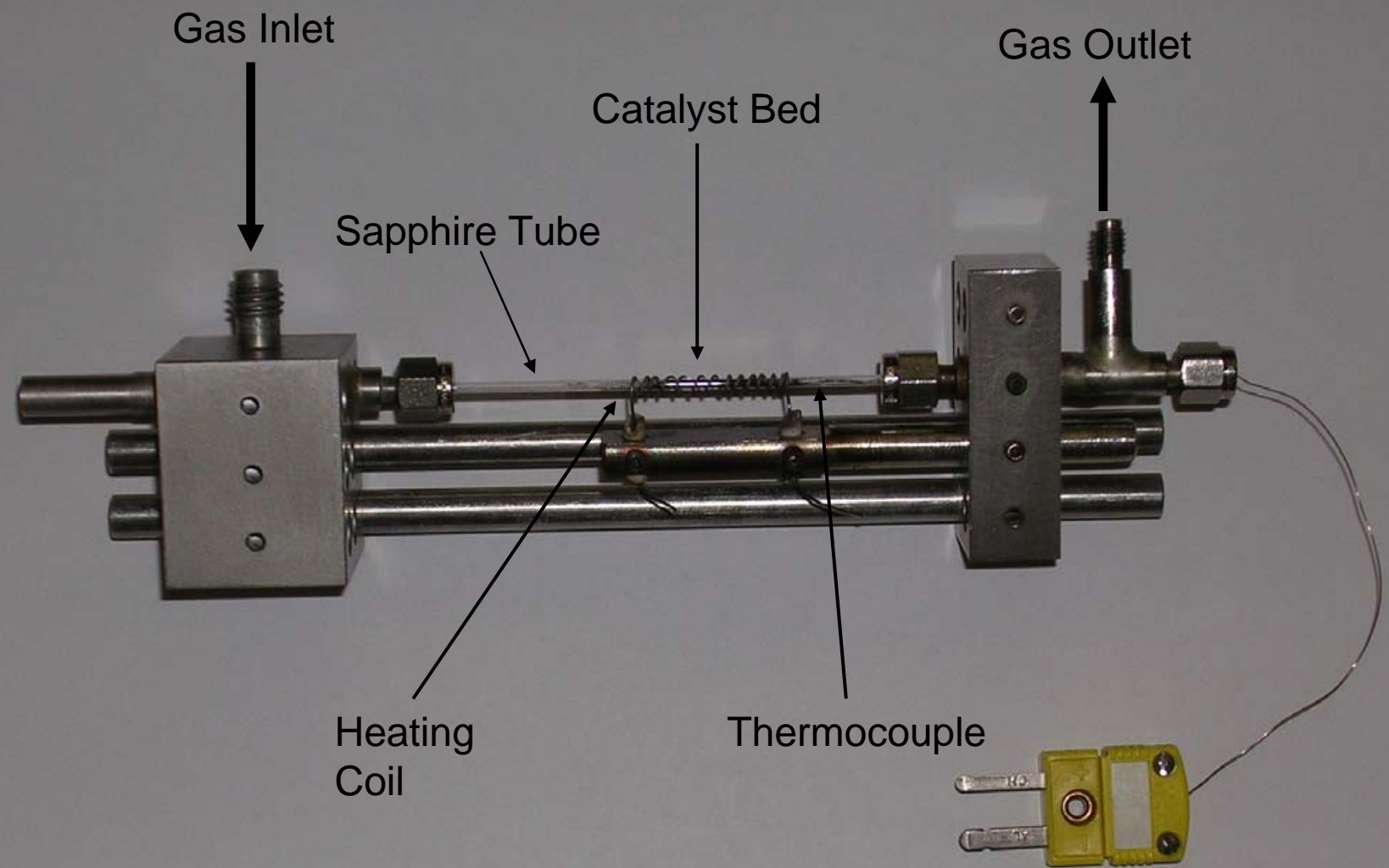

Figure 4: Labeled pictorial diagram of in-situ XRD flow cell (35) 
(NSLS) at Brookhaven National Laboratory (BNL) in Upton, NY. Simultaneous temperatureprogrammed reaction and XRD were carried out in a fixed-bed-sapphire-tube micro-reactor shown in Figure 4 (35). The micro-reactor was designed and machined by the catalysis group at BNL.

Temperature control for the apparatus was provided using an un-insulated 24 AWG Kanthal wire coiled around the sample, functioning as a simple resistance heater. A small loop is placed in the wire to prevent the Kanthal wire from interfering with x-ray diffraction. Gas flow through the sapphire tube was kept at approximately $20 \mathrm{~mL}$ per minute for all in-situ XRD runs. The synchrotron x-rays used had an approximate wavelength of 0.92 angstroms. The distance from the sample to the image plate detector varies, but was calibrated each visit using a $\mathrm{LaB}_{6}$ standard (34). All x-ray calibration data is provided in Appendix C.

Spent catalyst samples, used in benzene hydrogenation experiments, were run in $0.5 \mathrm{~mm}$ quartz micro-capillaries using beamline X7B with an image plate detector. Spent catalysts were run ex-situ, with no flowing gas, or heating element.

\subsection{Temperature Programmed Reaction (TPR)}

Temperature programmed reaction (TPR) was carried out in a Micromeretics AutoChem 2920 with the effluent gas analyzed by a ThermoONIX Prima dB scanning sector mass spectrometer. This apparatus was set up and is operated by the catalyst characterization group at the National Energy Technology Laboratory (NETL) in Morgantown, WV. A block flow diagram of the experimental setup is shown in Figure 5. These experiments were carried out using $150 \mathrm{mg}$ of catalyst under $50 \mathrm{sccm}$ of flowing $\mathrm{H}_{2} / \mathrm{Ar}(5 / 95), \mathrm{CO} / \mathrm{He}(10 / 90)$, and $\mathrm{Ar}$ (Linde UHP 99.999\%). 


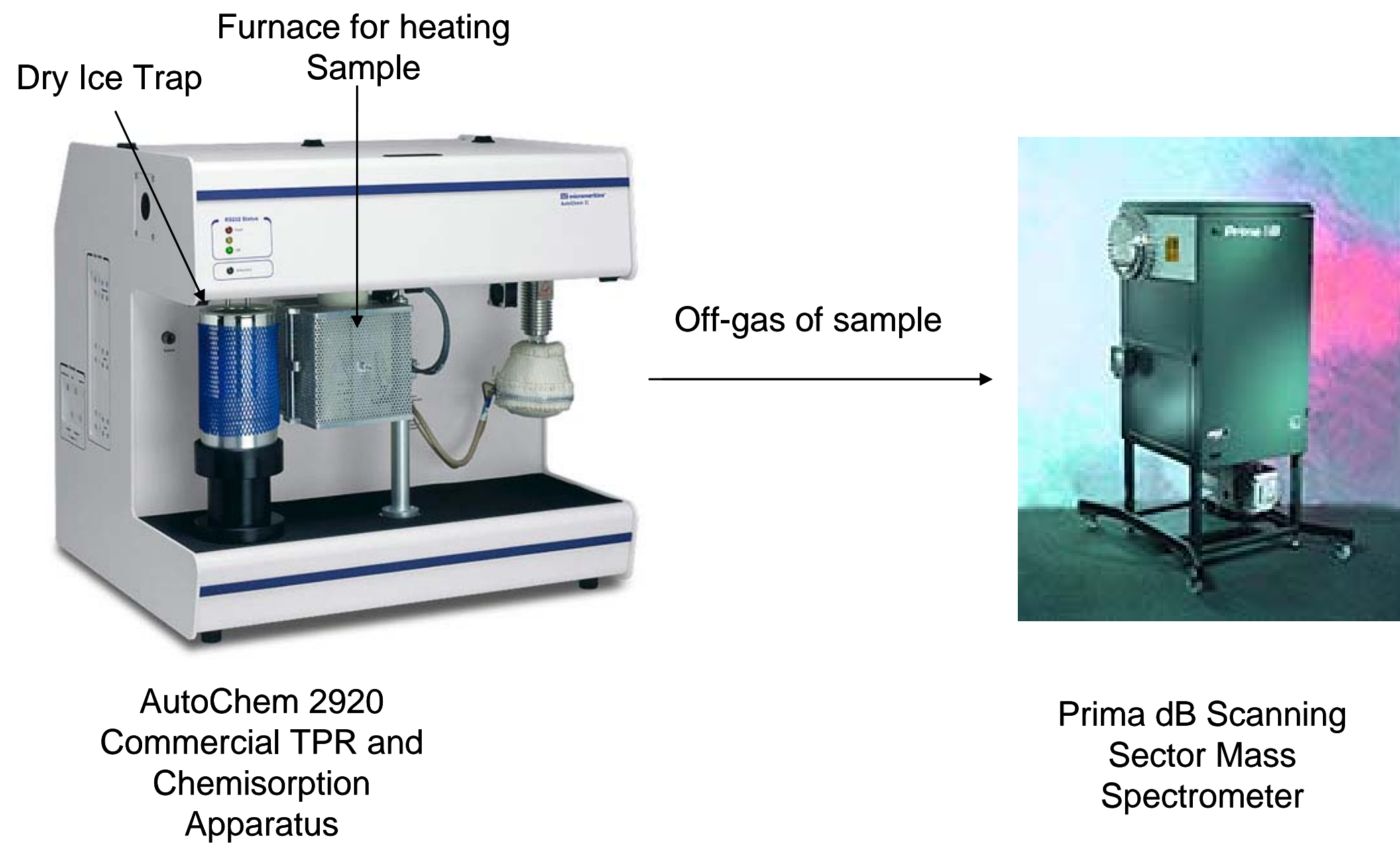

Figure 5: Flow diagram of TPR-MS apparatus at the National Energy and Technology Laboratory in Morgantown, WV. 


\subsection{CO Chemisorption}

Measurements of chemisorbed $\mathrm{CO}$ were made on both commercial $\mathrm{Pt} / \mathrm{Al}_{2} \mathrm{O}_{3}$ catalyst (manufactured by Pressure Chemical) and molybdenum-on-carbon catalysts. CO chemisorption was performed on a unit constructed "in-house" for use in TPR experiments (3). A flow diagram of the apparatus is provided in Figure 6. During the operation of the apparatus shown in Figure 6, reduction gas flows first through the reference of the TCD of a Hewlett Packard 5890 Series II gas chromatograph (GC), then through the sample. Upon exit of the reference of the GC, but prior to the sample, the gas flows through a six-port dosing valve. Through the use of this valve, known volumes of a gas ( $\mathrm{such}$ as $\mathrm{CO}$ or $\mathrm{H}_{2}$ ) can be used to titrate the catalyst sample. The sample off-gas is then measured by GC.

Before chemisoption measurement, the samples are first reduced in approximately 30 ccm of flowing reduction gas, either $5 \% \mathrm{H}_{2}$ (balance Ar), $\mathrm{UHP} \mathrm{H}_{2}$, or $10 \% \mathrm{CO}$ (balance Ar). The samples are then cooled in $\operatorname{Ar}$ flow $(30 \mathrm{ccm})$ to $100^{\circ} \mathrm{C}$. Once cooled, pulses of $250 \mu \mathrm{L}$ of either $5 \% \mathrm{H}_{2}$ (balance Ar) or 10\% CO (balance Ar) are dosed over the sample. The dosing is performed using a Valco six-port valve and a Valco $250 \mu \mathrm{L}$ loop. The sample is dosed with $\mathrm{CO}$ or $\mathrm{H}_{2}$ until the gas concentration eluted from the sample was constant. Constant gas concentration is determined by monitoring the eluted peaks using a GC-TCD. Once the eluted peak area is found to be constant the sample is said to be saturated and dosing is terminated (36). 


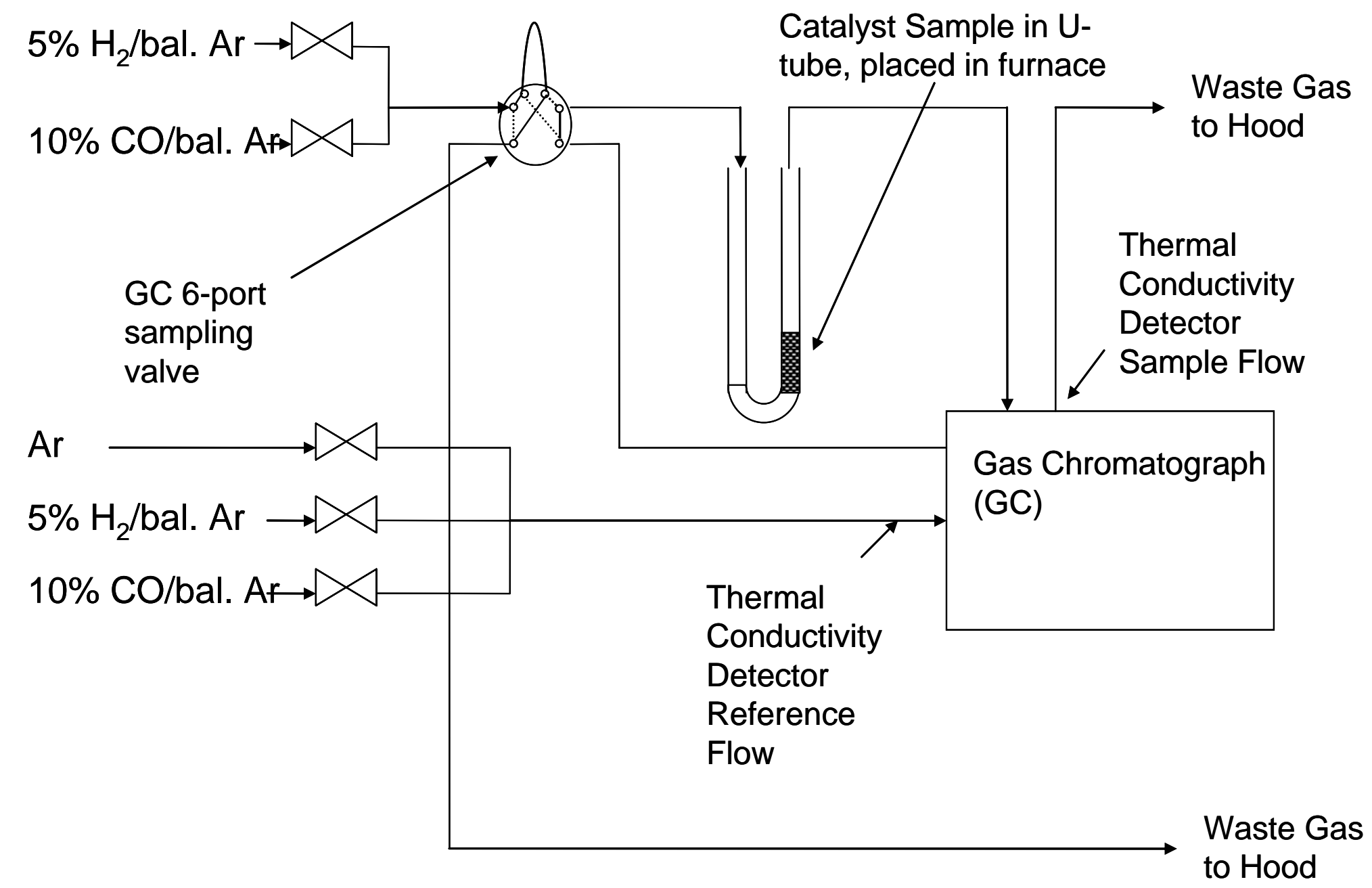

Figure 6: Flow diagram of chemisorption and TPR apparatus constructed in the West Virginia University reactions engineering laboratory 


\subsection{Safety}

The chemicals used in these experiments are ammonium heptamolybdate, activated carbon, benzene, acetone, $5 \% \mathrm{H}_{2}$ gas (balance inert), $5 \% \mathrm{CO}$ gas (balance inert), $10 \% \mathrm{CO}$ gas (balance inert), UHP $\mathrm{H}_{2}$, UHP He, UHP Ar, and cryogenic solid $\mathrm{CO}_{2}$. The MSDS for ammonium heptamolybdate state that exposure to the skin should be avoided and ingestion prohibited. For activated carbon, skin exposure and ingestion of large quantities should be avoided. Benzene safety precautions include a warning against skin contact and a prohibition of ingestion or inhalation. Benzene is a flammable liquid so that it should keep away from open flames and other ignition sources. Great care must be taken to prevent inhalation, ingestion, or skin exposure as benzene is a suspected carcinogen. Acetone safety precautions include a warning against skin contact and a prohibition of ingestion, but go on to include flammability precautions that state one should keep it away from open flames and other ignition sources. All of the gases pose certain inhalation hazards, but the CO permissible exposure limit (PEL) is 50 ppm (39). Electronic monitoring is present near the work area to warn of exposure. $\mathrm{He}, \mathrm{Ar}, \mathrm{CO}_{2}$ and $5 \% \mathrm{H}_{2}$ (balance inert) are asphyxiators so that they pose a danger if they displace air from the lab. Hoods eliminate inert-gas hazard by bringing fresh air into the lab. UHP $\mathrm{H}_{2}$ is flammable, but 5\% CO (balance inert), $10 \% \mathrm{CO}$ (balance inert), and 5\% $\mathrm{H}_{2}$ (balance inert) are not flammable. The gas cylinders, $5 \% \mathrm{H}_{2}$ (balance $\mathrm{Ar}$ ), $5 \% \mathrm{CO}$ (balance $\mathrm{He}$ ), $10 \% \mathrm{CO}$ (balance Ar), UHP $\mathrm{H}_{2}$, UHP He, and UHP Ar, are secured to the walls by chains and connected with stainless steel tube. Periodic checks for leaks are made. Additionally, the reactor outlet after gas sampling is plumbed directly to the hood to prevent any gas or vapor inhalation. For solid cryogenic $\mathrm{CO}_{2}$, proper attire is worn, cryogenic gloves, goggles, and a lab coat, and a Dewar flask was used for cryogenic transport. 


\section{Results and Discussions}

\subsection{Benzene Hydrogenation}

Benzene hydrogenation was carried out in the reactor shown in Figure 3 and described in Section 3.2. Reduction and benzene hydrogenation were carried out by methods described in Section 3.3 and Section 3.4. All molybdenum-on-carbon catalysts were approximately $13 \mathrm{wt} . \%$ molybdenum (metal basis), in the form of AHM, on the activated carbon support.

Figure 7 is a plot of the rate of disappearance of benzene for all catalysts prepared in a UHP $\mathrm{H}_{2}$ reduction environment with a soak time of 15 minutes. The rate of disappearance of benzene is defined by the design equation for a differential reactor, Equation 9 (40).

$$
-r_{\text {benzene }}=\frac{F_{\text {Benzzen } 0} X_{\text {benzene }}}{W}
$$

Where, $-r_{\text {benzene }}$ is the rate of consumption of benzene, $F_{\text {benzene } 0} 0$ is the inlet molar flow of benzene, $X_{\text {benzene }}$ is benzene conversion based on gas chromatography, and $W$ is the weight of catalyst used in the experiment. Detailed calculations of $-r_{\text {benzene }}$ are given in Appendix D.

The major notable feature of Figure 7 is that all molybdenum-on-carbon catalysts, reduced in $\mathrm{UHP} \mathrm{H}_{2}$, have rates of reaction one order-of-magnitude less than that of the commercial 5\% $\mathrm{Pt} / \mathrm{Al}_{2} \mathrm{O}_{3}$. When looking at Figure 8, where the commercial $\mathrm{Pt} / \mathrm{Al}_{2} \mathrm{O}_{3}$ catalyst is not displayed, it is clearly seen that reduction temperature is a key variable in catalyst preparation. However, there is an optimum reduction temperature, $825^{\circ} \mathrm{C}$, above which the molybdenum-on-carbon catalysts are less active. The effect of changing soak time at the optimum reduction temperature, $825^{\circ} \mathrm{C}$, is shown in Figure 9. As soak time increases the catalyst activity decreases. Once the soak time reaches $1 \mathrm{~h}$, benzene hydrogenation is not observed. 


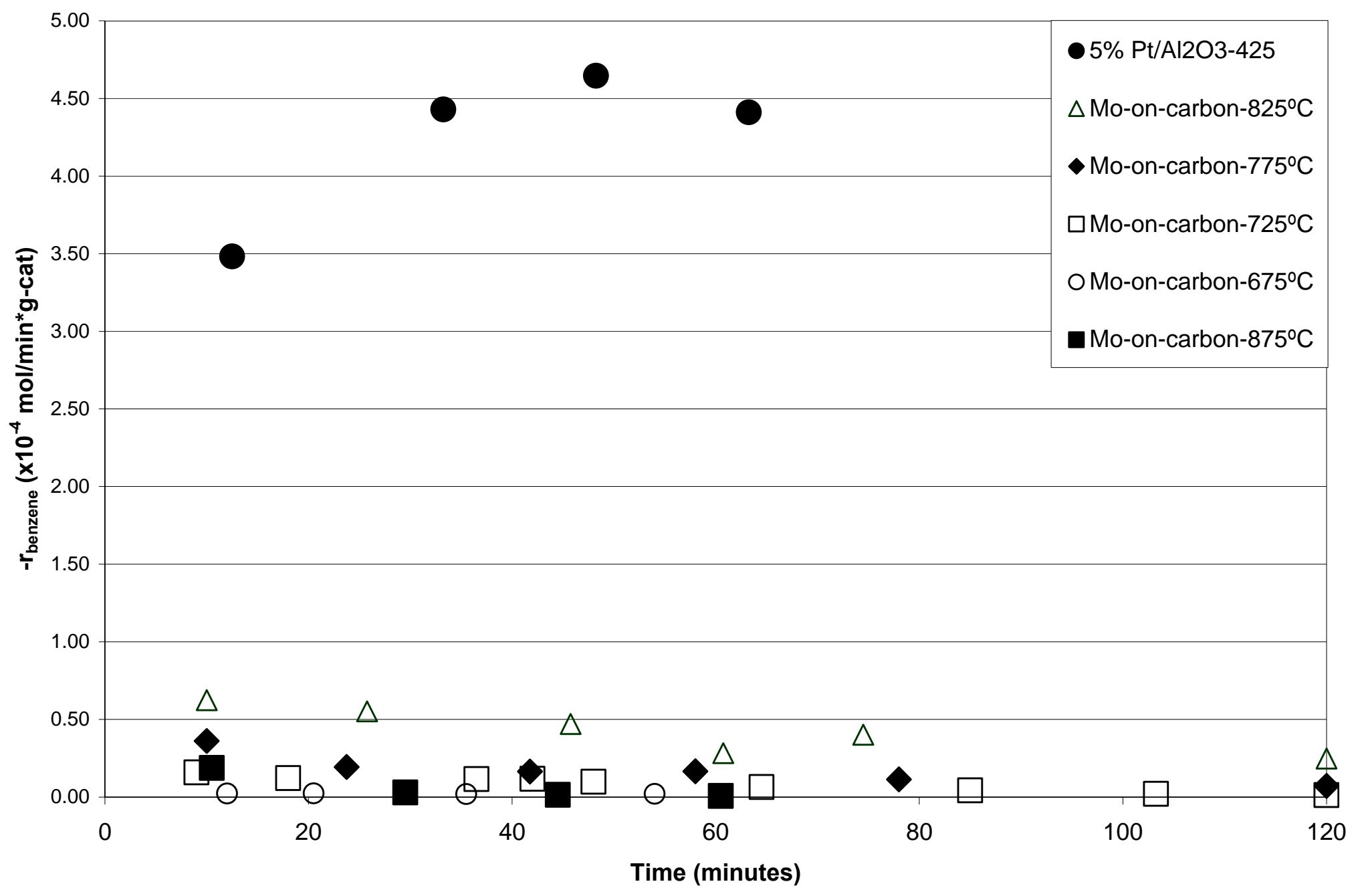

Figure 7: Effect of time on stream and final reduction temperature on the rate of disappearance of benzene for molybdenumon-carbon Samples reduced in UHP $\mathrm{H}_{2}$ and held at final temperature for 15 minutes (for data comparison for commercial $5 \%$ $\mathrm{Pt} / \mathrm{Al}_{2} \mathrm{O}_{3}$ is also shown) 


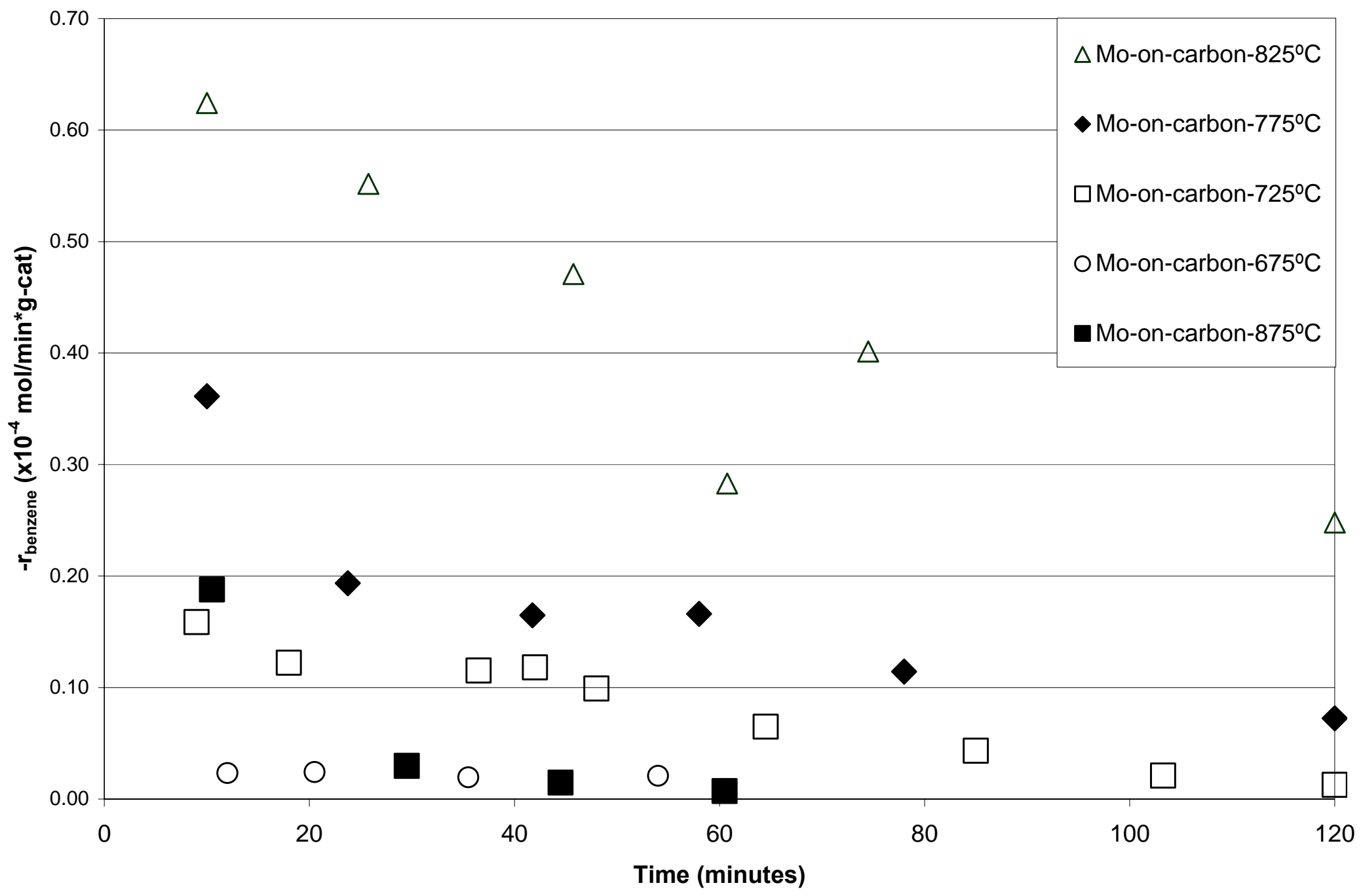

Figure 8: Effect of time on stream and final reduction temperature on the rate of disappearance of benzene for molybdenumon-carbon Samples reduced in UHP $\mathrm{H}_{2}$ and held at final temperature for 15 minutes 


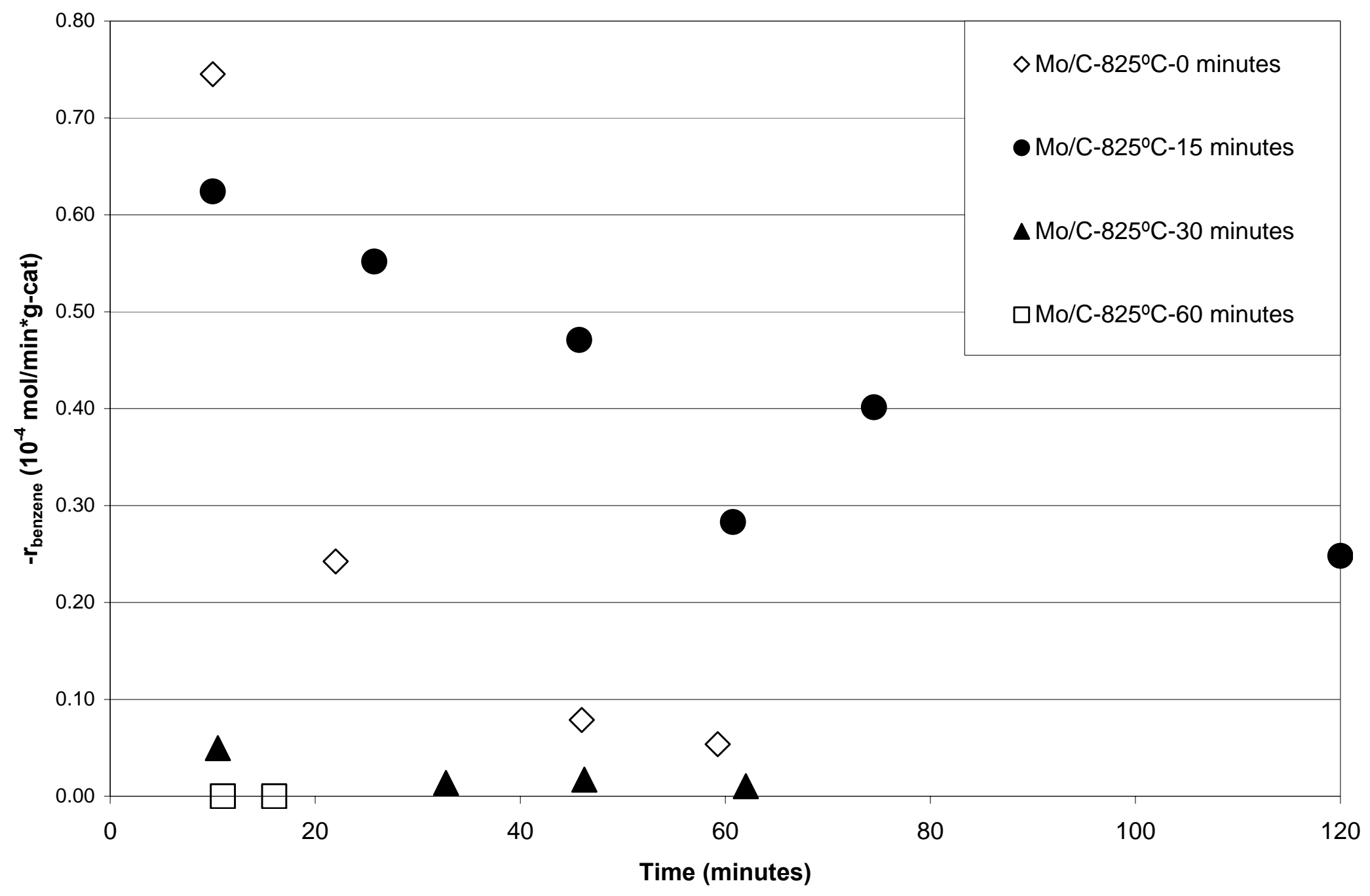

Figure 9: Effect of time on stream and soak time at final reduction temperature $\left(825^{\circ} \mathrm{C}\right)$ on the rate of disappearance of benzene for molybdenum-on-carbon catalysts 
All catalysts in Figures 7,8, and 9 deactivated quickly. This is consistent with findings in the literature for $\mathrm{Al}_{2} \mathrm{O}_{3}$ supported and unsupported $\mathrm{Mo}_{2} \mathrm{C}(6,11-13)$. This deactivation is most likely due to residual air dissolved in the benzene (12). This air is undetectable to the GC-TCD as its concentration is below the sensitivity limits of the detector. This oxygen is expected to passivate the surface with unreactive $\mathrm{MoO}_{2}$ (4).

No benzene hydrogenation activity was observed for molybdenum-on-carbon catalysts calcined in $\mathrm{He}$ (presumed $\mathrm{Mo}_{2} \mathrm{C}$ ) or reduced in $\mathrm{CO}$ (presumed $\mathrm{MoC}$ ). Calcination possibly leads to uncontrollable build-up of surface carbon. This phenomenon will be discussed further in Section 4.4. Additionally, if CO reduction is used for preparation, chemisorbed CO could block reaction sites (12).

\subsection{XRD of Spent Benzene Hydrogenation Catalysts}

Post-run XRD was performed for the catalysts reduced in $\mathrm{UHP}_{2}$ and subsequently tested for benzene hydrogenation. This analysis was revealing as to the nature of the benzene hydrogenation deactivation as either reduction temperature or soak time at temperature increased.

Figure 10 shows the analysis of XRD performed on a spent-catalyst reduced at $825^{\circ} \mathrm{C}$ and held at $825^{\circ} \mathrm{C}$ for $1 \mathrm{~h}$, and then tested for benzene hydrogenation activity. XRD was performed at beamline X7B at the National Synchrotron Light Source at Brookhaven National Laboratory, by methods described in Section 3.5. Clear lines for $\mathrm{Mo}_{2} \mathrm{C}$ are found between $2 \theta$ values of $20^{\circ}$ and $28^{\circ}$. Strong lines for $\mathrm{SiO}_{2}$ impurities appear at $2 \theta$ values of $12^{\circ}$ and $16^{\circ}$. Additionally, a weak line for graphite appears at a $2 \theta$ value of $26^{\circ}$. Although this assignment for graphite seems difficult, the peak at $26^{\circ} 2 \theta$ could not be assigned to any other structure with Mo, $\mathrm{Si}, \mathrm{O}$, or $\mathrm{C}$ through use of the International Center for Diffraction Database and the XRD 


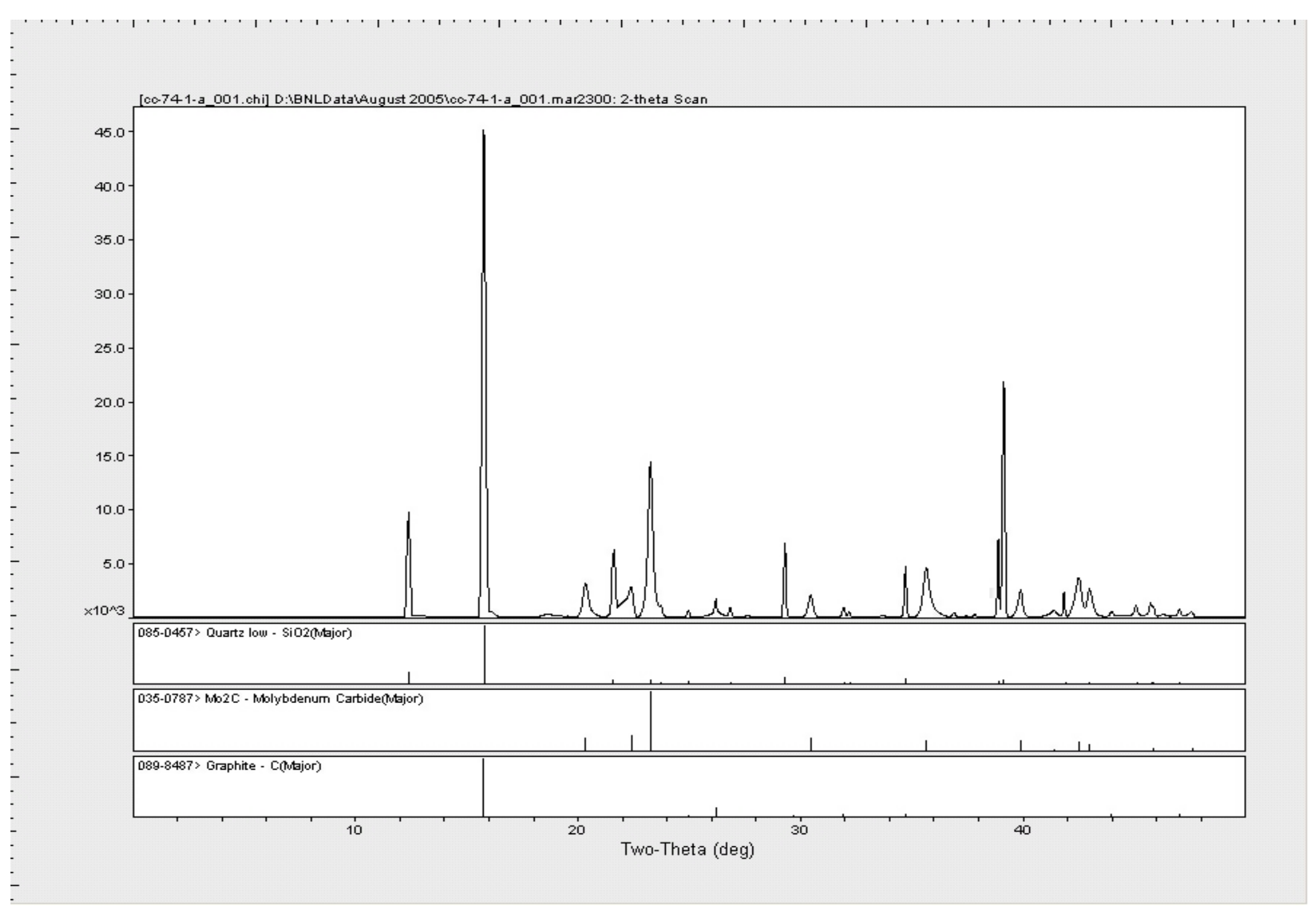

Figure 10: XRD pattern of molybdenum-on-carbon catalyst tested for benzene hydrogenation, catalyst was reduced at $825^{\circ} \mathrm{C}$ and held at $825^{\circ} \mathrm{C}$ for 60 minutes 
analysis software JADE. Since no other significant impurities have been seen in XRD or elemental analysis, it is believed this assignment is correct. The small intensity of the peak is most likely due to the weak scattering of carbon due to its small molecular weight (33). Of the catalysts tested, this one had the most intense peaks for graphite and for $\mathrm{Mo}_{2} \mathrm{C}$, but had no catalytic activity for benzene hydrogenation.

Figure 11 shows the analysis of XRD performed on a catalyst reduced at $825^{\circ} \mathrm{C}$ for 15 minutes. Clear, strong lines are found for $\mathrm{Mo}_{2} \mathrm{C}$ between a $2 \theta$ value of $20^{\circ}$ and $28^{\circ}$. Lines for the $\mathrm{SiO}_{2}$ impurities appear at $2 \theta$ values of $12^{\circ}$ and $16^{\circ} 2 \theta$. Interestingly, there is only an extremely weak, arguably non-existent, peak for graphite at a $2 \theta$ value of $26^{\circ}$. Unlike the catalyst in Figure 10 which has strong lines for $\mathrm{Mo}_{2} \mathrm{C}$ and much more intense lines for graphite, but was inactive for benzene hydrogenation, the catalyst in Figure 11 is the most stable and the second-most active for benzene hydrogenation.

Figure 12 shows the growth of the graphite peak at a $2 \theta$ value of $26.2^{\circ}$ with soak time at $825^{\circ} \mathrm{C}$ in $\mathrm{UHP}_{2}$. Clearly the longer the molybdenum-on-carbon sample stays at high temperature the more prevalent this XRD line for crystalline graphite is. It is theorized that this crystalline graphite is occluding the $\mathrm{Mo}_{2} \mathrm{C}$ surface preventing reaction. This is similar to graphitization proposed by the Stanford Group on unsupported $\mathrm{Mo}_{2} \mathrm{C}$ (4).

Figure 13 shows the analysis of XRD performed on a catalyst reduced at $775^{\circ} \mathrm{C}$ for 15 minutes. Again, XRD on this sample was performed at beamline X7B at the National Synchrotron Light source at Brookhaven National Laboratory using methods described in section 3.2. When looking at this, sample lines for the $\mathrm{SiO}_{2}$ impurities are the only distinguishable lines that appear. The non-existence of $\mathrm{Mo}_{2} \mathrm{C}$ lines is strange due to the significant benzene hydrogenation activity observed on this sample. 


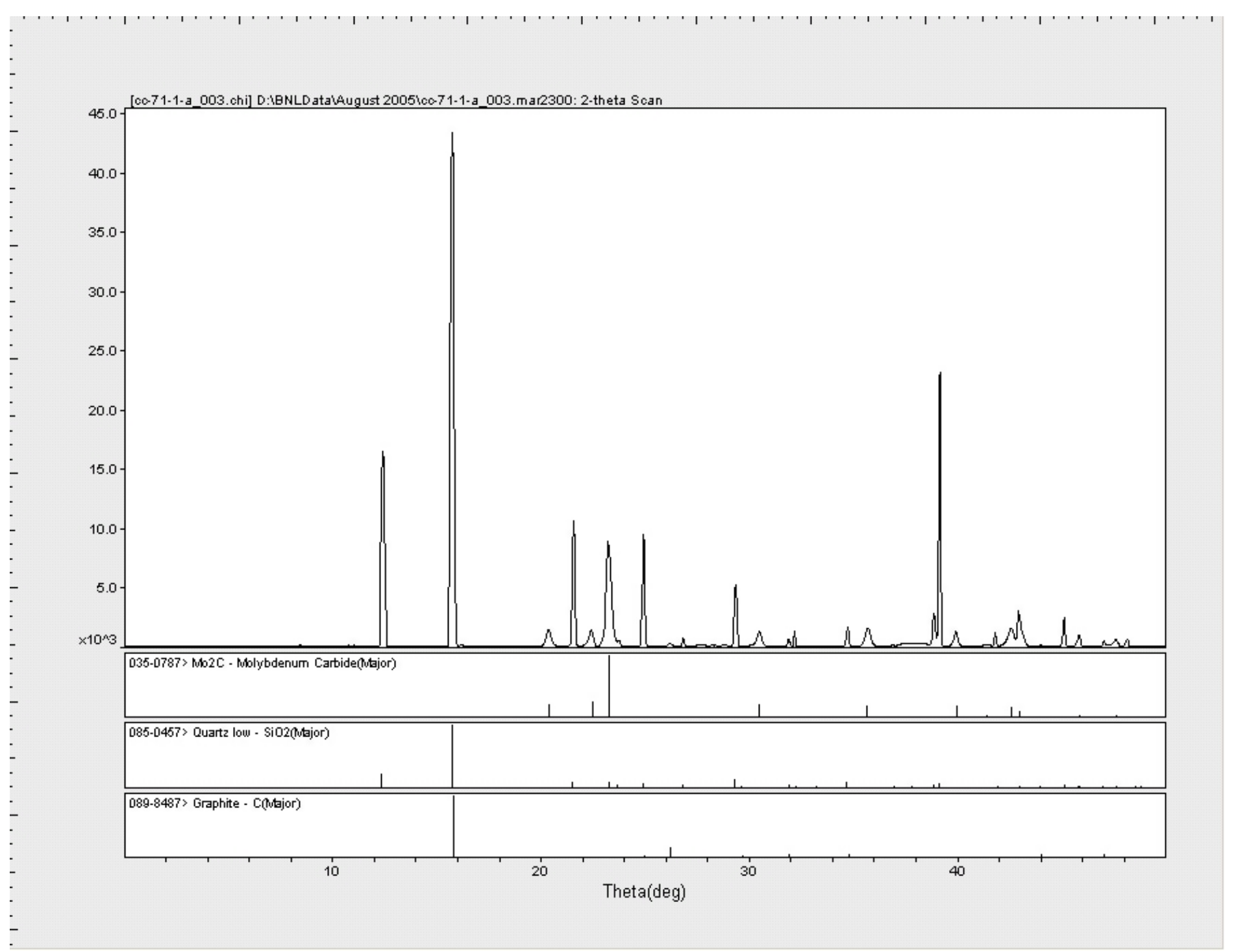

Figure 11: XRD pattern of molybdenum-on-carbon catalyst tested for benzene hydrogenation, catalyst was reduced at $825^{\circ} \mathrm{C}$ and held at $825^{\circ} \mathrm{C}$ for 15 minutes 


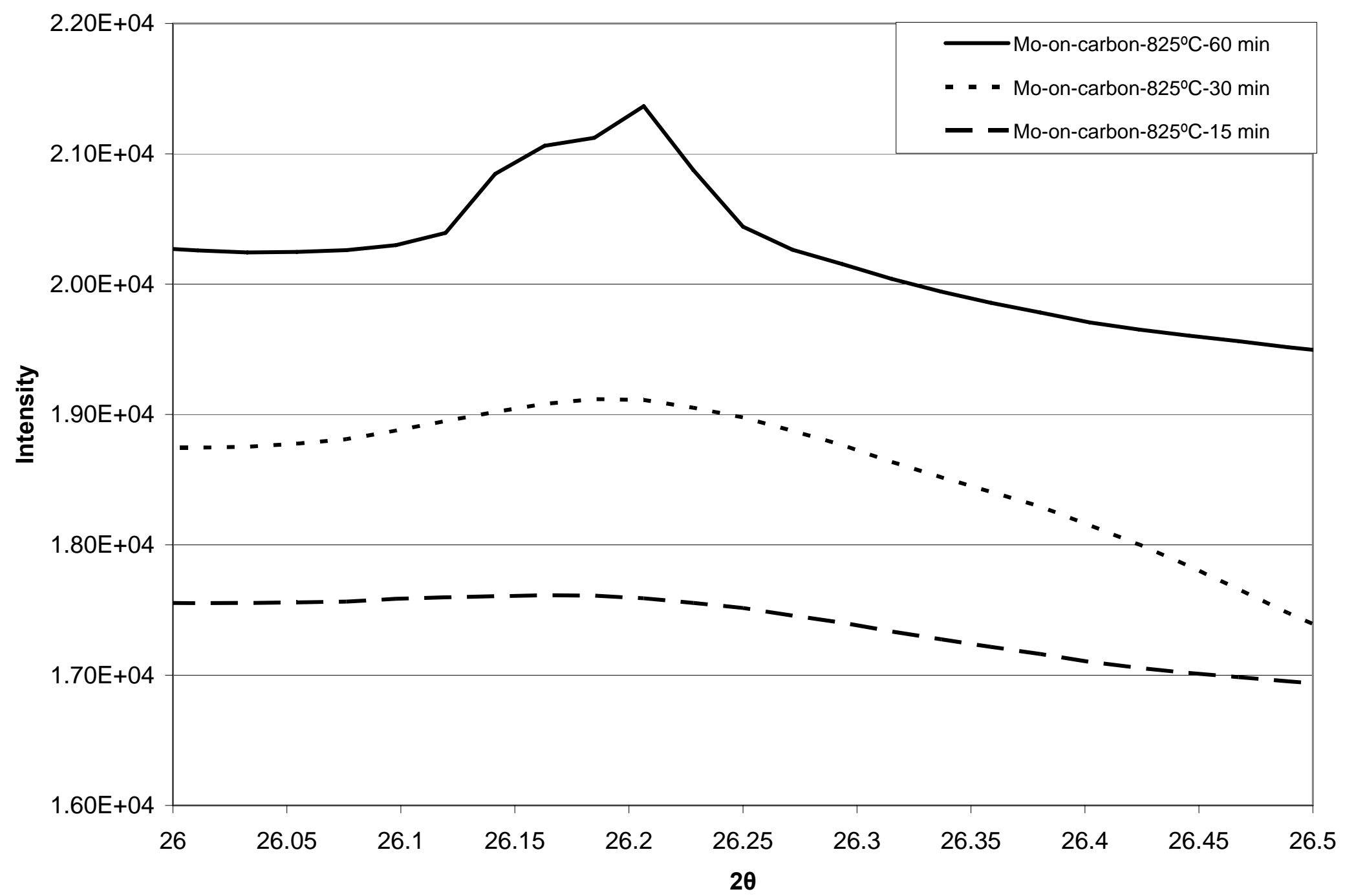

Figure 12: Plot illustrating growth of graphite XRD peak at $26.2^{\circ} 2 \theta$ with increasing time at maximum reduction temperature $\left(825^{\circ} \mathrm{C}\right)$ 


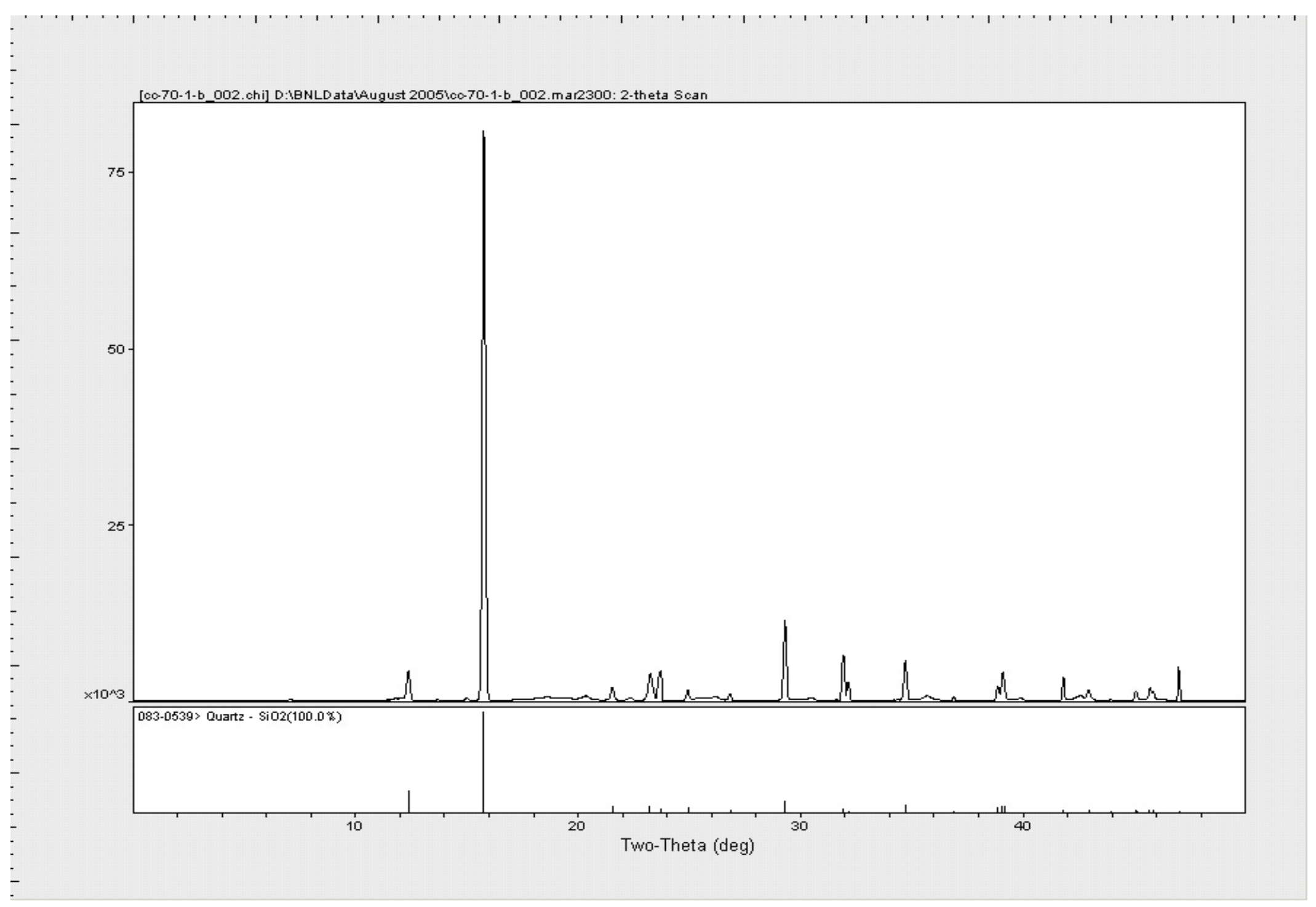

Figure 13: XRD Pattern of molybdenum-on-carbon catalyst tested for benzene hydrogenation, catalyst was reduced at $775^{\circ} \mathrm{C}$ and held at $775^{\circ} \mathrm{C}$ for 15 minutes 
When comparing XRD patterns in Figure 12 and benzene hydrogenation data for the same catalyst in Figure 9, it appears that graphite XRD lines grow as the catalyst becomes less active for benzene hydrogenation, to the point where no activity is observed. Inverse to this, $\mathrm{Mo}_{2} \mathrm{C}$ line intensities increase with reduction temperature and length of soak time at reduction temperature, even when the catalyst has no reactive surface. It is, therefore, possible that small surface particles, barely visible or invisible to $\mathrm{XRD}$, play the key role in $\mathrm{Mo}_{2} \mathrm{C}$ hydrogenation activity. Analyzed XRD patterns for all spent catalysts found to have benzene hydrogenation activity are found in Appendix E.

\subsection{In-situ XRD}

On an October 2003 visit to the National Synchrotron Light Source (NSLS) by Edwin Kugler, experiments were carried out to measure the phase transitions of molybdenum-on-carbon (Mo/C) catalysts reduced in $\mathrm{H}_{2}$. Figure 14 shows the results of the in-situ XRD of $18 \% \mathrm{Mo} / \mathrm{C}$ reduced in $\mathrm{H}_{2}$. This sample was heated from $25-825^{\circ} \mathrm{C}$ at a rate of $5^{\circ} \mathrm{C}$ per minute then held at $825^{\circ} \mathrm{C}$ for 1 hour. Each XRD scan in Figure 14 was taken in a 5 minute interval, thus, each scan represents $25^{\circ} \mathrm{C}$ of heating.

Two major changes can be seen in the XRD patterns in Figure 14 . First at $\sim 500^{\circ} \mathrm{C}$, where there is a background shift in the low $2 \theta$ angles. Furthermore, at $\sim 700^{\circ} \mathrm{C}$ the peaks for $\mathrm{MoO}_{2}$, between $2 \theta$ values of $18^{\circ}$ and $28^{\circ}$, disappear and broad peaks for $\mathrm{Mo}_{2} \mathrm{C}$ appear. Figure 14 shows that during the transition to $\mathrm{Mo}_{2} \mathrm{C}$ there is no formation of $\mathrm{Mo}^{0}$, instead there is a direct transition from $\mathrm{MoO}_{2}$ to $\mathrm{Mo}_{2} \mathrm{C}$. Possibly, excess carbon prevents the transition of the material to $\mathrm{Mo}^{0}$ and instead drives the transition to $\mathrm{Mo}_{2} \mathrm{C}$. 


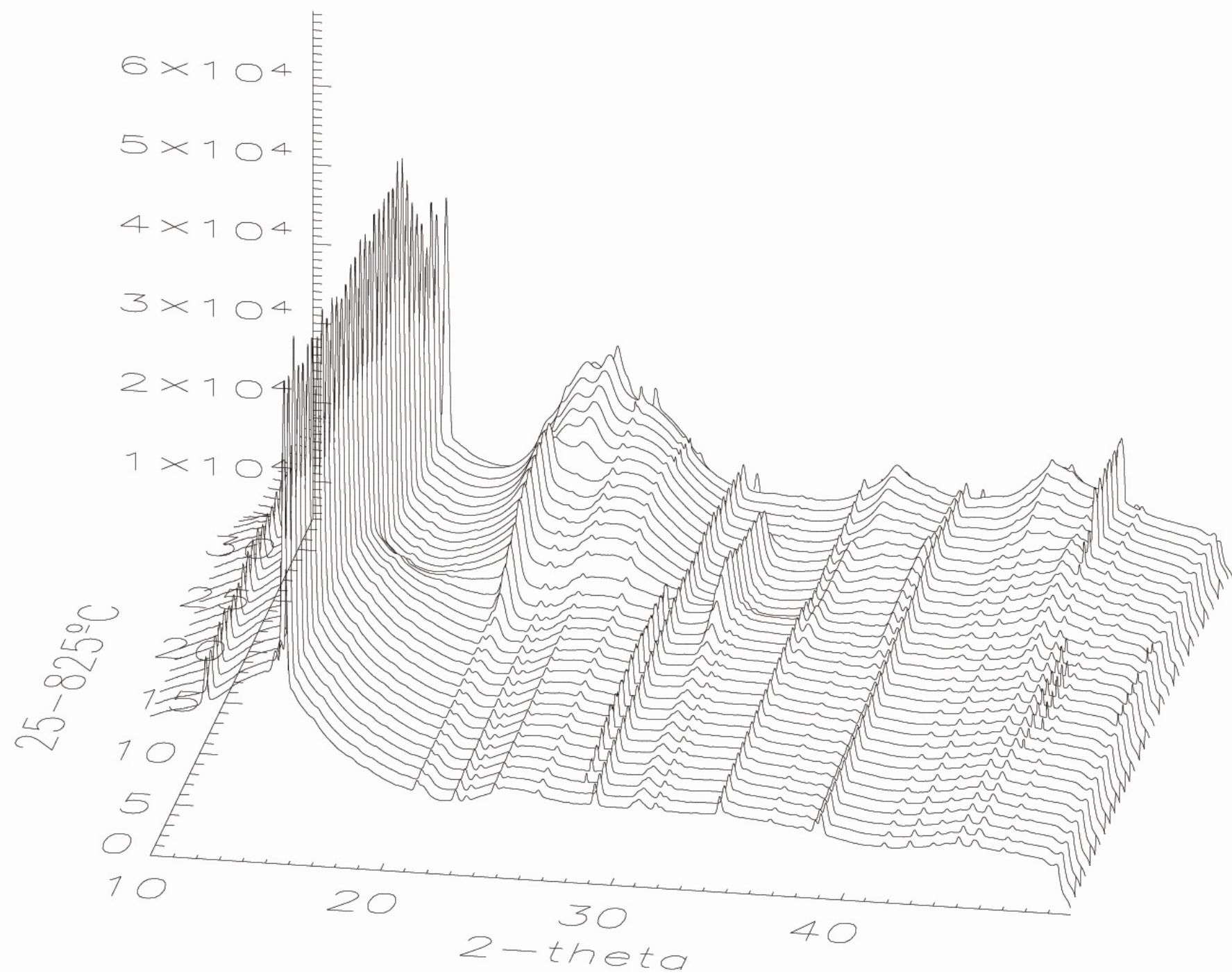

Figure 14: In-situ XRD scans of the reduction of $18 \% \mathrm{Mo} / \mathrm{C}$ to $825^{\circ}$ at $5^{\circ} \mathrm{C}$ per minute in $5 \% \mathrm{H}_{2}$ (balance $\mathrm{He}$ ). Each scan represents $25^{\circ} \mathrm{C}$ of heating 
Figure 15 shows the peak fitting of the bulk structures of the predominant materials at the end of reduction in $\mathrm{H}_{2}$. This analysis was performed using the XRD analysis software JADE. Through peak matching of The International Centre for Diffraction Data (ICDD) database, a database of experimental and calculated crystal diffraction patterns, the XRD analysis reveals that the predominant structures found in the sample are that of hexagonal $\mathrm{Mo}_{2} \mathrm{C}$ and $\mathrm{SiO}_{2} . \mathrm{SiO}_{2}$ is an impurity found in the activated carbon purchased from Sigma-Aldrich. This impurity is useful as a marker due to its persistence throughout reduction. From Debye-Scherrer line broadening of the $\mathrm{x}$-ray diffraction pattern, it is found that the average $\mathrm{Mo}_{2} \mathrm{C}$ particle size is 2 $\mathrm{nm}$. It should be noted that $2 \mathrm{~nm}$ lies within the lower limit of the effectiveness of the linebroadening technique (33).

On another visit it to NSLS in March 2004, experiments were carried out by Edwin Kugler, Christopher Clark, and James Wright, this time to measure phase transitions of molybdenum-on-carbon catalysts calcined in He. Figure 16 shows these results of the in-situ $\mathrm{XRD}$ of $24 \% \mathrm{Mo} / \mathrm{C}$ calcined in He. This sample heated from $25-825^{\circ} \mathrm{C}$ at a rate of $5^{\circ} \mathrm{C}$ per minute then held at $825^{\circ} \mathrm{C}$ for 1 hour. Each XRD scan in Figure 16 was taken in a 5-minute interval, thus each scan represents $25^{\circ} \mathrm{C}$ of heating.

Two major changes can be seen in the XRD patterns in Figure 16. The first of these changes is the growth of intensity of $\mathrm{MoO}_{2}$ peaks at between a $2 \theta$ value of $18^{\circ}$ and $28^{\circ}$. This change from weak broad peaks to sharp intense peaks is indicative of larger particles (13). This particle growth can be seen starting at $\sim 500^{\circ} \mathrm{C}$ and continuing to $800^{\circ} \mathrm{C}$. The second change happens suddenly at $\sim 800^{\circ} \mathrm{C}$ where the relatively intense peaks for $\mathrm{Mo}_{2} \mathrm{C}$ appear between a $2 \theta$ value of $20^{\circ}$ and $25^{\circ}$. Similar to the case of $\mathrm{H}_{2}$ reduction, no $\mathrm{Mo}^{0}$ is seen. However, even without the presence of $\mathrm{H}_{2}$ the material transitions to $\mathrm{Mo}_{2} \mathrm{C}$. 


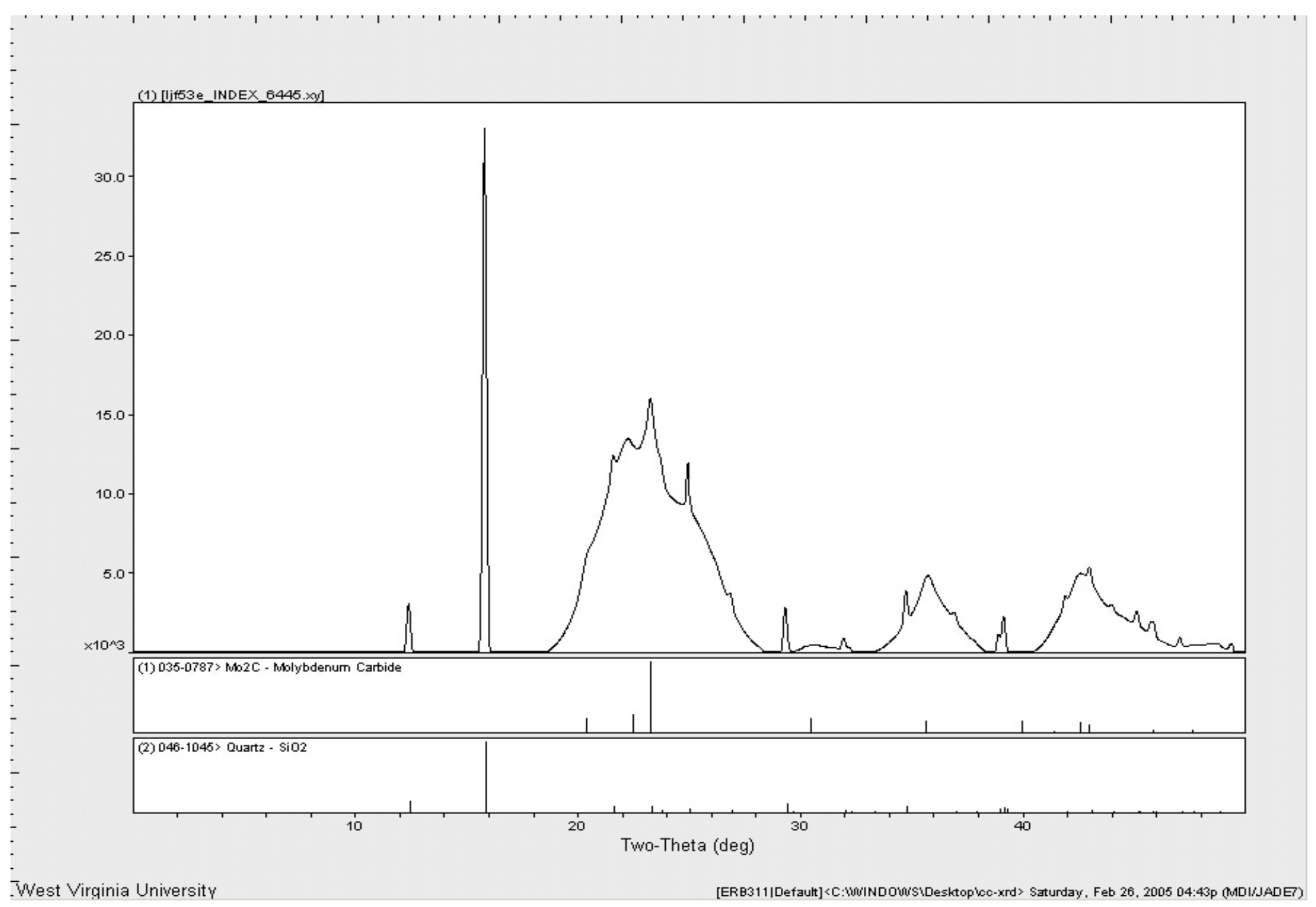

Figure 15: XRD Profile, with peak fitting, of final product of in-Situ reduction of $18 \% \mathrm{Mo} / \mathrm{C}$ in $5 \% \mathrm{H}_{2}$ (balance $\mathrm{He}$ ) 


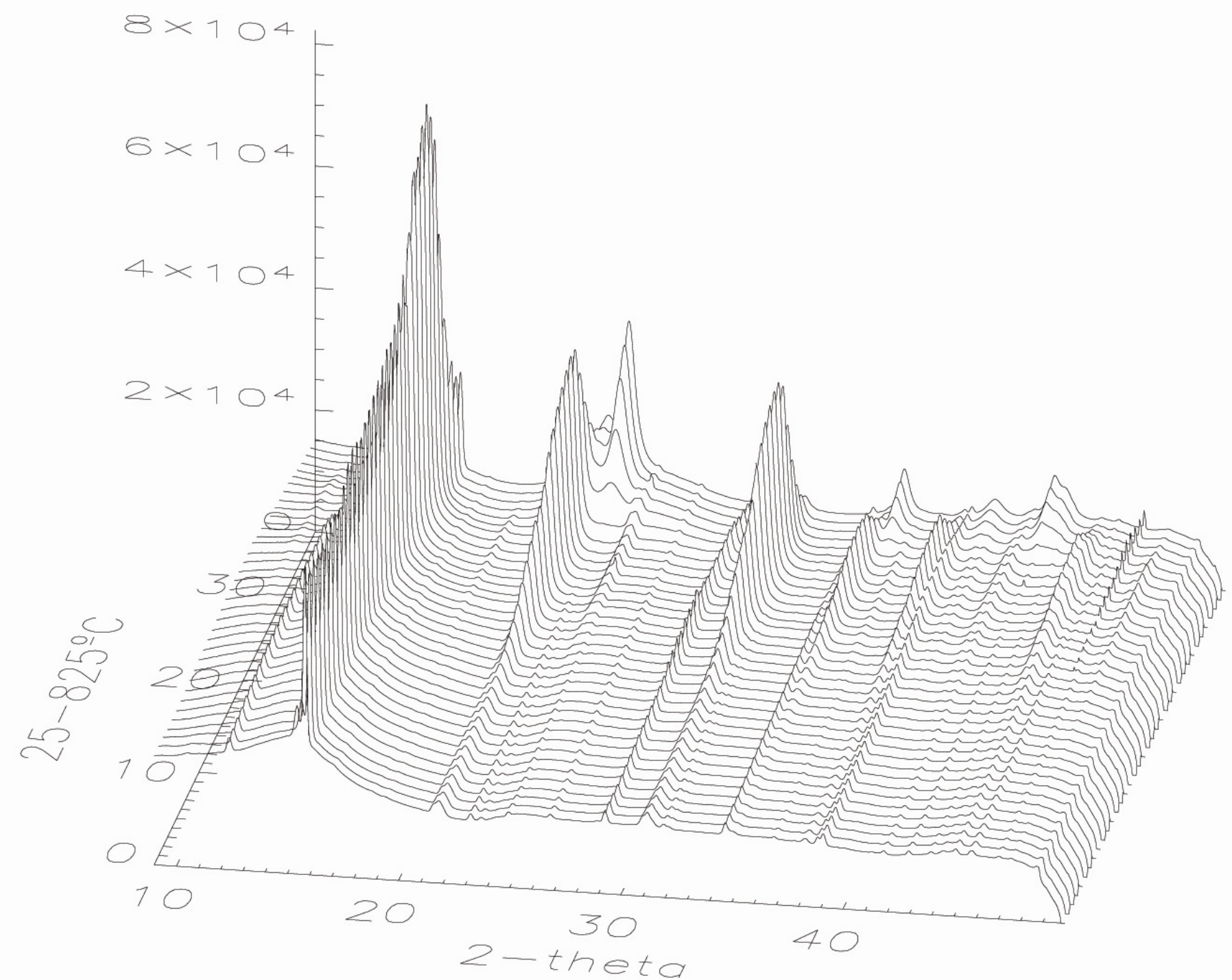

Figure 16: In-situ XRD scans of the reduction of $24 \% \mathrm{Mo} / \mathrm{C}$ to $825^{\circ}$ at $5^{\circ} \mathrm{C}$ per minute in He. Each scan represents $25^{\circ} \mathrm{C}$ of heating up to $825^{\circ} \mathrm{C}$ then held at $825^{\circ}$ for 30 minutes 
Figure 17 shows the peak fitting of the bulk structures of the predominant materials at the end of calcination in He. This analysis was performed using the XRD analysis software JADE. Through peak matching using JADE and the ICDD database, the XRD analysis reveals that the predominant structures are found to be that of hexagonal $\mathrm{Mo}_{2} \mathrm{C}$, and $\mathrm{SiO}_{2}$. From line broadening, the average $\mathrm{Mo}_{2} \mathrm{C}$ particle size is found to be $9 \mathrm{~nm}$. During calcination in He, the particles formed are much larger, and the transition happens at higher temperatures, in comparison to the case of $\mathrm{H}_{2}$ reduction. In this case of calcination in He the particles are larger due to the formation of large $\mathrm{MoO}_{2}$ precursors prior to the transition to $\mathrm{Mo}_{2} \mathrm{C}$.

On an April 2004 visit to NSLS, experiments were carried out by Edwin Kugler to measure the phase transitions of molybdenum on carbon catalysts reduced in 5\% $\mathrm{CO}$ (balance He). During this visit, a curious new transition was measured. Figure 18 shows the results of the in-situ XRD of Mo/C reduced in CO. This sample was heated from $25^{\circ} \mathrm{C}-825^{\circ} \mathrm{C}$ at a rate of $5^{\circ} \mathrm{C}$ per minute then held at $825^{\circ} \mathrm{C}$ for 1 hour. Each XRD scan in Figure 18 was taken in a 5-minute interval, thus each scan represents $25^{\circ} \mathrm{C}$ of heating. Only one major transition occurs in this material, a shift at approximately $650^{\circ} \mathrm{C}$ from $\mathrm{MoO}_{2}$ to $\mathrm{MoC}$. This transition is marked by disappeareance of $\mathrm{MoO}_{2}$ peaks found at $2 \theta$ values of $20^{\circ}$ and 28 and the sudden appearance of very broad $\mathrm{MoC}$ peaks between $2 \theta$ values of $17^{\circ}$ and $28^{\circ}$. The very broad nature of the $\mathrm{MoC}$ peaks is indicative of very small particle size.

Figure 19 shows the peak fitting of the bulk structures of the predominant materials at the end of reduction in 5\% $\mathrm{CO}$ (balance $\mathrm{He}$ ). This analysis was performed using the XRD analysis software JADE. Again, through peak matching using JADE and the ICDD database the predominant structures are those of cubic $\mathrm{MoC}$ and $\mathrm{SiO}_{2}$. 


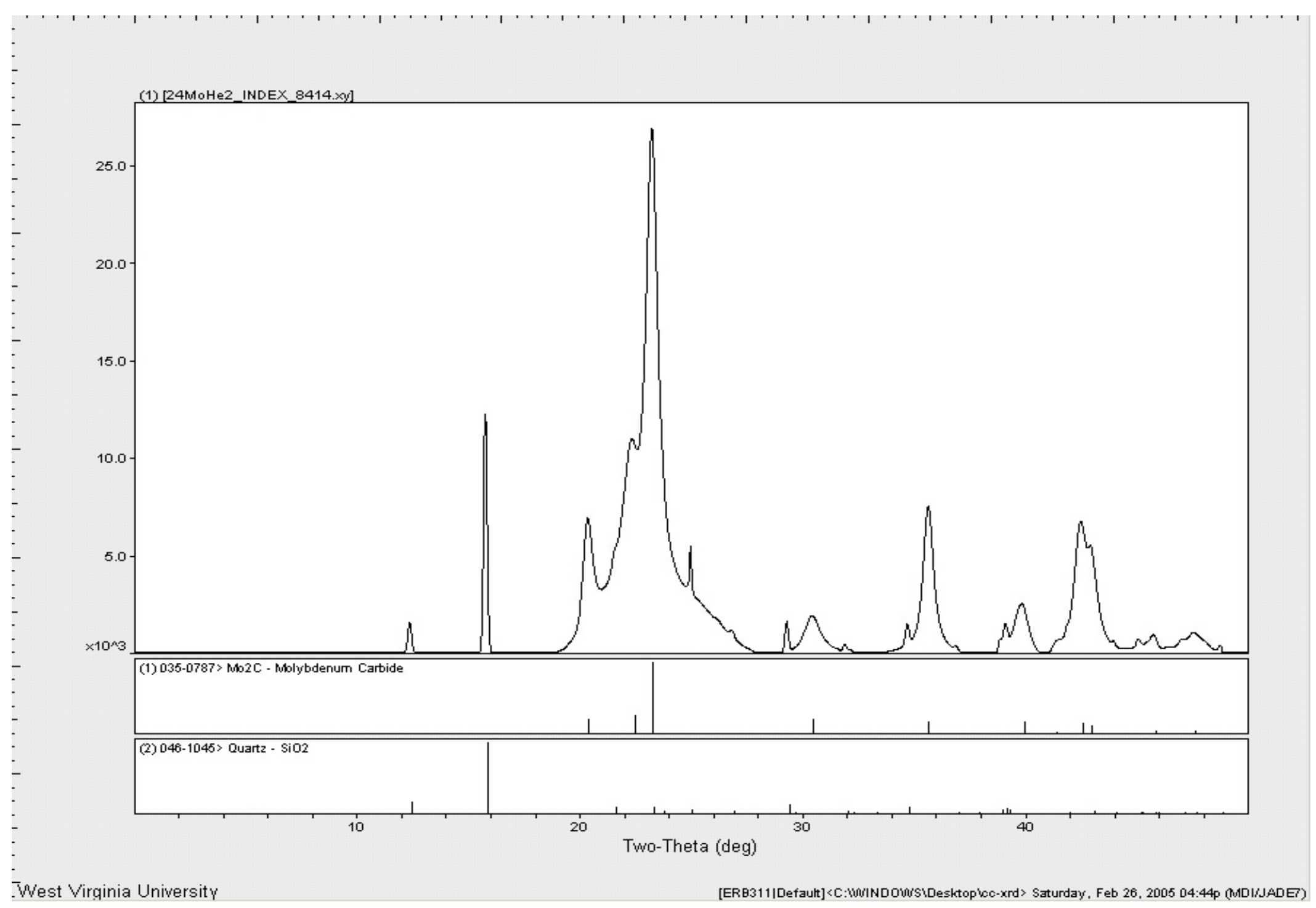

Figure 17: XRD profile, with peak fitting, of final product of in-Situ calcination $24 \% \mathrm{Mo} / \mathrm{C}$ in $\mathrm{He}$ 


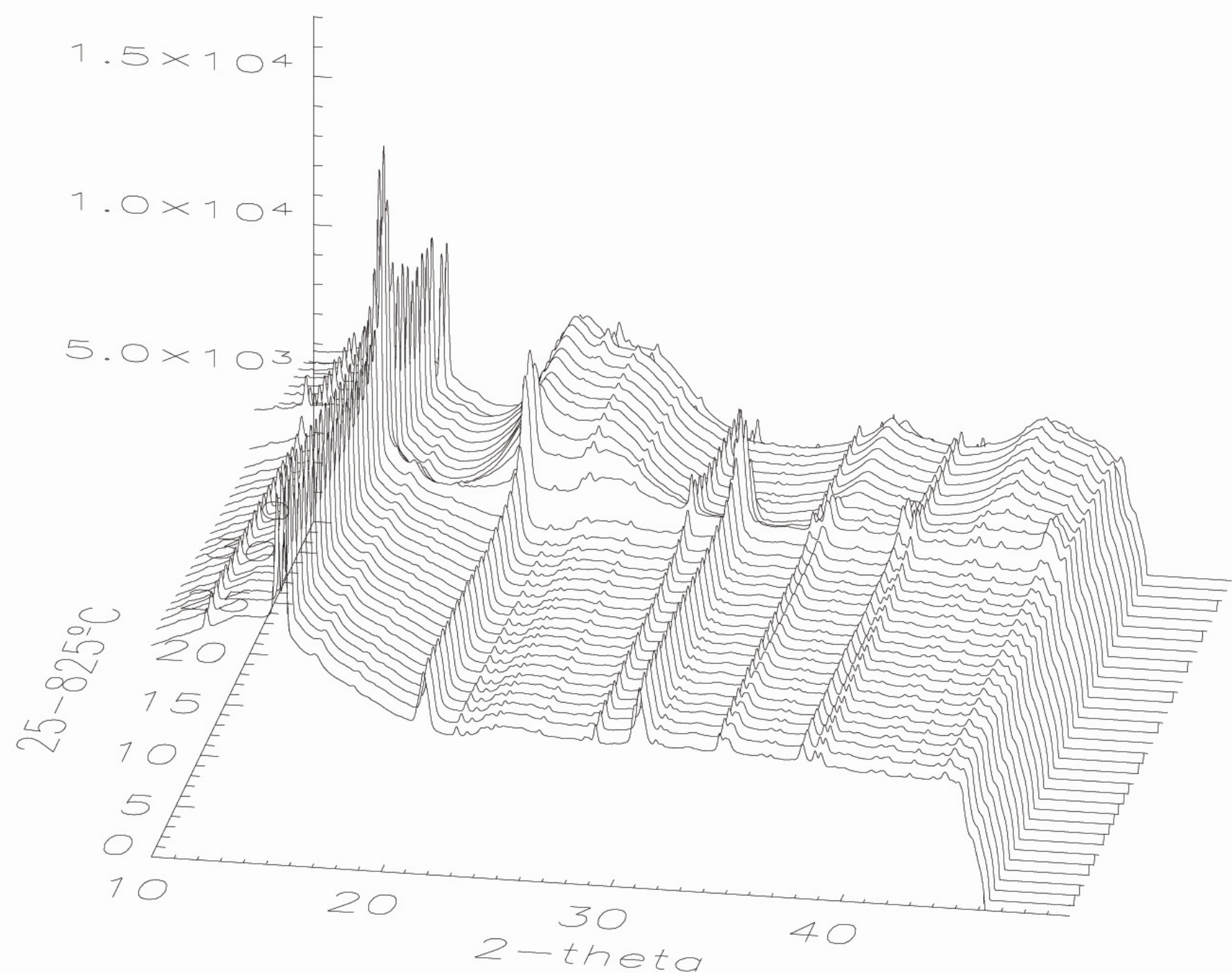

Figure 18: Plot of in-situ XRD scans of the reduction of $21 \% \mathrm{Mo} / \mathrm{C}$ to $825^{\circ}$ at $5^{\circ} \mathrm{C}$ per minute in $5 \% \mathrm{CO}$ (balance $\mathrm{He}$ ). Each scan represents $25^{\circ} \mathrm{C}$ of Heating 


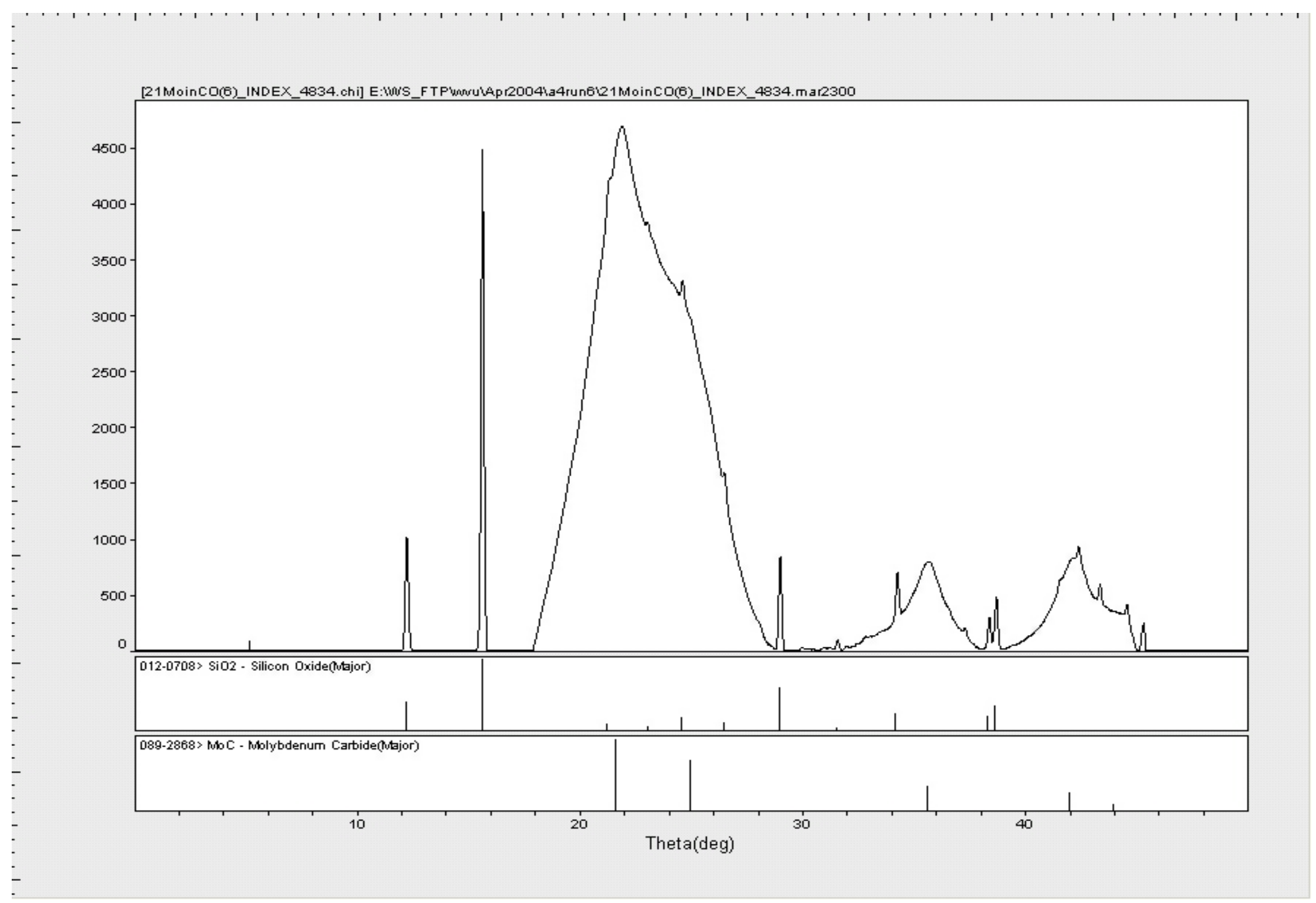

Figure 19: Profile, with peak fitting, of final product of in-Situ calcination $21 \% \mathrm{Mo} / \mathrm{C}$ in $5 \% \mathrm{CO}$ (balance He) 


\subsection{Temperature Programmed Reaction-Mass Spectrometry (TPR-MS)}

Temperature programmed reaction (TPR) experiments, where the gas effluent was measured using a mass spectrometer, have been performed at the National Energy Technology Laboratory (NETL) by Todd Gardner. These experiments used a Micromeritics Autochem 2920 Catalyst Characterization System with the sample off-gas analyzed by a ThermoONIX Prima $\delta \beta$ magnetic sector mass spectrometer, described in Section 3.6. TPR was performed on Mo/C samples pretreated in flowing $\mathrm{H}_{2}, \mathrm{CO}$, and Ar.

Figure 20 illustrates the observed TPR-MS pattern of Mo/C reduced in 5\% $\mathrm{H}_{2}$ (balance Ar). The sample was heated at $10^{\circ} \mathrm{C} / \mathrm{min}$. to $900^{\circ} \mathrm{C}$. At approximately $500^{\circ} \mathrm{C}, \mathrm{H}_{2}$ is consumed with carbon monoxide evolved at near $800^{\circ} \mathrm{C}$. Trace amounts of $\mathrm{NH}_{3}$ are evolved at $\sim 200^{\circ} \mathrm{C}$ in the breakdown of the ammonium heptamolybdate complex, but only trace amounts of $\mathrm{CO}_{2}$ are produced. Additionally, $\mathrm{H}_{2}$ seems to be produced at high temperatures. This can be seen as the value of $\mathrm{H}_{2} \mathrm{~mol} \%$ in Figure 20 increases as temperature reaches $900^{\circ} \mathrm{C}$. When comparing the $\mathrm{H}_{2}$ consumption in Figure 20 to transitions observed in the in-situ XRD in Figure 14, one sees that the largest $\mathrm{H}_{2}$ consumption in the TPR correlates to only a background shift in the XRD pattern. It is believed that this XRD background shift is the formation of small $\mathrm{MoO}_{2}$ precursors. Furthermore, if we correlate the $\mathrm{CO}$ evolution in Figure 20 to the in-situ XRD in Figure 14, we see that the $\mathrm{CO}$ evolution roughly correlates to the transition from $\mathrm{MoO}_{2}$ to $\mathrm{Mo}_{2} \mathrm{C}$.

Figure 21 illustrates the observed TPR pattern of Mo/C, now calcined in Ar. As above, the sample was heated at $10^{\circ} \mathrm{C} / \mathrm{min}$. to $900^{\circ} \mathrm{C}$ and then held at $900^{\circ} \mathrm{C}$ for 130 minutes. At near $850^{\circ} \mathrm{C}, \mathrm{CO}$ is evolved with $\mathrm{H}_{2}$ being evolved at approximately $900^{\circ} \mathrm{C}$. When comparing Figure 21 (calcination in Ar), to Figure 20 (reduction in $5 \% \mathrm{H}_{2}$ (balance Ar), one finds that $\mathrm{CO}$ evolution occurs at a higher temperature $\left(850^{\circ} \mathrm{C}\right)$ in the case of calcinations in $\mathrm{Ar}$. 


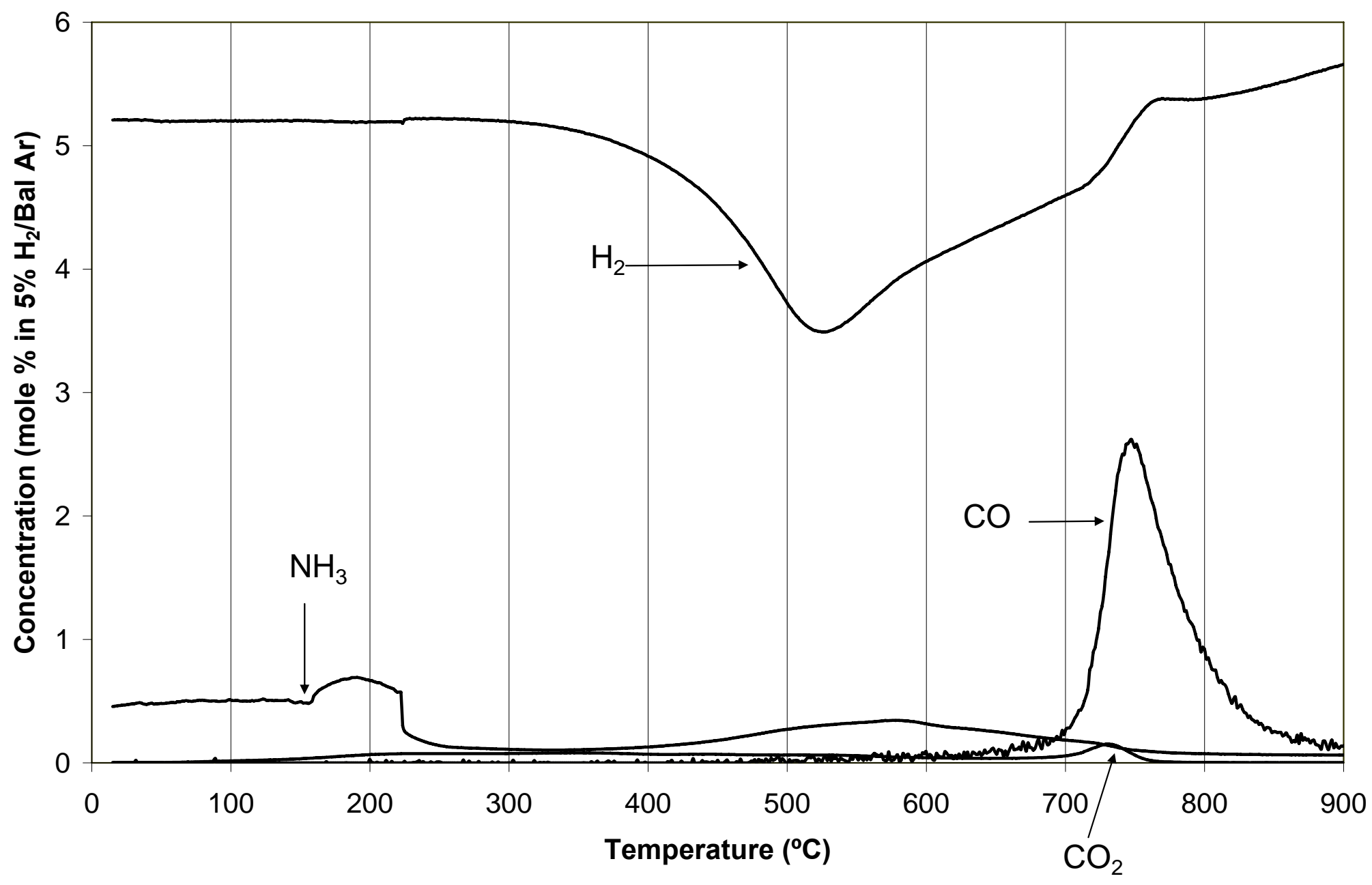

Figure 20: TPR-MS Spectra of Mo/C Reduced in $5 \% \mathrm{H}_{2}$ (balance Ar) from $25^{\circ} \mathrm{C}$ to $900^{\circ} \mathrm{C}$ at $10^{\circ} \mathrm{C}$ per minute 


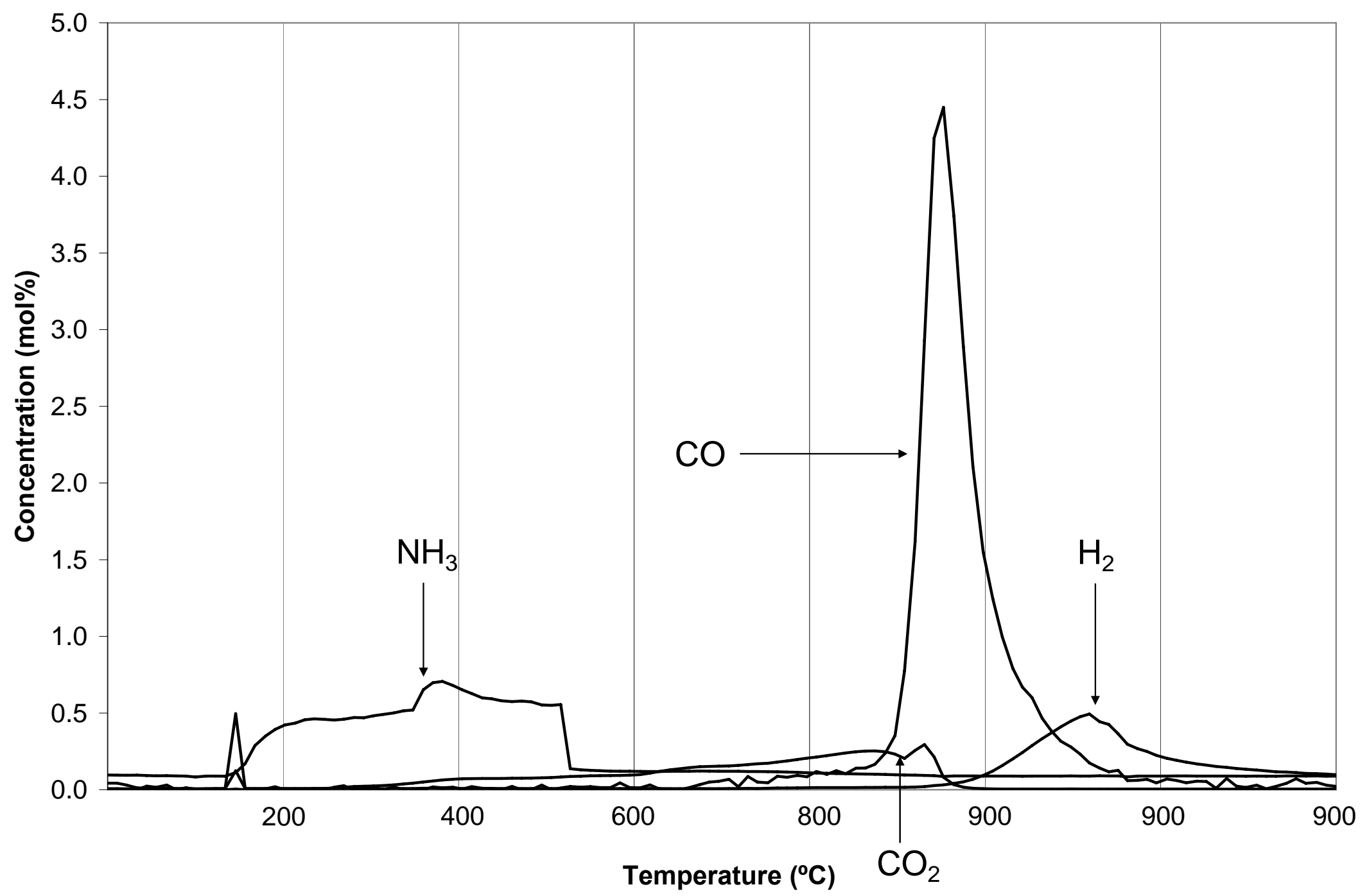

Figure 21: TPR-MS Spectra of Mo/C calcined in $\mathrm{Ar}$ from $25^{\circ} \mathrm{C}$ to $900^{\circ} \mathrm{C}$ at $10^{\circ} \mathrm{C}$ per minute, then held at $900^{\circ} \mathrm{C}$ for 130 minutes (plot of only 40 minutes of 130 -minute temperature soak at $900^{\circ} \mathrm{C}$ ) 
Trace amounts of $\mathrm{NH}_{3}$ are evolved in the breakdown of the ammonium heptamolybdate complex at $\sim 400^{\circ} \mathrm{C}$, with only small quantities of $\mathrm{CO}_{2}$ produced. It is interesting to note that $\mathrm{NH}_{3}$ is produced at a slightly higher temperature during calcinations than during reduction in $\mathrm{H}_{2}$. When comparing Figure 21 and the in-situ XRD for TPD in inert found in Figure 16, one can correlate $\mathrm{CO}$ evolution to the formation of $\mathrm{Mo}_{2} \mathrm{C}$. However, there is no change in the XRD pattern correlating to the evolution of $\mathrm{H}_{2}$ at high temperatures.

Figure 21 signifies that reduction of the $\mathrm{MoO}_{2} / \mathrm{C}$ catalyst does not occur from the gas environment, but is instead carburized directly from the activated carbon support. One possible mechanism for this reduction is:

$$
\begin{aligned}
& 2 \mathrm{MoO}_{2}+3 \mathrm{C} \Leftrightarrow \mathrm{Mo}_{2} \mathrm{C}+2 \mathrm{CO}_{2} \\
& \mathrm{CO}_{2}+\mathrm{C} \Leftrightarrow 2 \mathrm{CO}
\end{aligned}
$$

For this proposed mechanism, it is of interest to see how well the TPR-MS data compare to that predicted by thermodynamics. For the gas phase reaction shown in Equation 11, the equilibrium $\mathrm{CO}_{2}$ concentration was calculated by:

$$
\begin{aligned}
& \Delta G_{r}=-R T \ln \left(K_{a}\right) \\
& K_{a}=\frac{\left(y_{c o}\right)^{2} P}{y_{c o_{2}}}
\end{aligned}
$$

where $\Delta G_{r}$ is the Gibbs free energy of reaction for Equation 12 calculated using tabulated data (40), $R$ is the gas constant, $T$ is temperature in Kelvin, $K_{a}$ is the equilibrium constant, $P$ is total pressure, $y_{c o}$ and $y_{c o 2}$ are the equilibrium mole fraction of $\mathrm{CO}$ and $\mathrm{CO}_{2}$. This calculation is shown in detail in Appendix F. The equilibrium value for $\mathrm{CO}_{2}$ corresponding to the observed maximum $\mathrm{CO}$ concentration, occurring at $875^{\circ} \mathrm{C}$, has been calculated. When $\mathrm{CO}$ is at its observed maximum concentration of 4.5 mole $\%$, the equilibrium concentration of $\mathrm{CO}_{2}$ is 0.0066 
mole $\%$. When we compare this equilibrium calculation to the experimental data in Figure 21 they are consistent, there is no significant observed or equilibrium $\mathrm{CO}_{2}$ produced at $875^{\circ} \mathrm{C}$. Indeed, the equilibrium for Equation 11 explains the large $\mathrm{CO}$ evolution and the absence of $\mathrm{CO}_{2}$. However, when one looks at the equilibrium $\mathrm{CO}$ and $\mathrm{CO}_{2}$ concentrations prior to $875^{\circ} \mathrm{C}$ in Figure 21, it is difficult to say anything about the reaction mechanism as both $\mathrm{CO}$ and $\mathrm{CO}_{2}$ are in small concentrations. It should be noted that the equilibrium constant for the reaction in Equation 11 is equal to one at approximately $700^{\circ} \mathrm{C}$, and possible error in this temperature is associated with extrapolation of the Gibbs free energies of formation for $\mathrm{CO}$ and $\mathrm{CO}_{2}$ given only to $1000 \mathrm{~K}(41)$.

During a discussion with Jae-Soon Choi (42), a researcher working on unsupported molybdenum carbides, he noted that when preparing unsupported molybdenum carbide in $\mathrm{CH}_{4} / \mathrm{H}_{2}$ one needs to take great care in not using high temperatures or $\mathrm{CH}_{4} / \mathrm{H}_{2}$ molar ratios exceeding 1/9. Going to high temperatures or exceeding $10 \% \mathrm{CH}_{4} /$ balance $\mathrm{H}_{2}$ would lead to carbon build up on the surface. It is believed that a similar phenomenon is present in the carbon supported system, but one has little or no control over carbon sources for carburization.

Figure 22 illustrates the observed TPR pattern of Mo/C reduced in CO. As before, the sample was heated at $10^{\circ} \mathrm{C} / \mathrm{min}$ to $900^{\circ} \mathrm{C}$, and then held at $900^{\circ} \mathrm{C}$ for 130 minutes. At approximately $600^{\circ} \mathrm{C}, \mathrm{CO}$ is consumed with $\mathrm{CO}_{2}$ being evolved proportional to the $\mathrm{CO}$ being consumed. Trace amounts of $\mathrm{NH}_{3}$ are not evolved in this sample, and this sample only, due to pre-calcination of the $13 \% \mathrm{Mo} / \mathrm{C}$ in $\mathrm{N}_{2}$ at $500^{\circ} \mathrm{C}$. When comparing TPR spectra in Figure 22 with the in-situ XRD spectra, Figure 19, it is seen that CO consumption begins at approximately the same temperature, $625^{\circ} \mathrm{C}$, that $\mathrm{MoO}_{2}$ converts to $\mathrm{MoC}$. 


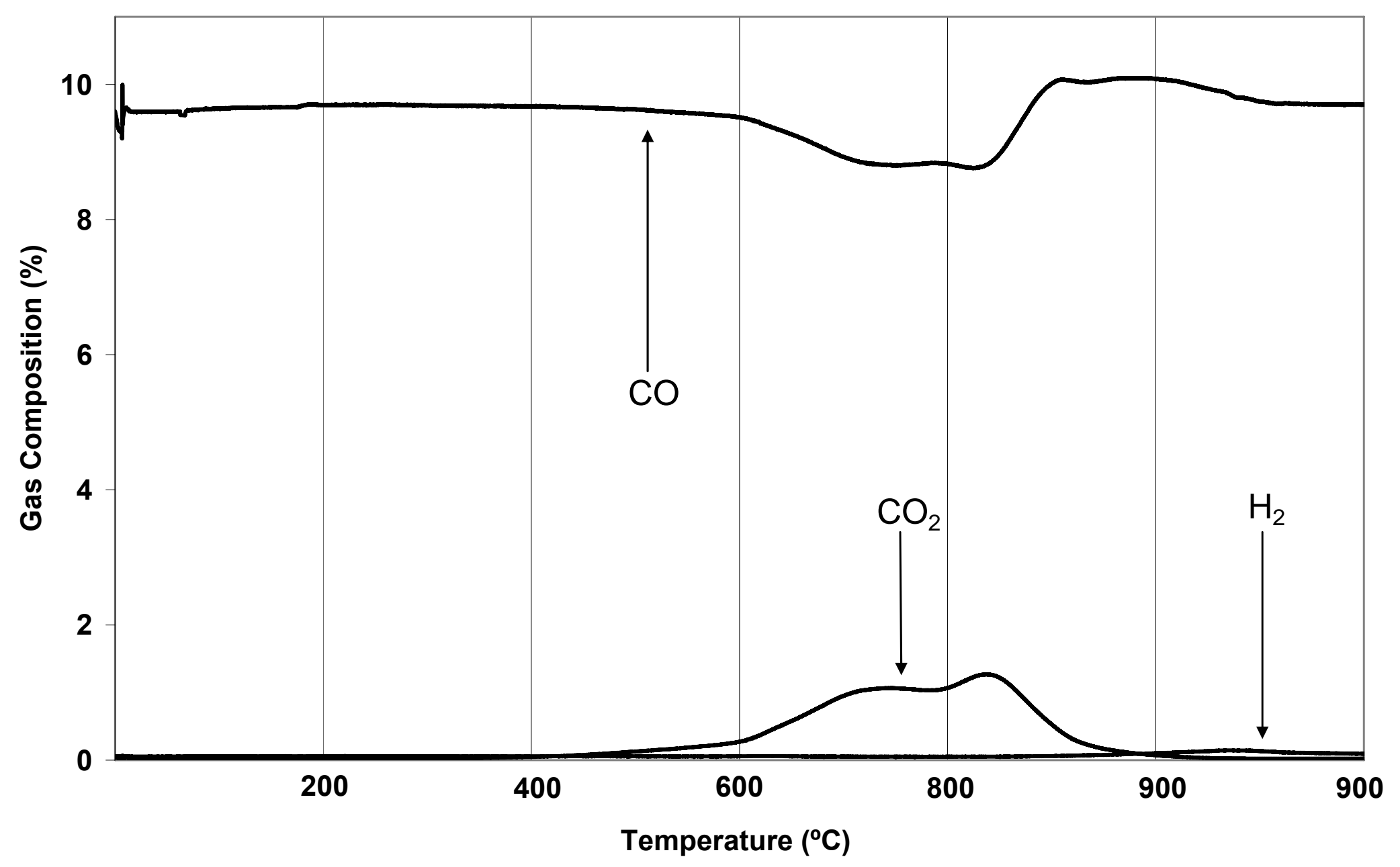

Figure 22: TPR-MS spectra of Mo/C calcined in $10 \% \mathrm{CO}$ (balance $\mathrm{Ar}$ ) from $25^{\circ} \mathrm{C}$ to $900^{\circ} \mathrm{C}$ at $10^{\circ} \mathrm{C}$ per minute, then held at $900^{\circ} \mathrm{C}$ for 130 minutes (plot of only 20 minutes of 130 -minute temperature soak at $900^{\circ} \mathrm{C}$ ) 


\subsection{CO Chemisorption}

CO chemisorption was attempted on all catalysts found to be active for benzene hydrogenation. However, good chemisorption data could not be obtained for active Mo/C catalysts. For commercial 5\% $\mathrm{Pt} / \mathrm{Al}_{2} \mathrm{O}_{3}$, purchased from Pressure Chemical, the chemisorption apparatus described in Section 3.4 consistently yielded data comparable to literature values (6, 43). Data for pulse $\mathrm{CO}$ chemisorption over $5 \% \mathrm{Pt} / \mathrm{Al}_{2} \mathrm{O}_{3}$ is provided in Figure 23 . Figure 23 indicates that the $5 \% \mathrm{Pt} / \mathrm{Al}_{2} \mathrm{O}_{3}$ sample is saturated with $\mathrm{CO}$ after 16 doses. This value corresponds to a CO uptake of $111 \mu \mathrm{mol} / \mathrm{g}$-sample.

A sample prepared to be $\mathrm{MoO}_{2}$-on-carbon (by calcination in $\mathrm{Ar}$ ) consistently gave good data revealing no $\mathrm{CO}$ uptake. Pulse chemisorption of $\mathrm{CO}$ over $\mathrm{MoO}_{2}$-on-carbon is provided in Figure 24. In many cases where CO chemisorption was attempted on what should be an active $\mathrm{Mo}_{2} \mathrm{C}$-on-carbon surface, the data showed strange behavior for $\mathrm{CO}$ uptake. Pulse chemisorption of $\mathrm{CO}$ over $\mathrm{Mo} / \mathrm{C}$, prepared through reduction in flowing $\mathrm{H}_{2}$ to $825^{\circ} \mathrm{C}$ at $10^{\circ}$ per minute and held at $825^{\circ} \mathrm{C}$ for 15 minutes, is provided in Figure 25. CO chemisorption data in Figure 25 showed odd peak heuristics for the $\mathrm{Mo}_{2} \mathrm{C}$-on-carbon catalyst. However, pyrophric behavior was observed upon removal from the TPR-chemisorption unit. This pyrophoric behavior of the $\mathrm{Mo} / \mathrm{C}$ catalyst is independent evidence for activity. It is, therefore, strange that good $\mathrm{CO}$ chemisorption, similar to that obtained for Pt catalysts, was not observed.

\subsection{Active Site Determination}

To counter this problem, $\mathrm{CO}$ chemisorption data were collected for the $5 \% \mathrm{Pt} / \mathrm{Al}_{2} \mathrm{O}_{3}$, as shown in Figure 23. This was then combined with benzene hydrogenation rate data, to give a number for rate-per-active-site, or average turn-over-frequency (TOF). TOF is defined by: 


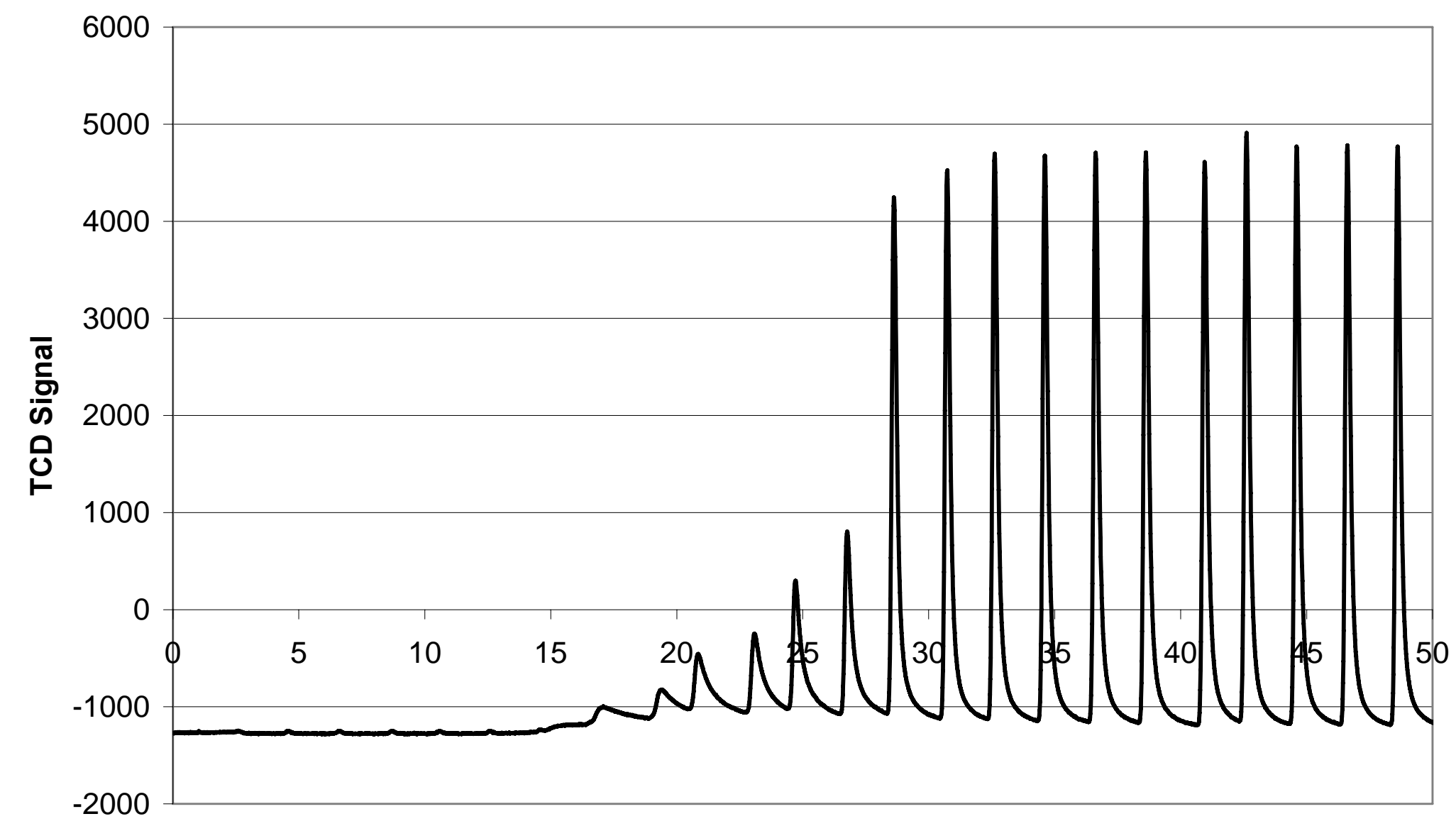

Time (minutes)

Figure 23: Pulse CO chemisorption over 0.1078g Pressure Chemical 5\% $\mathrm{Pt} / \mathrm{Al}_{2} \mathrm{O}_{3}$ reduced in $\mathrm{H}_{2}$ to $425^{\circ} \mathrm{C}$ 


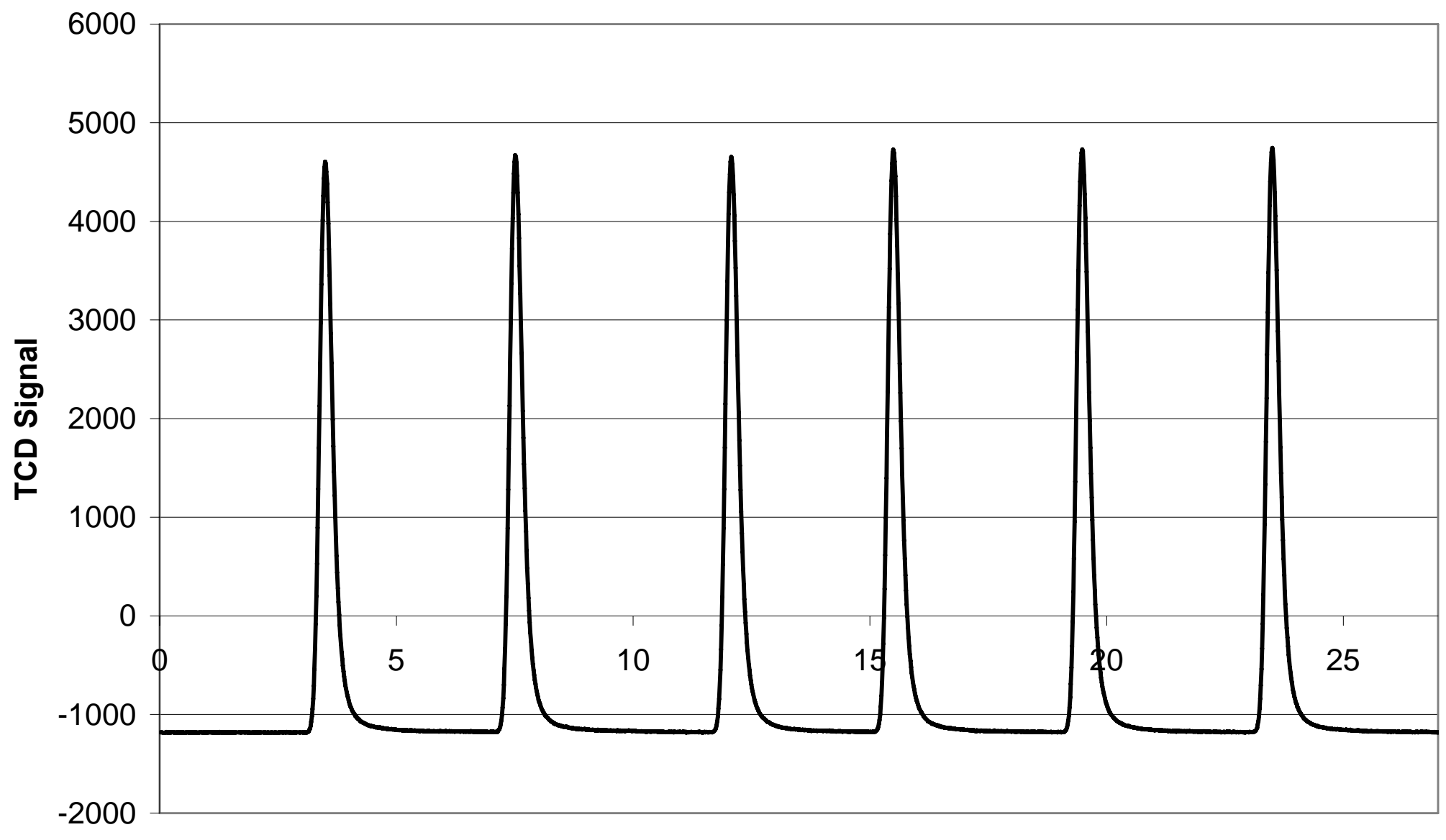

Time (minutes)

Figure 24: Pulse CO chemisorption over $0.1074 \mathrm{~g}$ molybdenum-on-carbon calcined in flowing $\mathrm{Ar}$ to $615^{\circ} \mathrm{C}$ 
48

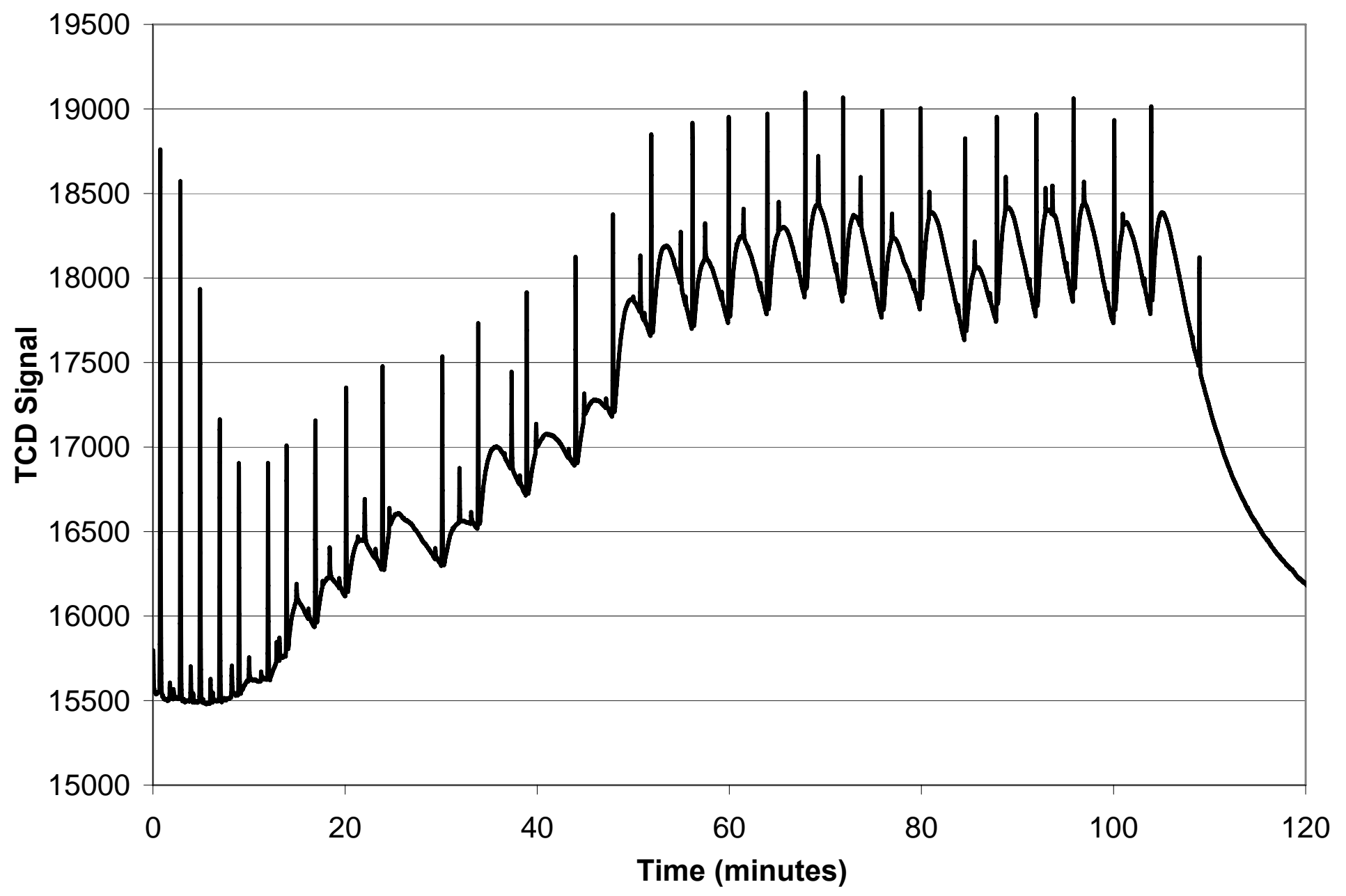

Figure 25: Pulse CO chemisorption over 0.1258 g molybdenum-on-carbon, prepared through reduction in flowing $\mathrm{UHP}_{2} \mathrm{H}_{2}$ to $825^{\circ} \mathrm{C}$ at $10^{\circ}$ per minute and held at $825^{\circ} \mathrm{C}$ for 15 minutes 
$T O F=\frac{-r_{\text {benzene }}}{[S]}$

Where $-r_{\text {benzene }}$ is the initial rate of benzene consumption calculated by Equation $14,[S]$ is surface site concentration, and TOF is site time yield. An average TOF was first calculated for $5 \% \mathrm{Pt} / \mathrm{Al}_{2} \mathrm{O}_{3}$. This value is 3.80 (reactions/site-min), for an average $-r_{\text {benzene }}$ of $4.24 \times 10^{-4}$ $\left(\mathrm{mol}^{*} \min ^{-1}(\text { g-catalyst })^{-1}\right)$. Once TOF was calculated for $\mathrm{Pt} / \mathrm{Al}_{2} \mathrm{O}_{3}$, it was assumed to be constant for the benzene hydrogenation reaction. This number could therefore be applied to other catalysts. Surface site concentration was then calculated for Mo/C samples by Equation 14 (44). Table 1 gives calculated values for surface site concentration for catalysts found to be active for benzene hydrogenation. Values for $\left(-r_{\text {benzene }}\right)_{0}$ were found by fitting curves to the experimental data for $-r_{\text {benzene }}$ and extrapolating to zero time (12). Fitting of the $-r_{\text {benzene }}$ data as well as the precise calculation method for $[S]$ from this data can be found in Appendix D. The data in Table 2 serve to quantify the activity effects of reduction temperature and soak time as discussed in Section 4.1. It should be noted that Table 1 contains only calculated CO adsorption site concentrations. 
Table 1: Surface Site concentrations as measured by either by benzene hydrogenation

\begin{tabular}{|c|c|c|c|c|c|}
\hline Catalyst & $\begin{array}{c}\text { Reduction } \\
\text { Temperature } \\
\left({ }^{\circ} \mathrm{C}\right)\end{array}$ & $\begin{array}{l}\text { Heating } \\
\text { Rate } \\
\left({ }^{\circ} \mathrm{C} / \mathrm{min}\right)\end{array}$ & $\begin{array}{l}\text { Soak Time at } \\
\text { Reduction } \\
\text { Temperature } \\
\text { (min) }\end{array}$ & $\begin{array}{c}\text { Initial }-r_{\text {benzene }} \\
\text { as extrapolated } \\
\text { from } \\
\text { experimental } \\
\text { data } \\
(\text { mol } /(\text { min } * g- \\
\text { catalyst)) }\end{array}$ & $\begin{array}{c}\text { Surface Site } \\
\text { Concentration } \\
(\mu \mathrm{mol} / \mathrm{g}- \\
\text { catalyst })\end{array}$ \\
\hline $13 \% \mathrm{Mo} / \mathrm{C}$ & 675 & 10 & 15 & $2.50 * 10^{-6}$ & 0.76 \\
\hline $13 \% \mathrm{Mo} / \mathrm{C}$ & 725 & 10 & 15 & $2.45 * 10^{-5}$ & 7.45 \\
\hline $13 \% \mathrm{Mo} / \mathrm{C}$ & 775 & 10 & 15 & $3.25 * 10^{-5}$ & 9.88 \\
\hline $13 \% \mathrm{Mo} / \mathrm{C}$ & 825 & 10 & 15 & $6.98 * 10^{-5}$ & 21.2 \\
\hline $13 \% \mathrm{Mo} / \mathrm{C}$ & 875 & 10 & 15 & $3.77 * 10^{-5}$ & 11.5 \\
\hline $13 \% \mathrm{Mo} / \mathrm{C}$ & 825 & 10 & 0 & $9.95 * 10^{-5}$ & 30.3 \\
\hline $13 \% \mathrm{Mo} / \mathrm{C}$ & 825 & 10 & 30 & $5.45^{*} 10^{-6}$ & 1.66 \\
\hline $13 \% \mathrm{Mo} / \mathrm{C}$ & 825 & 10 & 60 & 0 & 0 \\
\hline
\end{tabular}

\section{Conclusions}

The molybdenum-on-carbon catalysts reduced in $\mathrm{UHP}_{2}$ clearly have benzene hydrogenation activity, but do not have activity comparable to a commercial $\mathrm{Pt} / \mathrm{Al}_{2} \mathrm{O}_{3}$ catalyst. Additionally, the $\mathrm{Mo} / \mathrm{C}$ catalysts deactivate quickly, possibly due to residual oxygen in the benzene feed, compared to the commercial Pt catalyst. However, molybdenum-on-carbon has some interesting features that could lend themselves to further development and fundamental insight.

In-situ XRD patterns indicate that the $\mathrm{MoO}_{2}$ reduces to $\mathrm{Mo}_{2} \mathrm{C}$ or $\mathrm{MoC}$ between $650^{\circ} \mathrm{C}$ and $750^{\circ} \mathrm{C}$ in all reduction cases. When correlating these transitions to benzene hydrogenation, one finds that only during the transitions to molybdenum carbide is the catalyst active. Upon completion of the TPR, some phenomenon passivates the surface. Independent evidence for this passivation was found during $\mathrm{CO}$ chemisorption experiments over the catalysts. For $\mathrm{CO}$ chemisorption on catalysts having the highest benzene hydrogenation activity, pyrophoric behavior was observed on disposing of the catalyst. Previous to this, no molybdenum carbide- 
on-carbon catalyst had shown this tendency to violently oxidize in air (burn). When the catalysts that had no benzene hydrogenation activity were handled in a similar manner, no burning was observed. This lends evidence to the presence of surface poison occurring at high temperatures or long soak times.

The benzene hydrogenation reaction was used to determine metal surface site concentration. It was found through this method that the best surface site concentration per gram of catalyst for any of the Mo/C samples was approximately $25 \%$ of that measured for the commercial 5\% Pt/ $\mathrm{Al}_{2} \mathrm{O}_{3}$ catalyst. Additionally, this chemisorption study yielded the first observation of pyrophoric Mo/C, observed on catalyst disposal.

Taking into account the observed deactivation with reduction temperature and soak time at reduction temperature, it is believed that a carbon layer is occluding the active surface. Three possible mechanisms for this are: carbon lay-down from $\mathrm{CH}_{4}$ formed (Equation 1), carbon laydown from $\mathrm{CO}$ formed (Equation 5), or mobile carbon used in the reduction of the $\mathrm{Mo}_{2} \mathrm{C}$ that migrates to the surface. Evidence for one or all of these mechanisms can be found in the formation of graphite, as seen by XRD, as the catalyst becomes increasingly inactive.

When looking at the formation of molybdenum carbides in $\mathrm{H}_{2}$, inert, and $\mathrm{CO}$, one finds that in none of the cases is $\mathrm{Mo}^{0}$ observed. This is shown clearly in the in-situ XRD patterns, Figures 17, 19, and 21. It is interesting that $\mathrm{Mo}^{0}$ is not seen as this is the carburization mechanism proposed by the Stanford Group, as seen in Equation 2. Instead $\mathrm{MoO}_{2}$ is the starting material, after the initial decomposition of ammonium heptamolybdate, which then reduces at high temperature to $\mathrm{Mo}_{2} \mathrm{C}$.

Additionally, for the case of $\mathrm{Mo}_{2} \mathrm{C}$ formation in $\mathrm{H}_{2}$ or inert, one finds that $\mathrm{CO}$ is evolved during the reduction of $\mathrm{MoO}_{2}$ to $\mathrm{Mo}_{2} \mathrm{C}$. This $\mathrm{CO}$ evolution implies that the reaction path to 
$\mathrm{Mo}_{2} \mathrm{C}$ does not use methane as the reducing agent, as proposed by Lee et al. (4), but instead is using the carbon support. This is seen in correlating the TPR-MS, Figure 21, and in-situ XRD, Figure 16. From the TPD-MS in inert gas, it seems clear that the Mo/C samples are reduced to $\mathrm{Mo}_{2} \mathrm{C}$-on-carbon by the carbon support, not the gas environment. This is supported by the equilibrium calculation (Equation 11). For the case of the reduction in 5\% CO (balance inert), the consumption of $\mathrm{CO}$ and production of $\mathrm{CO}_{2}$, seen in the TPR-MS spectra Figure 22, corresponds to the same temperature as the transition of $\mathrm{MoO}_{2}$ to $\mathrm{MoC}$, seen in Figure 18. In all cases, active carbon appears to be the reducing agent.

Molybdenum carbide shows promise as a hydrogenation catalyst, but needs further materials refinement to optimize hydrogenation activity. This study has observed that noble metals and unsupported molybdenum carbides outperform carbon-supported molybdenum catalysts.

\section{Recommendations}

Future work should involve the probing of the surface of $\mathrm{Mo}_{2} \mathrm{C}$-on-carbon. Understanding the mechanism and rate of carbon build up on the particle surface should lead to forming a more stable and more active catalyst. Infrared (IR) spectroscopy or x-ray near edge spectroscopy should lend itself to this pursuit. One should be able to observe the surface carbon build-up by these methods.

Furthermore, when reducing the $\mathrm{Mo}_{2} \mathrm{C}$ catalyst formed in $\mathrm{UHP} \mathrm{H}_{2}$, the hydrogenation activity could be improved by increasing $\mathrm{H}_{2}$ concentration to assure that the metal surface is clean. Due to limitations in the apparatus constructed for these experiments, high $\mathrm{H}_{2}$ pressures could not be reached, but future work should reduce these $\mathrm{Mo} / \mathrm{C}$ catalysts under higher $\mathrm{H}_{2}$ pressures. This high $\mathrm{H}_{2}$ concentration should drive carbon off the surface as $\mathrm{CH}_{4}$ by the reaction 
in Equation 1 and leave a clean metal surface. Finally, with $\mathrm{MoC}$ reduced in $\mathrm{CO}$, the study of co-feeding $\mathrm{CO}_{2}$ might reveal that surface carbon can be cleaned up and catalytic activity achieved. The reaction in Equation 5 lends evidence to this phenomenon. 


\section{References}

1. Leclercq, L, Imura, K, Yoshida, S., Barbee, T., and Boudart, M., Synthesis of New Catalytic Materials: Metal Carbides of the Group VI B Elements, Studies in Surface Science and Catalysis 3: Preparation of Catalyst II, 1979, 3, 627.

2. Mordenti, D., Brodzki, D., and Djéga-Mariadassou, G., New Synthesis of $\mathrm{Mo}_{2} \mathrm{C} 14 \mathrm{~nm}$ Average Size Supported on High Specific Surface Area Carbon Material, Journal of Solid State Chemistry, 1998, 141,114.

3. Feng, L., Xianguo, L., Dadyburjor, D.B., and Kugler, E.L., A Temperature-ProgrammedReduction Study on Alkali-Promoted Carbon-Supported Molybdenum Catalysts, Journal of Catalysis, 2000, 190, 1.

4. Lee, J.S., Oyama, S.T., Boudart, M., Molybdenum Carbide Catalysts I.: Synthesis of Unsupported Powders, Journal of Catalysis, 1987, 106, 125.

5. Lee, J.S., Volpe, L., Ribeiro, F.H., and Boudart, M, Molybdenum Carbide Catalysts II.: Topatactic Synthesis of Unsupported Powders, Journal of Catalysis, 1988, 112, 44.

6. Lee, J.S., Yeom, M.H., Park, K.Y., Nam, I. S., Chung, J.S., Kim, Y. G., and Moon, S. H., Preparation and Benzene Hydrogenation Activity of Supported Molybdenum Carbide Catalysts, Journal of Catalysis, 1991, 128, 126.

7. Chen, J.G., and Fruhberger, B., Similarities in Decomposition and Dehydrogenation of Cyclohexene on (4x4)-C/Mo(110) and Pt (111), Surface Science, 1996, 367, L102.

8. Dhandapani, B., St. Clair, T., and Oyama, S.T., Simultaneous Hydrodesulfurization, Hydrodeoxygenation, and Hydrogenation with Molybdenum Carbide, Applied Catalysis A: General, 1998, 168, 219.

9. Montéverdi, S., Bettahar, M.M., Bégin, D., and Maréché, F., Characteristics and Hydrogenating Properties of Active Carbon Supported $\beta-\mathrm{Mo}_{2} \mathrm{C}$, Fuel Processing Technology, 2002, 77, 119.

10. Li, Y., Fan, Y., He, J., Xu, B., Yang, H., Miao, J., and Chen, Y., Selective Liquid Hydrogenation of Long Chanin Linear Alkadienes on Molybdenum Carbide Modified by Oxygen, Chemical Engineering Journal, 2004, 99, 213.

11. Marquez-Alvarez, C., Claridge, J.B., York, A.P.E., Sloan, J., and Green, M.L.H., Benzene Hydrogenation over Transition Metal Carbides, Surface Science and Catalysis, 1997, , 485. 
13. Choi, J., Bugli, G., and Djéga-Mariadassou, G., Deactivation by Oxygen and Subsequent Activation of Bulk $\mathrm{Mo}_{2} \mathrm{C}$ for Benzene Hydrogenation at $298 \mathrm{~K}$, Studies in Surface Science and Catalysis, 2000, 130, 2885.

12. Choi, J., Bugli, G., and Djéga-Mariadassou, G., Influence of the Degree of Carburization on the Density of Sites and Hydrogenating Activity of Molybdenum Carbides, Journal of Catalysis, 2000, 193, 238.

14. Rocha, A.S., da Silva, V. L. T., Leitao, A.A., Herbst, M.H., and Faro, A.C., Low Temperature Low Pressure Benzene Hydrogenation on Y Zeolite Supported Carbided Molybdenum, Catalysis Today, 2004, 98, 281.

15. Schlatter, J.C., Oyama, S.T., Metcalfe, J.E., and Lambert, J.M., Catalytic Behavior of Selected Transition-Metal Carbides, Nitrides, and Borides in the Hydrodenitrogenation of Quinoline, Ind. Eng. Chem. Res., 1988, 27, 1648-1653

16. Li, S., Lee, J.S., Hyeon, T., and Suslick, K.S., Catalytic Hydrodenitrogenation of Indole over Molybdenum Nitride and Carbide with Different Structures, Applied Catalysis A: General, 1999, 184, 1.

17. Schwartz, V., and Oyama, S.T., Reaction Network of Pyridine Hydrodenitrogenation over Carbide and Sulfide Catalysts, Journal of Molecular Catalysis A: Chemical, 2000, 163, 269.

18. Schwartz, V., da Silva, V.T., and Oyama, S.T., Push-pull Mechanism of Hydrodenitrogenation over Carbide and Sulfide Catalysts, Journal of Molecular Catalysis A: Chemical, 2000, 163, 251.

19. Sayag, C., Benkhaled, M., Suppan, S., Trawczynski, J., and Djéga-Mariadassou, G., Comparative Kinetic Study of Hydrodenitrogenation of Indole over Activated Cabon Black Composites (CBC) Supported Molybdenum Carbides, Applied Catalysis A: General, 2004, 275, 15.

20. Lee, J. S., and Boudart, M., Hydrodesulfurization of Thiophene Over Unsupported Molybdenum Carbide, Applied Catalysis, 1985, 19, 207.

21. St. Clair, T.P., Oyama, S.T., and Cox, D.F., Adsorption and Reaction of Thiophene on $\alpha-$ $\mathrm{Mo}_{2} \mathrm{C}$ (0001), Surface Science, 2002, 511, 294.

22. Naito, S., Tsuji, M., and Miyao, T., Mechanistic Difference of the $\mathrm{CO}_{2}$ of $\mathrm{CH}_{4}$ over Unsupported and Supported Molybdenum Carbide Catalysts, Catalysis Today, 2002, 77, 161.

23. Darujati, A.R.S., LaMont, D.C., and Thomson, W.J., Oxidation Stability of $\mathrm{Mo}_{2} \mathrm{C}$ Catalysts Under Fuel Reforming Conditions, Applied Catalysis A: General, 2003, 253, 397. 
24. LaMont, D.C., Gilligan, A.J., Darujati, A.R.S., Chellappa, A.S., and Thomson, W.J., Applied Catalysis A: General, 2003, 255, 239.

25. Zhu, Q., Zhang, B., Zhoa, J., Shengfu, J., Yang, J., Wang, J., and Hanqing, W., The Effect of Secondary Metal on $\mathrm{Mo}_{2} \mathrm{C} / \mathrm{Al}_{2} \mathrm{O}_{3}$ Catalyst for the Partial Oxidation of Methane to Syngas, Journal of Molecular Catalysis A: Chemical, 2004, 213, 199.

26. Lacheen, H.S., and Iglesia, E., Stability, Structure, and Oxidation State of Mo/H-ZSM-5 Catalysts during Reactions of $\mathrm{CH}_{4}$ and $\mathrm{CH}_{4}-\mathrm{CO}_{2}$ Mixtures, Journal of Catalysis, 2005, 230, 173.

27. Delporte, P., Pham-Huu, C., and Ledoux, M.J., Effect of the Reaction Temperature and Hydrocarbon Partial Pressure on the Activity of Carbon-Modified $\mathrm{MoO}_{3}$ for n-hexane Isomerization, Applied Catalysis A: General, 1997, 149, 151.

28. Lamic, A.F., Pham, T.L.H, Potvin, C., Manoli, J.M., and Djéga-Mariadassou, G., Kinetics of Bifunctional Isomerization over Carbides (Mo, W), Journal of Molecular Catalysis A: Chemical, 2005, 237, 109.

29. Ma, D., Shu, Y., Cheng, M., Xu, Y., and Bao, X., On the Induction Period of Methane Aromatization over Mo-Based Catalysts, Journal of Catalysis, 2000, 194, 105.

30. Yuan, S., Hamid, S.B.D.A., Li, Y., Ying, P., Xin, Q., Drouane, E.G., and Li, C., Preparation of $\mathrm{Mo}_{2} \mathrm{C} / \mathrm{HZSM}-5$ and its Catalytic Performance for the Conversion of n-butane into Aromatics, Journal of Molecular Catalysis A: Chemical, 2002, 184, 257.

31. Solymosi, F., and Széchenyi, Aromatization of n-butane and n-butene over Supported $\mathrm{Mo}_{2} \mathrm{C}$ Catalyst, Journal of Catalysis, 2004, 223, 221.

32. Kojima, R., and Aika, K., Molybdenum Nitride and Carbide Catalysts for Ammonia Synthesis, Applied Catalysis A: General, 2001, 219, 141.

33. Suryanarayana, C., and Grant Norton, M., X-ray Diffraction a Practical Approach, New York: Plenum Press, 1998

34. Rodriguez, J.A., Chaturvedi, S., Hanson, J.C., Albornoz, A., and Brito, J.L., Electronic Properties and Phase Transformations in $\mathrm{CoMoO}_{4}$ and $\mathrm{NiMoO}_{4}$ : XANES and TimeResolved Synchrotron XRD Studies, Journal of Physical Chemistry B, 1998, 102, 1347.

35. Chupas, P.J., Ciraolo, M.F., Hanson, J.C., and Grey, C.P., In Situ X-ray Diffraction and Solid-State NMR Study of the Fluorination of $\gamma-\mathrm{Al}_{2} \mathrm{O}_{3}$ with $\mathrm{HCF}_{2} \mathrm{Cl}$, Journal of the American Chemical Society, 2001, 123, 1694.

36. Freel, J., Chemisorption on Supported Platinum I. Evaluation of a Pulse Method, Journal of Catalysis, 1971, 25, 139. 
37. Li, X., Feng, L., Zhang, L., Dadyburjor, D.B., and Kugler, E.L., Alcohol Synthesis over PreReduced Activated Carbon Supported Molybdenum-Based Catalysts, Molecules, 2003, 8, 13.

38. Lide, D.R. (ed.), Handbook of Chemistry and Physics, $86^{\text {th }}$ Edition, Taylor \& Francis CRC Press, 2005.

39. Occupational Safety and Health Administration (OSHA), http://www.osha.gov/SLTC/healthguidelines/carbonmonoxide/recognition.html, accessed August 29, 2005.

40. Fogler, S.F., Elements of Chemical Reaction Engineering, Upper Saddle River, New Jersey: Prentice Hall, 1999.

41. Yaws, C.L., Yaws' Handbook of Thermodynamic and Physical Properties of Chemical Compounds, Knovel, 2003.

42. Choi, J.S., Personal Communication, July 20, 2005 by phone.

43. Sarkany, J., and Gonzalez, R.D., On the use of the Dynamic Pulse Method to Measure Metal Surface Areas, Journal of Catalysis, 1982, 76, 75.

44. Fajardie, F., Tempére, J.F., Djéga-Mariadassou, G., and Blanchard, G., Benzene Hydrogenation as a Tool for the Determination of metal Exposed on Low Loaded Ceria Supported Rhodium Catalysts, Journal of Catalysis, 1996, 163, 77.

45. Dietz, W.A., Response Factors for Gas Chromatographic Analyses, Journal of Gas Chromatography, 1967, 5, 68. 


\section{Appendix A: Mass Flow Controller Calibration}

This appendix provides calibration curves for the Brooks mass flow controllers used for reduction and reaction in the benzene hydrogenation reactor shown in Figure 3.

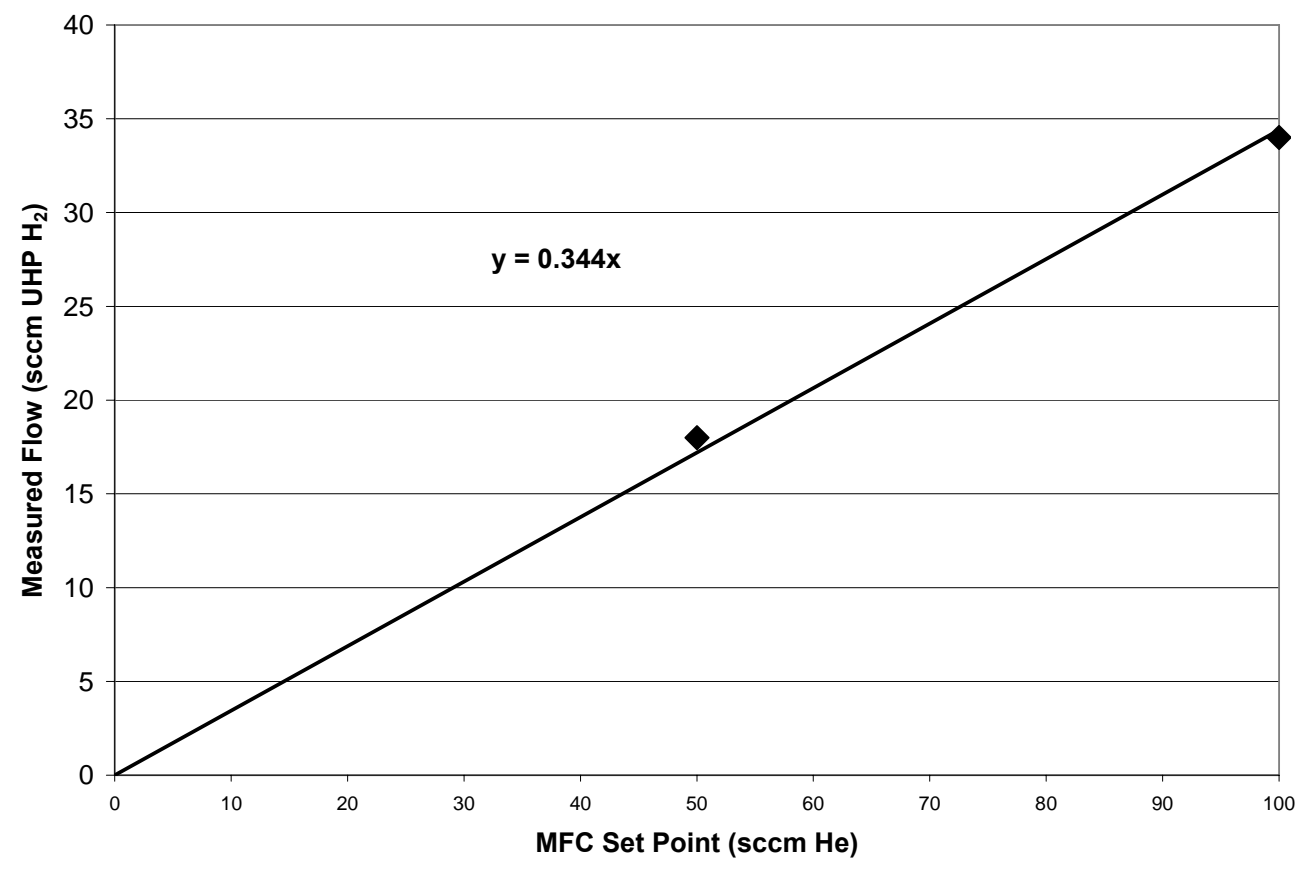

Figure 26: Calibration of MFC for UHP $\mathrm{H}_{2}$ Flow

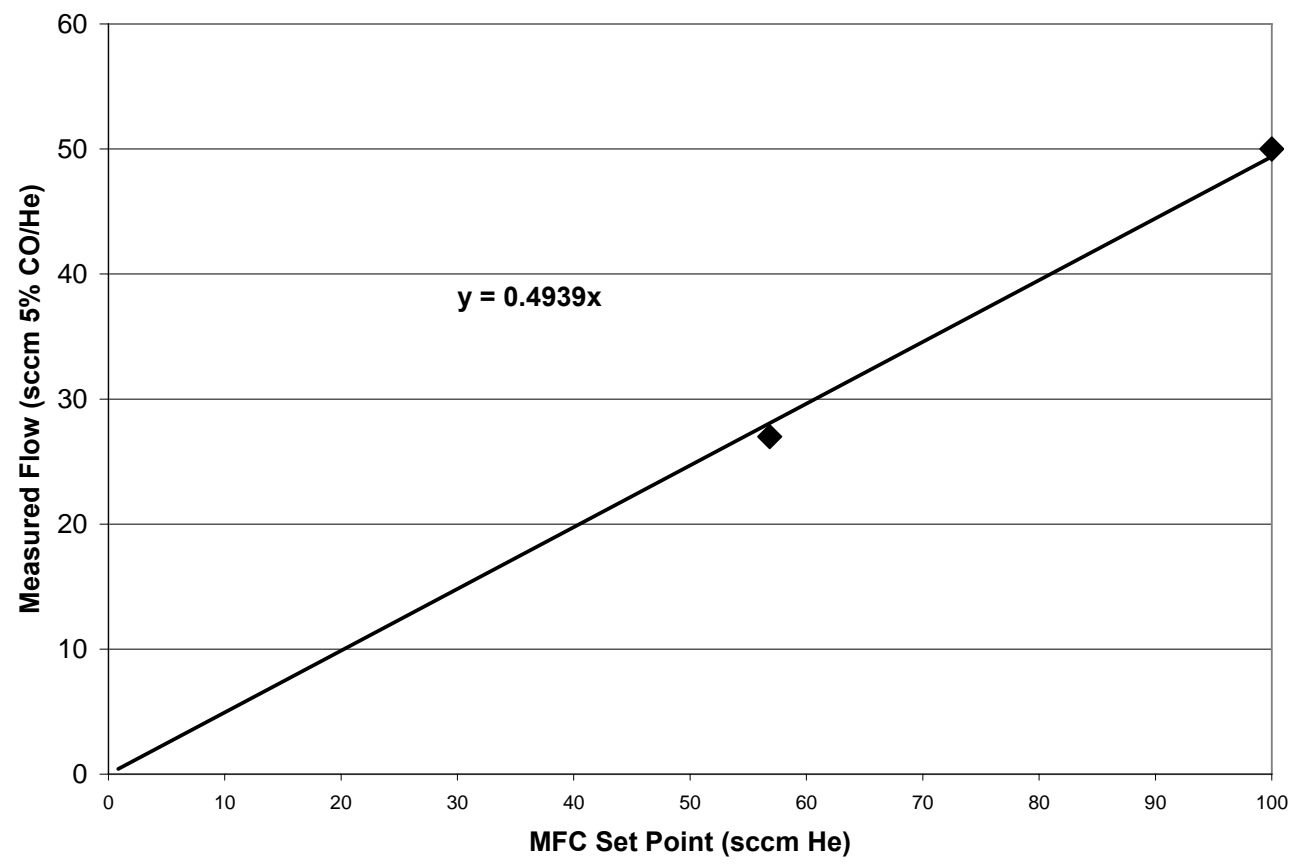

Figure 27: Calibration of MFC for $5 \% \mathrm{CO} / \mathrm{balance} \mathrm{He}$ 


\section{Appendix B: GC Separations}

This appendix provides test separations and column specifications for the $35 \% \mathrm{BC}-150$ on 100/120 Chromosorb P AW column used to separate cyclohexane from benzene. For the test separation, $1 \mu \mathrm{L}$ of an approximately $50 / 50$ weight $\%$ mixture of benzene and cyclohexane was injected into the Hewlett Packard 5890 series II gas chromatograph.

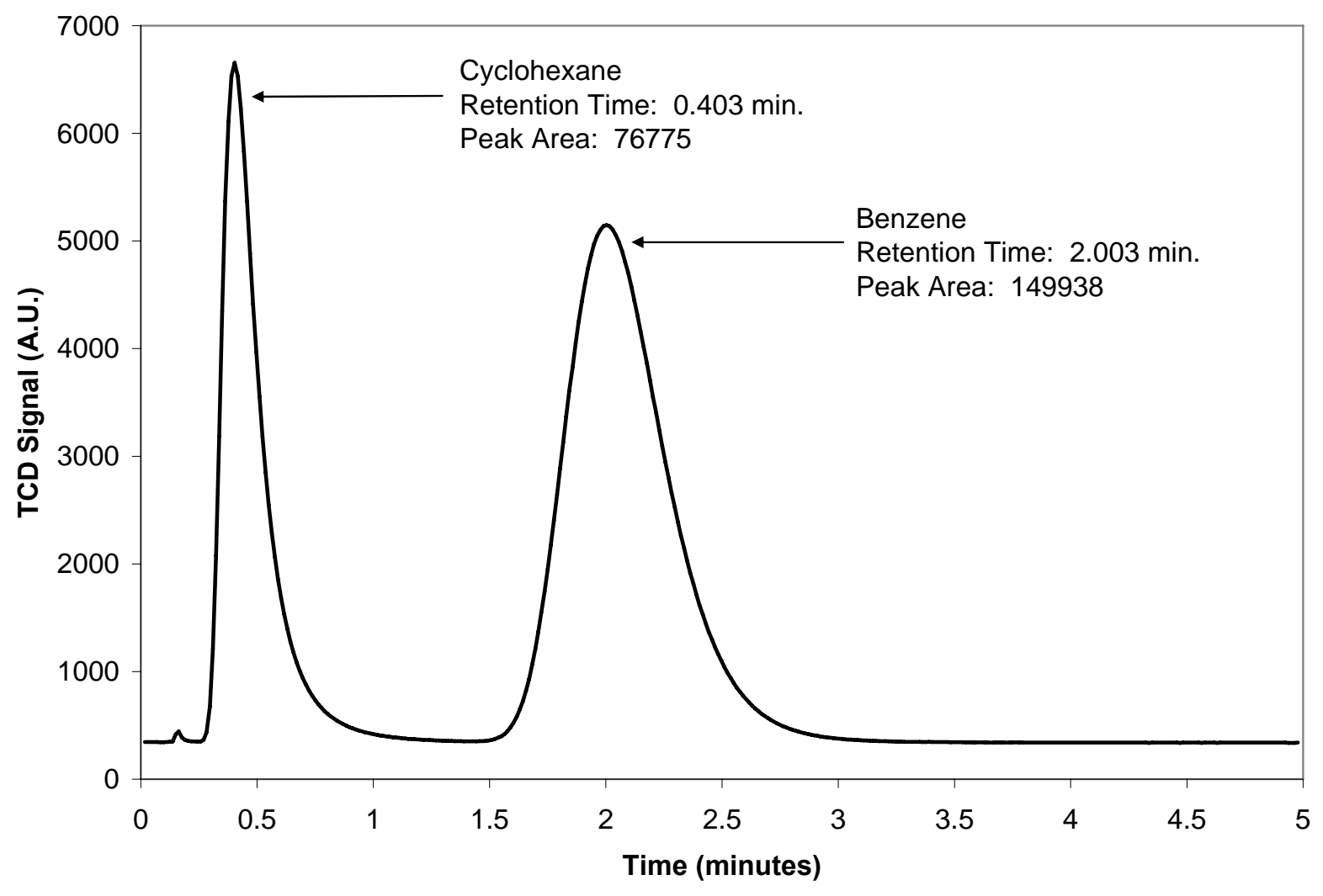

Figure 28: Chromatograph of $1 \mu \mathrm{L}$ injection of a $1 / 1$ mixture of benzene and cyclohexane, where the GC oven was kept isothermal at $120^{\circ} \mathrm{C}$ and data was collected for $5 \mathrm{~min}$. 


\section{Appendix C: XRD Calibrations}

In this appendix $\mathrm{LaBa}_{6}$ standards run for X7B distance and wavelength calibrations for data collected in: October 2003, March 2004, April 2004, and August 2005, is provided. This data is used in the integration of a circular diffraction image, as seen in Figure 2, to the standard 2-dimensional XRD pattern (Intensity vs. 20) (34).

Table 2: Data Collected through the Analysis of a $\mathrm{LaBa}_{6}$ Standard to Calibrate Experimental Conditions for XRD data Collected at NSLS.

\begin{tabular}{|c|c|c|c|c|c|c|c|c|}
\hline & \multicolumn{2}{|l|}{$10 / 2003$} & \multicolumn{2}{|l|}{$3 / 2004$} & \multicolumn{2}{|l|}{$4 / 2004$} & \multicolumn{2}{|l|}{$8 / 2005$} \\
\hline Sum of Squares & & 4.0471 & & 8.4712 & & 15.907 & & 0.044527 \\
\hline $\begin{array}{l}\text { Number of } \\
\text { Rejected } \\
\text { Coordinates }\end{array}$ & & 0 & & 0 & & 0 & & 0 \\
\hline $\begin{array}{l}\text { Refined Beam } \\
\text { Center (Pixels) }\end{array}$ & 1169.090 & 1153.449 & 1169.535 & 1155.183 & 1169.768 & 1152.535 & 1164.453 & 1153.268 \\
\hline $\begin{array}{l}\text { Refined Beam } \\
\text { Center (mm) }\end{array}$ & 175.364 & 173.017 & 175.430 & 173.277 & 175.465 & 172.880 & 174.668 & 172.990 \\
\hline $\begin{array}{l}\text { Refined Sample } \\
\text { to Detector } \\
\text { Distance }(\mathrm{mm})\end{array}$ & & 145.240 & & 148.324 & & 167.763 & & 152.321 \\
\hline $\begin{array}{l}\text { Refined } \\
\text { Wavelength (Á) }\end{array}$ & & 0.92246 & & 0.92130 & & 0.92233 & & 0.92042 \\
\hline Energy (keV) & & 13.44075 & & 13.45765 & & 13.44268 & & 13.47057 \\
\hline $\begin{array}{l}\text { Refined Tilt Plane } \\
\text { Rotation Angle }\left({ }^{\circ}\right)\end{array}$ & & 126.960 & & -61.278 & & -69.676 & & 142.716 \\
\hline $\begin{array}{l}\text { Refined Tilt } \\
\left.\text { Angle ( }{ }^{\circ}\right)\end{array}$ & & 0.161 & & -0.223 & & -0.206 & & 0.144 \\
\hline $\operatorname{ROT} X\left(^{\circ}\right)$ & & -0.090 & & -0.107 & & -0.072 & & -0.115 \\
\hline $\operatorname{ROT} Y\left(^{\circ}\right)$ & & 0.133 & & 0.195 & & 0.193 & & 0.087 \\
\hline $\begin{array}{l}\text { Stability } \\
\text { Indicator } \\
\text { (proportional to } \\
\text { D-spacing; } \\
\text { Angstroms) }\end{array}$ & & 1.55327 & & 1.57611 & & 1.73669 & & 1.60687 \\
\hline
\end{tabular}




\section{Appendix D: Benzene Hydrogenation and CO Chemisorption Data and Calculations}

This appendix provides calculations and raw data for benzene hydrogenation and $\mathrm{CO}$ chemisorption experiments.

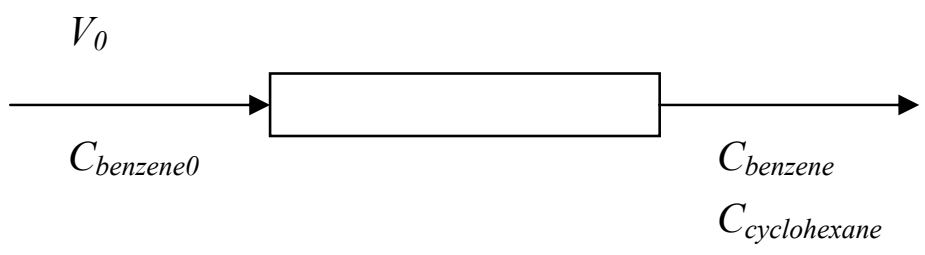

\section{Known Values:}

$P_{\text {benzene }}^{*}=32.44 \mathrm{~mm} \mathrm{Hg}$

$V_{0}=34 \frac{\mathrm{mL}}{\min }$

$W=$ varies with catalyst tested, but known

Thermal Response $_{\text {benzene }}=100$ - from Dietz (43)

Thermal Response cyclohexane $=114$ - from Dietz (43)

$T_{s}=274 \mathrm{~K}$

$[S]_{P_{t / A l_{2} O_{3}}}=111 \frac{\mu \mathrm{mol}}{\mathrm{g}-\text { catalyst }}$

Measured Variables:

TCD Peak Area benzene $_{1}$

TCD Peak Area $a_{\text {cyclohexane }}$

\section{Gas Constant Used:}

$R=82.057 \frac{\mathrm{ml}-\mathrm{atm}}{\mathrm{mol}-\mathrm{K}}$

Finding Initial Benzene Concentration: 
$C_{\text {benzene } 0}=\frac{P^{*}}{R T_{s}}$

Finding Outlet Benzene Concentration by Gas Chromatograph:

$y_{\text {benzene }}=\frac{C_{\text {benzene }}}{\left(C_{\text {benzene }}+C_{\text {cyclohexane }}\right)}=\frac{R F_{\text {benzene }}}{\left(R F_{\text {benzene }}+R F_{\text {cyclohexane }}\right)}-$ from Dietz, Fogler $(43,40)$

$R F=\frac{T C D \text { Peak Area }}{\text { Thermal Response }}-$ from Dietz (43)

Assuming 100\% Carbon Balance and a differential reactor model (conversion $<15 \%$ ):

$X_{\text {benzene }}=\frac{1-y_{\text {benzene }}}{y_{\text {benzene }} \varepsilon+1}$

$\varepsilon=\delta y_{\text {benzene } 0}$

$\delta=$ Stoichiometric Coefficients of Products - Stoichiometric Coefficients of Reactants $=-3$

$y_{\text {benzene0 }}=\frac{C_{\text {benzene0 }} R T_{\text {ambient }}}{P_{\text {ambient }}}$

$-r_{\text {benzene }}=\frac{X_{\text {benzene }} C_{\text {benzene } 0} V_{0}}{W}-$ from Fogler (40)

$T O F=\frac{-r_{\text {benzene }}}{[S]}-$ from Fogler $(40)$

Since we know $[S]_{P t / A l 2 O 3}, \mathrm{TOF}_{\mathrm{Pt} / \mathrm{Al} 2 \mathrm{O} 3}$ can be found:

$T O F_{P t / A l_{2} O_{3}}=\frac{\left(-r_{\text {benzene }}\right)_{P t / A l_{2} O_{3}}}{[S]_{P t / A l_{2} O_{3}}}$

Assuming that TOF is constant for benzene hydrogenation on all catalysts, $[\mathrm{S}]_{\mathrm{Mo} / \mathrm{C}}$ can be found:

$[S]_{M o / C}=\frac{\left(-r_{\text {benzene }}\right)_{M o / C}}{T O F_{P t / A l_{2} O_{3}}}$ 
Table 3: Raw Gas Chromatograph Data for Benzene Hydrogenation tested on Mo/C reduced in $\mathrm{UHP} \mathrm{H}_{2}$ to $675^{\circ} \mathrm{C}$ at $10^{\circ} \mathrm{C} / \mathrm{min}$, then held at $675^{\circ} \mathrm{C}$ for 15 minutes

\begin{tabular}{|c|c|c|}
\hline Time on Stream (min.) & Cyclohexane TCD Peak Area & Benzene TCD Peak Area \\
\hline 12.00 & 1574 & 410130 \\
\hline 20.50 & 1575 & 395460 \\
\hline 30.25 & 3061 & 329886 \\
\hline 35.50 & 1280 & 397047 \\
\hline 54.00 & 1223 & 356783 \\
\hline
\end{tabular}

Table 4: Raw Gas Chromatograph Data for Benzene Hydrogenation tested on Mo/C reduced in $\mathrm{UHP} \mathrm{H}_{2}$ to $725^{\circ} \mathrm{C}$ at $10^{\circ} \mathrm{C} / \mathrm{min}$, then held at $725^{\circ} \mathrm{C}$ for 15 minutes

\begin{tabular}{|c|c|c|}
\hline Time on Stream (min.) & Cyclohexane TCD Peak Area & Benzene TCD Peak Area \\
\hline 9.00 & 10682 & 403251 \\
\hline 18.00 & 8277 & 408328 \\
\hline 36.50 & 7235 & 378942 \\
\hline 42.00 & 7302 & 372981 \\
\hline 48.00 & 6019 & 367499 \\
\hline 64.50 & 3921 & 367740 \\
\hline 85.00 & 2577 & 363060 \\
\hline 103.25 & 1240 & 360758 \\
\hline 120.00 & 875 & 424706 \\
\hline
\end{tabular}

Table 5: Raw Gas Chromatograph Data for Benzene Hydrogenation tested on Mo/C reduced in $\mathrm{UHP} \mathrm{H}_{2}$ to $775^{\circ} \mathrm{C}$ at $10^{\circ} \mathrm{C} / \mathrm{min}$, then held at $775^{\circ} \mathrm{C}$ for 15 minutes

\begin{tabular}{|c|c|c|}
\hline Time on Stream (min.) & Cyclohexane TCD Peak Area & Benzene TCD Peak Area \\
\hline 10.00 & 23667 & 380848 \\
\hline 23.75 & 12710 & 393037 \\
\hline 41.75 & 10753 & 392546 \\
\hline 58.00 & 10305 & 373181 \\
\hline 78.00 & 7834 & 415611 \\
\hline 120.00 & 4866 & 410296 \\
\hline
\end{tabular}

Table 6: Raw Gas Chromatograph Data for Benzene Hydrogenation tested on Mo/C reduced in $\mathrm{UHP} \mathrm{H}_{2}$ to $825^{\circ} \mathrm{C}$ at $10^{\circ} \mathrm{C} / \mathrm{min}$, then held at $825^{\circ} \mathrm{C}$ for 0 minutes

\begin{tabular}{|c|c|c|}
\hline Time on Stream (min.) & Cyclohexane TCD Peak Area & Benzene TCD Peak Area \\
\hline 10.00 & 45702 & 324129 \\
\hline 22.00 & 15759 & 377022 \\
\hline 46.00 & 5619 & 425333 \\
\hline 59.25 & 3867 & 431511 \\
\hline
\end{tabular}


Table 7: Raw Gas Chromatograph Data for Benzene Hydrogenation tested on Mo/C reduced in $\mathrm{UHP} \mathrm{H}_{2}$ to $825^{\circ} \mathrm{C}$ at $10^{\circ} \mathrm{C} / \mathrm{min}$, then held at $825^{\circ} \mathrm{C}$ for 15 minutes

\begin{tabular}{|c|c|c|}
\hline Time on Stream (min.) & Cyclohexane TCD Peak Area & Benzene TCD Peak Area \\
\hline 10.00 & 40271 & 347487 \\
\hline 25.75 & 34037 & 336843 \\
\hline 45.75 & 28625 & 336960 \\
\hline 60.75 & 20376 & 412885 \\
\hline 74.50 & 23776 & 332521 \\
\hline 120.00 & 16648 & 387253 \\
\hline
\end{tabular}

Table 8: Raw Gas Chromatograph Data for Benzene Hydrogenation tested on $\mathrm{Mo} / \mathrm{C}$ reduced in $\mathrm{UHP} \mathrm{H}_{2}$ to $825^{\circ} \mathrm{C}$ at $10^{\circ} \mathrm{C} / \mathrm{min}$, then held at $825^{\circ} \mathrm{C}$ for 30 minutes

\begin{tabular}{|c|c|c|}
\hline Time on Stream (min.) & Cyclohexane TCD Peak Area & Benzene TCD Peak Area \\
\hline 10.50 & 3237 & 390515 \\
\hline 32.75 & 995 & 435798 \\
\hline 46.25 & 1081 & 380210 \\
\hline 62.00 & 783 & 453991 \\
\hline
\end{tabular}

Table 9: Raw Gas Chromatograph Data for Benzene Hydrogenation Data tested on Mo/C reduced in $\mathrm{UHP} \mathrm{H}_{2}$ to $825^{\circ} \mathrm{C}$ at $10^{\circ} \mathrm{C} / \mathrm{min}$, then held at $825^{\circ} \mathrm{C}$ for 60 minutes

\begin{tabular}{|c|c|c|}
\hline Time on Stream (min.) & Cyclohexane TCD Peak Area & Benzene TCD Peak Area \\
\hline 11.00 & 0 & 415599 \\
\hline 16.00 & 0 & 406853 \\
\hline
\end{tabular}

Table 10: Raw Gas Chromatograph Data for Benzene Hydrogenation Data tested on Mo/C reduced in $\mathrm{UHP} \mathrm{H}_{2}$ to $875^{\circ} \mathrm{C}$ at $10^{\circ} \mathrm{C} / \mathrm{min}$, then held at $875^{\circ} \mathrm{C}$ for 15 minutes

\begin{tabular}{|c|c|c|}
\hline Time on Stream (min.) & Cyclohexane TCD Peak Area & Benzene TCD Peak Area \\
\hline 10.50 & 12235 & 390361 \\
\hline 29.50 & 2140 & 443576 \\
\hline 44.50 & 910 & 379648 \\
\hline 60.50 & 431 & 371463 \\
\hline
\end{tabular}


Table 11: Raw Benzene Hydrogenation Data for $\mathrm{Pt} / \mathrm{Al}_{2} \mathrm{O}_{3}$ reduced in $\mathrm{UHP} \mathrm{H}_{2}$ to $425^{\circ} \mathrm{C}$ at $10^{\circ} \mathrm{C} /$ min, then held at $875^{\circ} \mathrm{C}$ for 0 minutes

\begin{tabular}{|c|c|c|}
\hline Time on Stream (min.) & Cyclohexane TCD Peak Area & Benzene TCD Peak Area \\
\hline 12.50 & 14149 & 391179 \\
\hline 33.25 & 17856 & 384264 \\
\hline 48.25 & 18686 & 382485 \\
\hline 63.25 & 17653 & 381567 \\
\hline
\end{tabular}

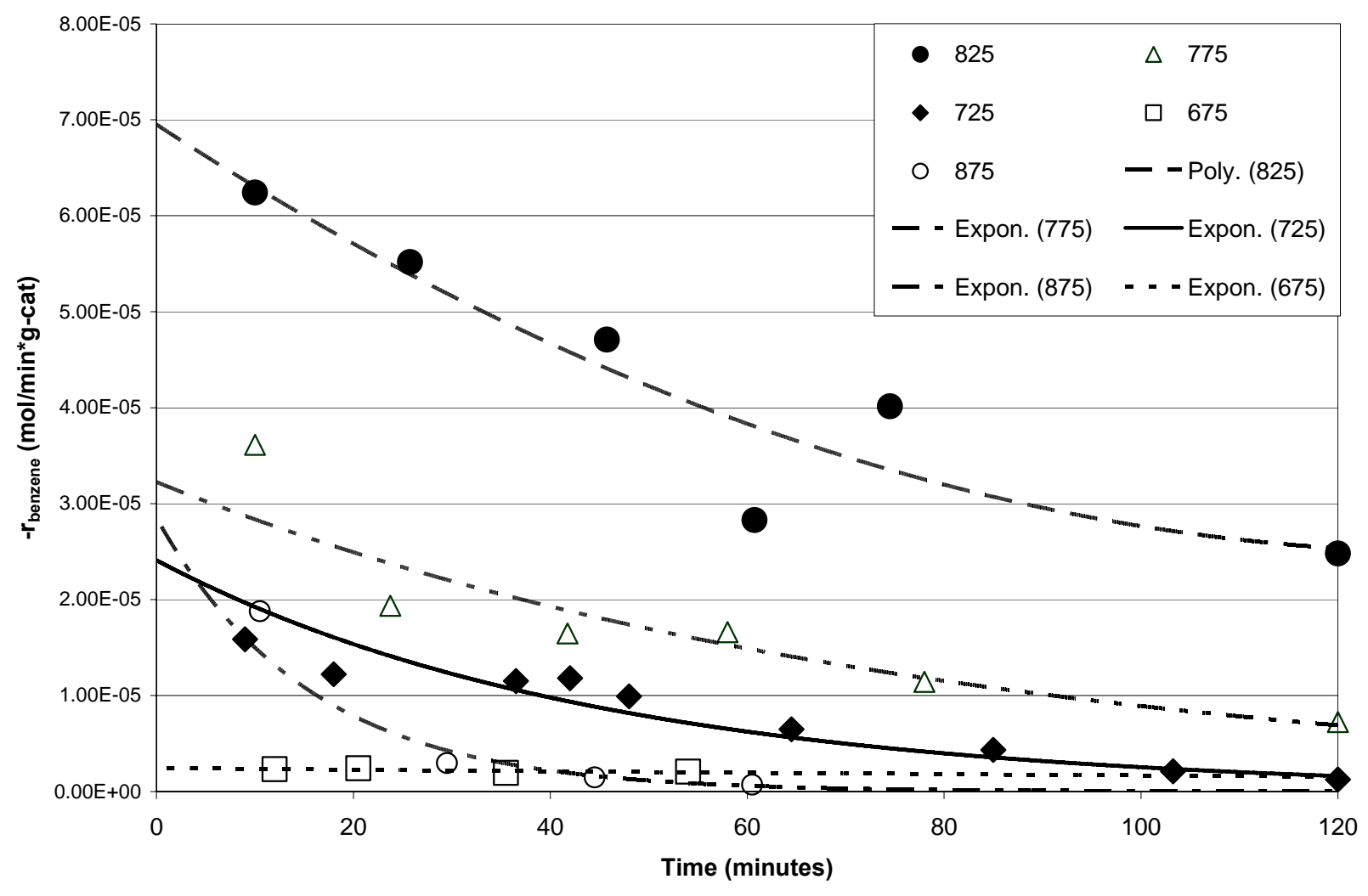

Figure 29: Effect of time-on-stream on the rate of disappearance of benzene for $\mathrm{Mo} / \mathrm{C}$ catalysts with varying final reduction temperature with exponential curve fitting to find initial rate of benzene disappearance 


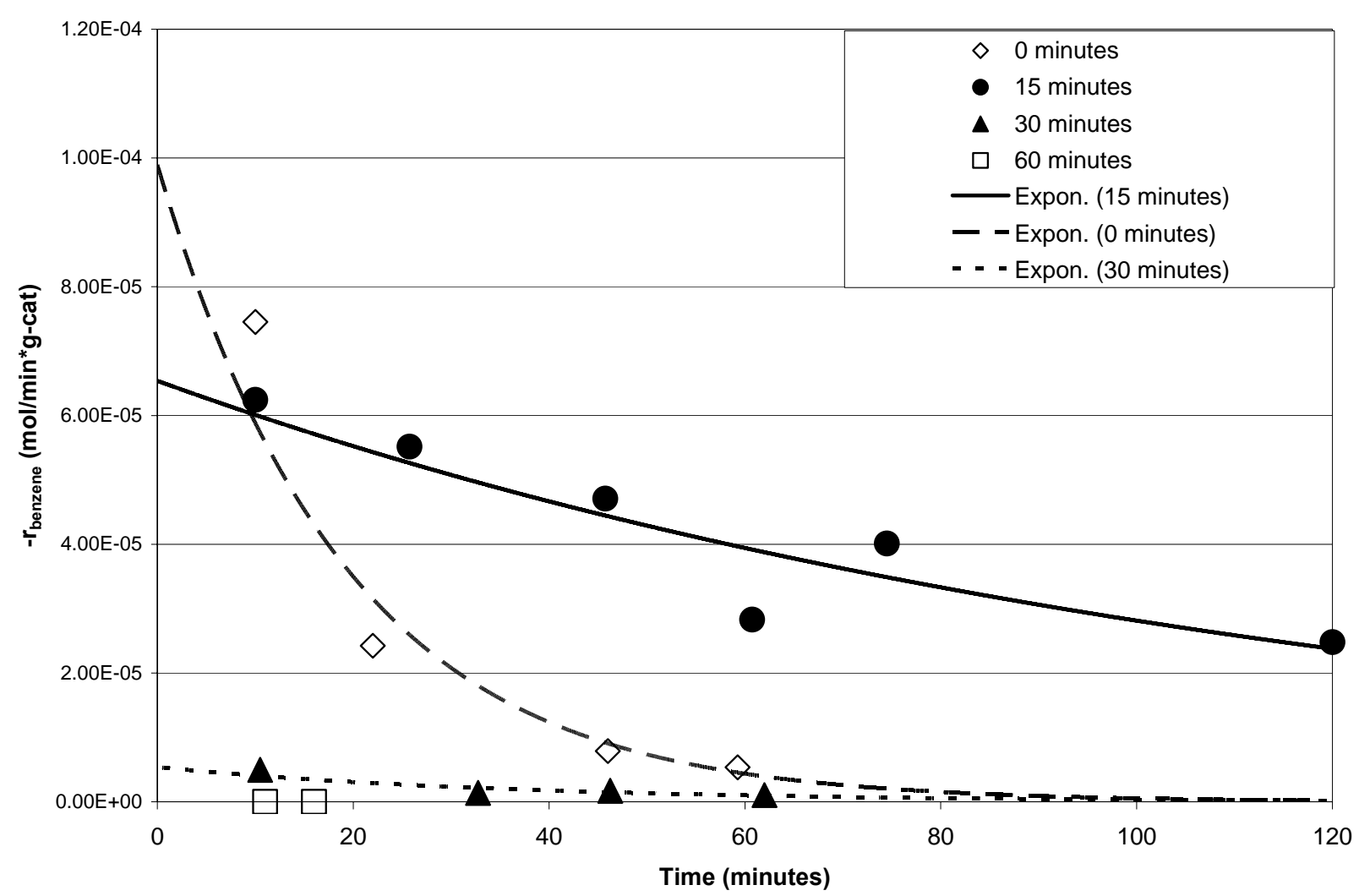

Figure 30: Effect of time on stream on rate of disappearance of benzene for $\mathrm{Mo} / \mathrm{C}$ catalysts with varying soak time at final reduction temperature $\left(825^{\circ} \mathrm{C}\right)$ with exponential curve fitting to find in rate of benzene disappearance 


\section{Appendix E: XRD Analysis of Spent Benzene Hydrogenation Catalysts}

Analysis of XRD patterns of spent catalysts found to have benzene hydrogenation activity will be provided in this appendix. 


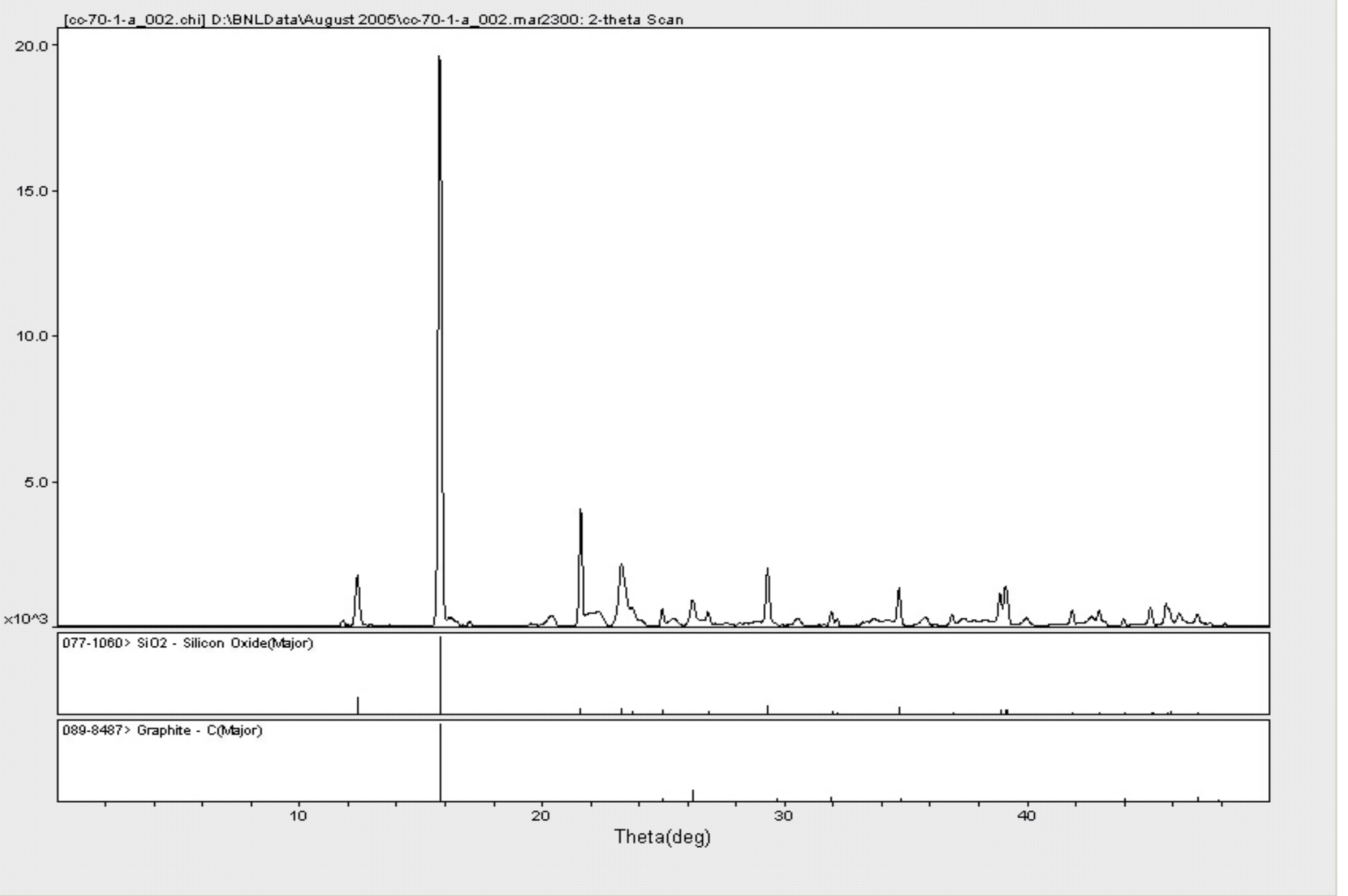

Figure 31: XRD pattern of Mo/C catalyst tested for benzene hydrogenation, catalyst was reduced at $675^{\circ} \mathrm{C}$ and held at $675^{\circ} \mathrm{C}$ for 15 minutes 


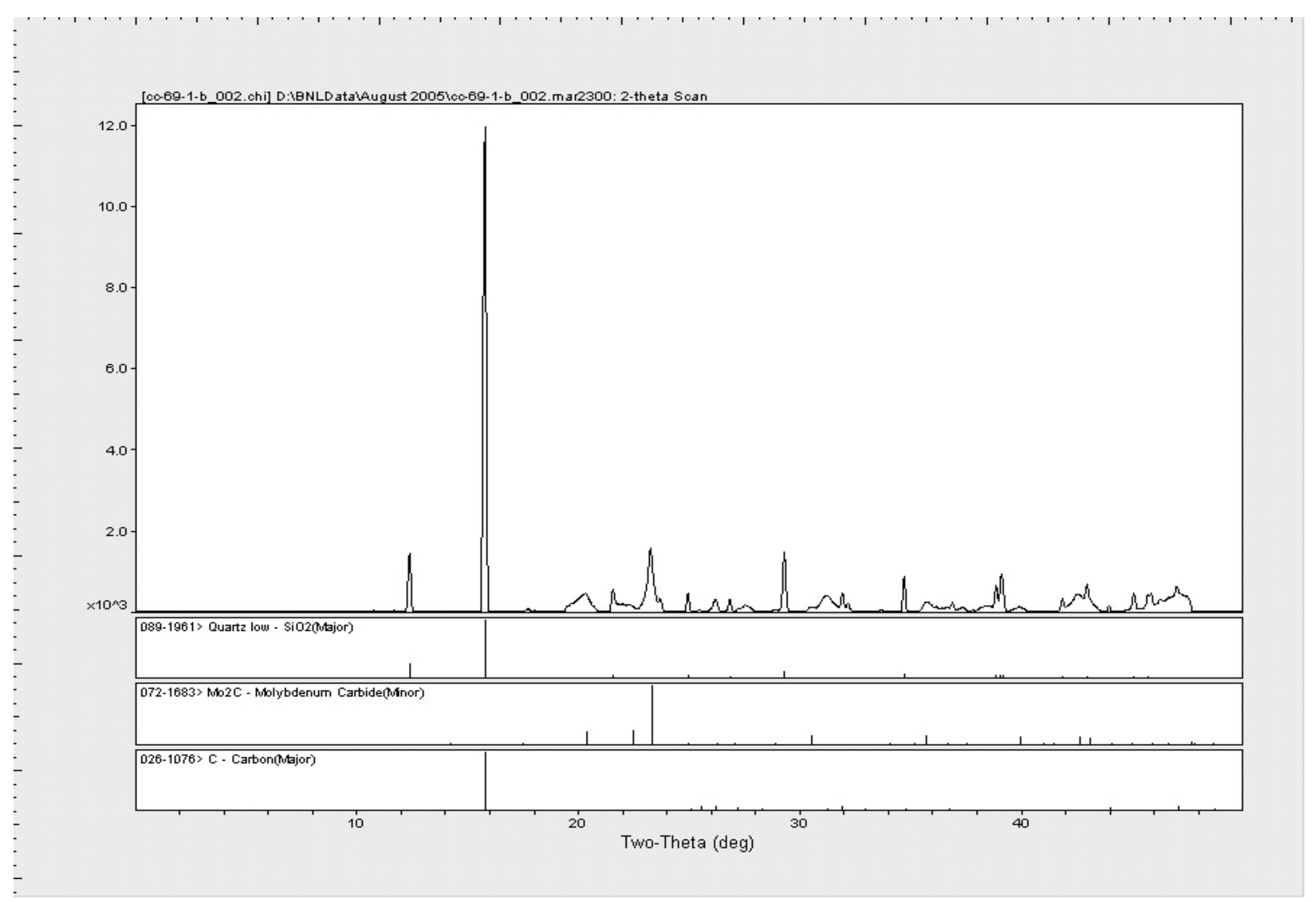

Figure 32: XRD pattern of Mo/C catalyst tested for benzene hydrogenation, catalyst was reduced at $725^{\circ} \mathrm{C}$ and held at $725^{\circ} \mathrm{C}$ for 15 minutes 


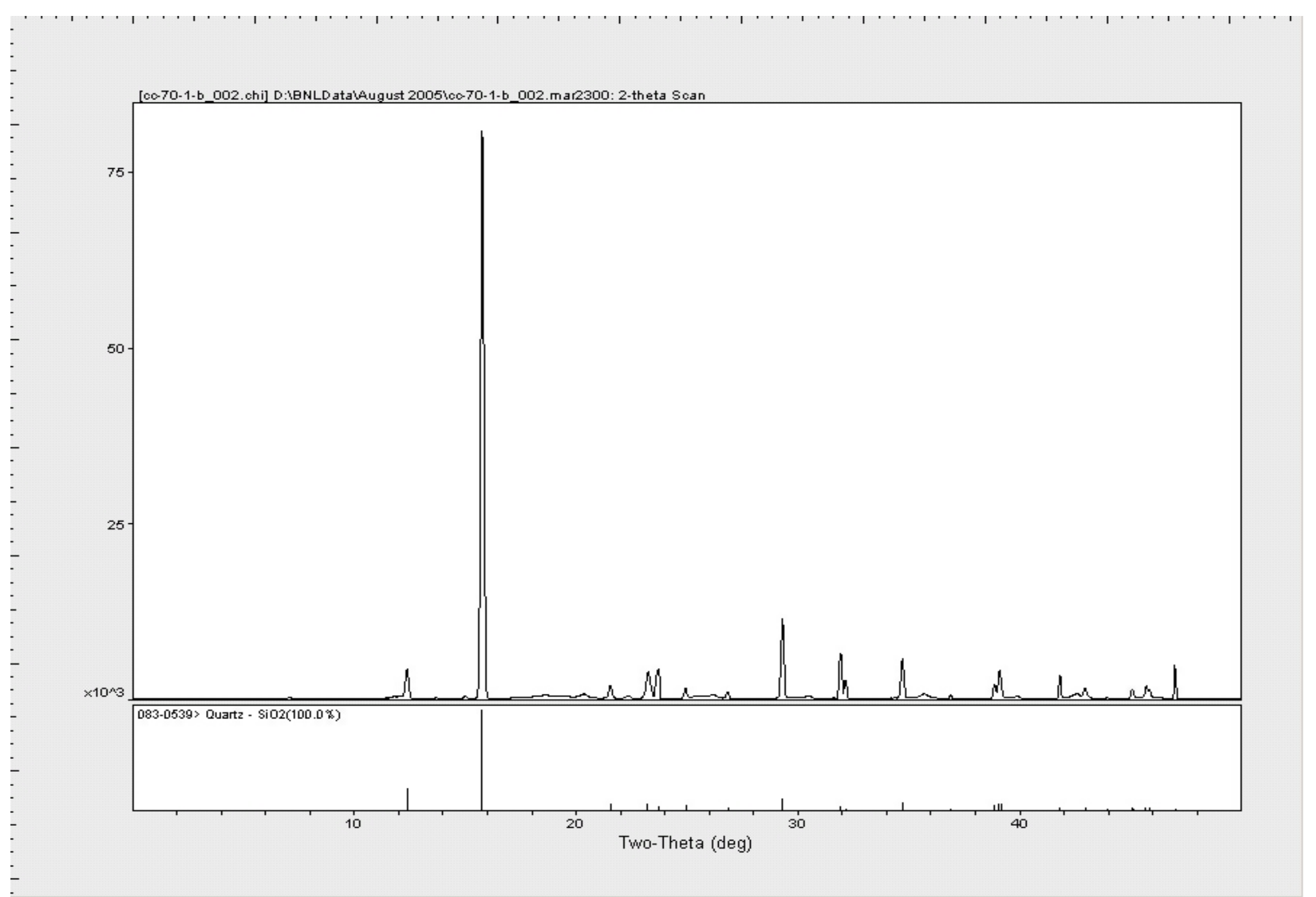

Figure 33: XRD pattern of Mo/C catalyst tested for benzene hydrogenation, catalyst was $\operatorname{Reduced}$ at $775^{\circ} \mathrm{C}$ and held at $775^{\circ} \mathrm{C}$ for 15 minutes 


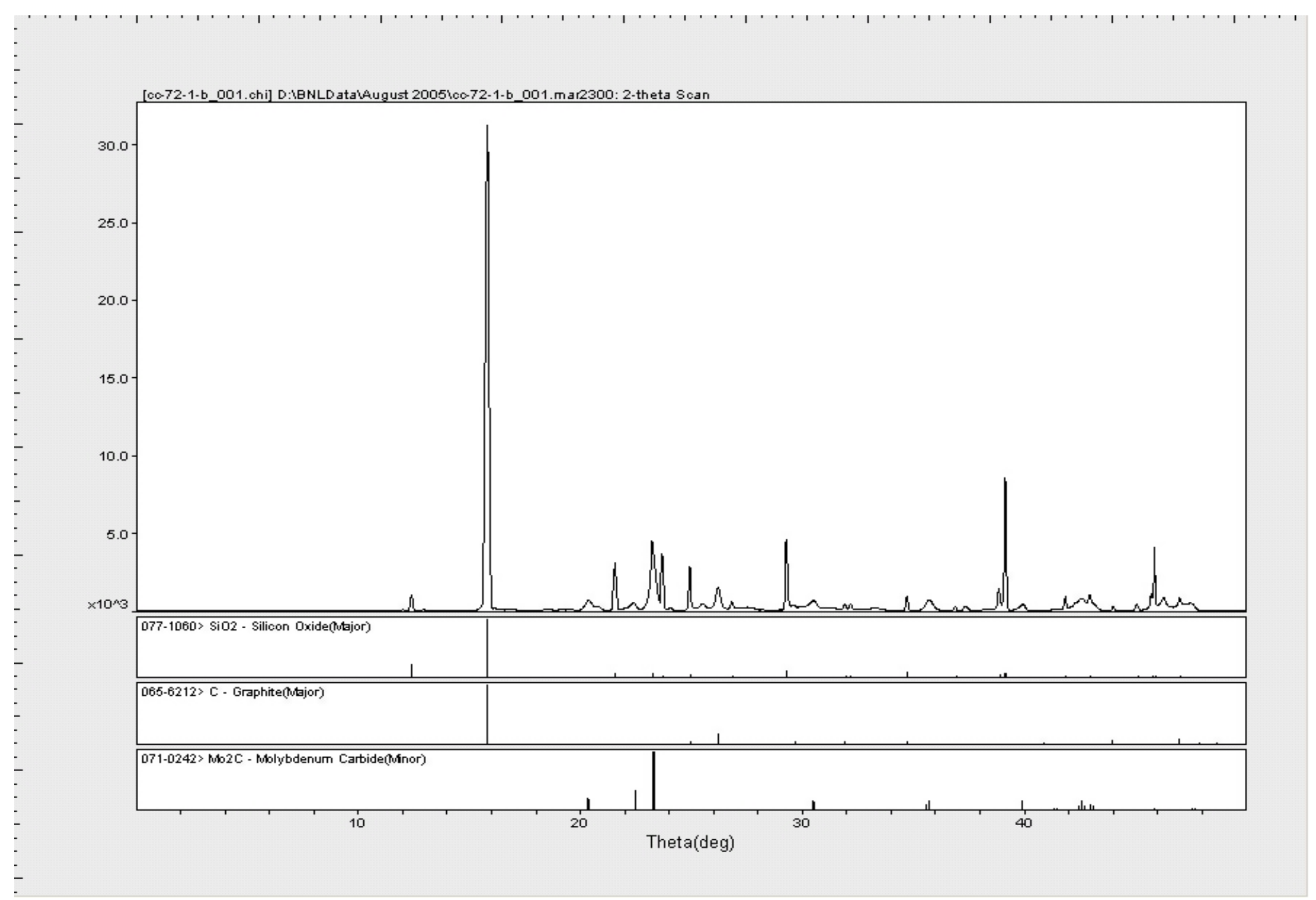

Figure 34: XRD pattern of Mo/C catalyst tested for benzene hydrogenation, catalyst was reduced at $825^{\circ} \mathrm{C}$ and held at $825^{\circ} \mathrm{C}$ for 0 minutes 


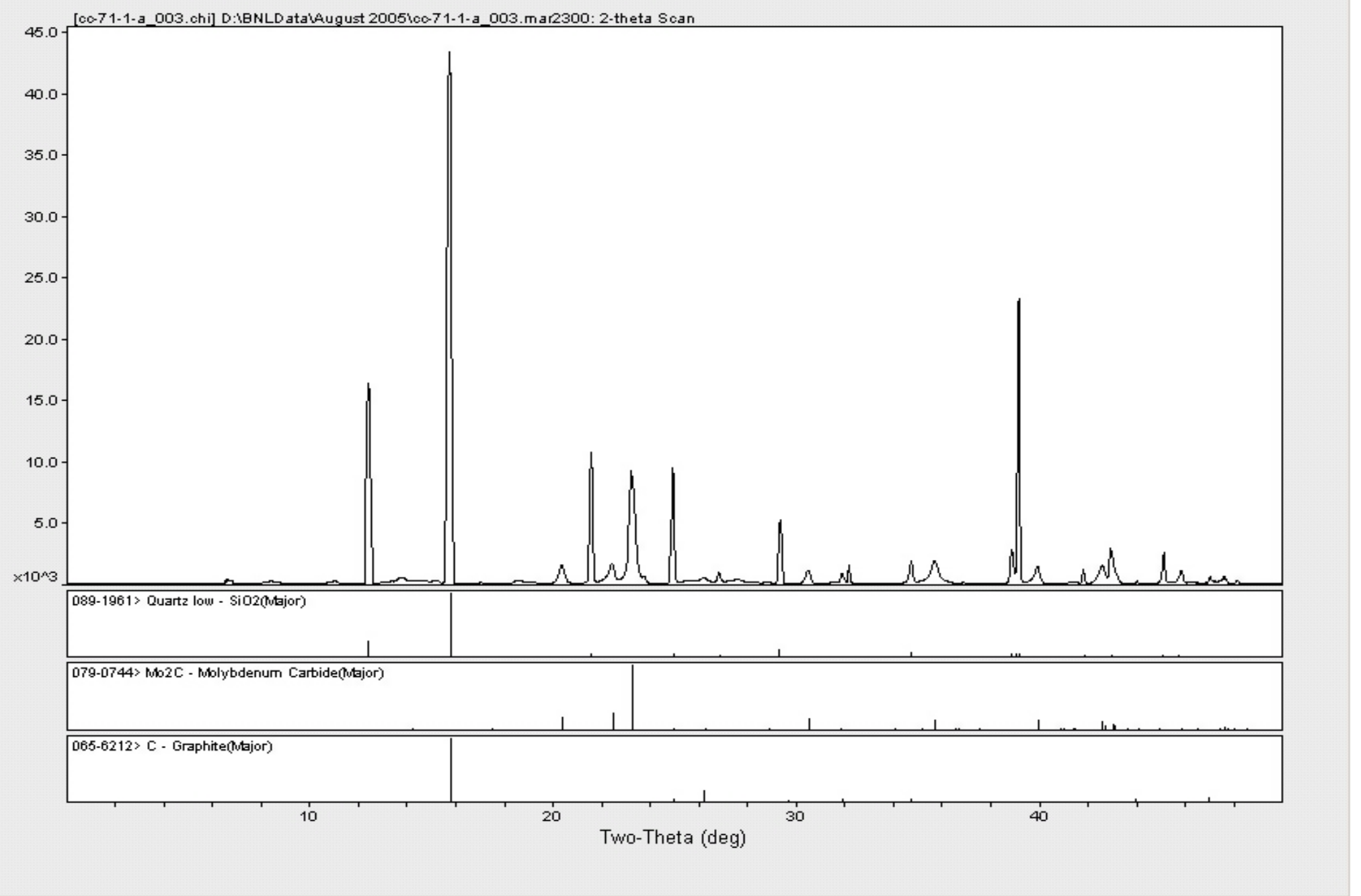

Figure 35: XRD pattern of Mo/C catalyst tested for benzene hydrogenation, catalyst was reduced at $825^{\circ} \mathrm{C}$ and held at $825^{\circ} \mathrm{C}$ for 15 minutes 


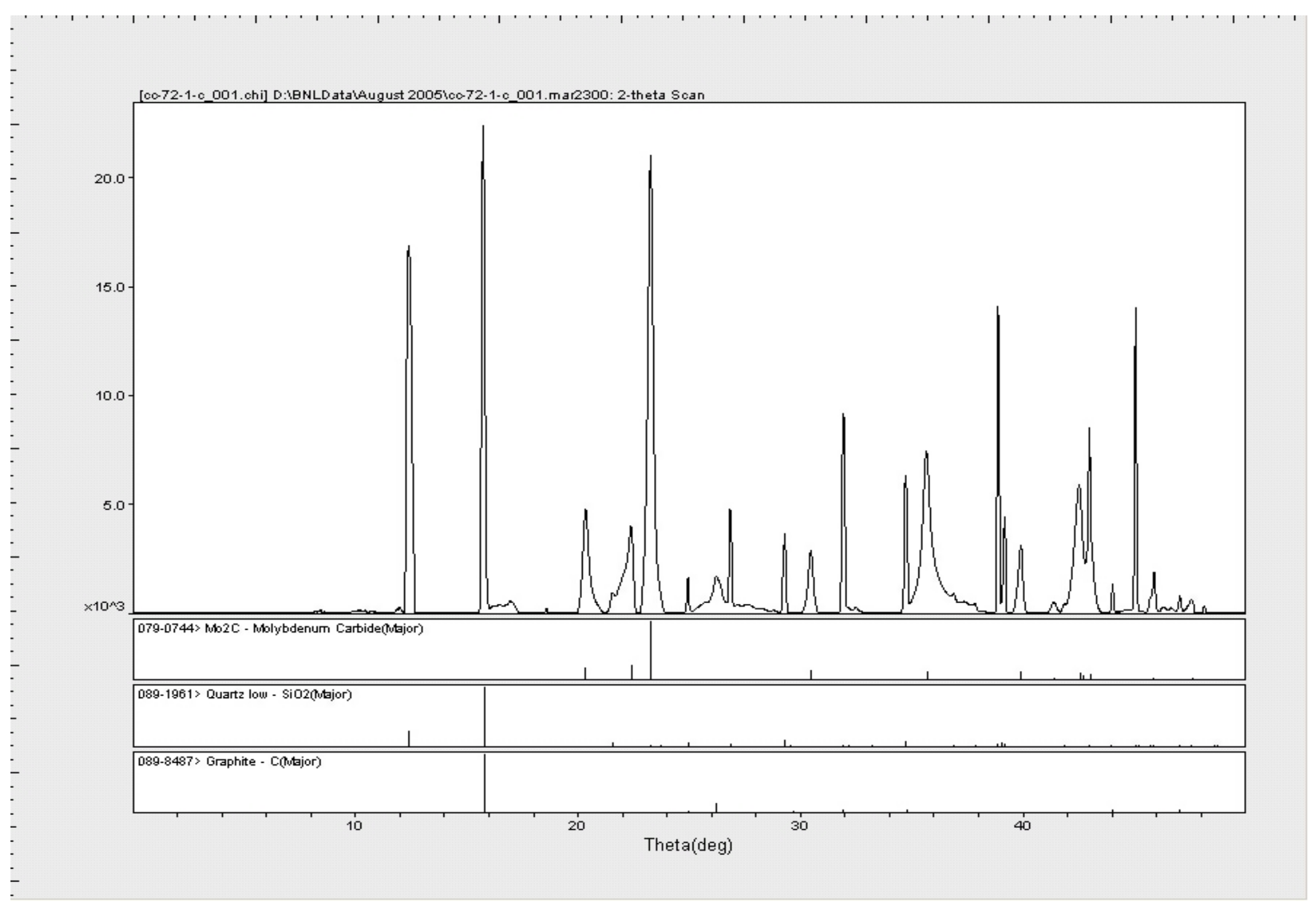

Figure 36: XRD pattern of Mo/C catalyst tested for benzene hydrogenation, catalyst was reduced at $825^{\circ} \mathrm{C}$ and held at $825^{\circ} \mathrm{C}$ for 30 minutes 


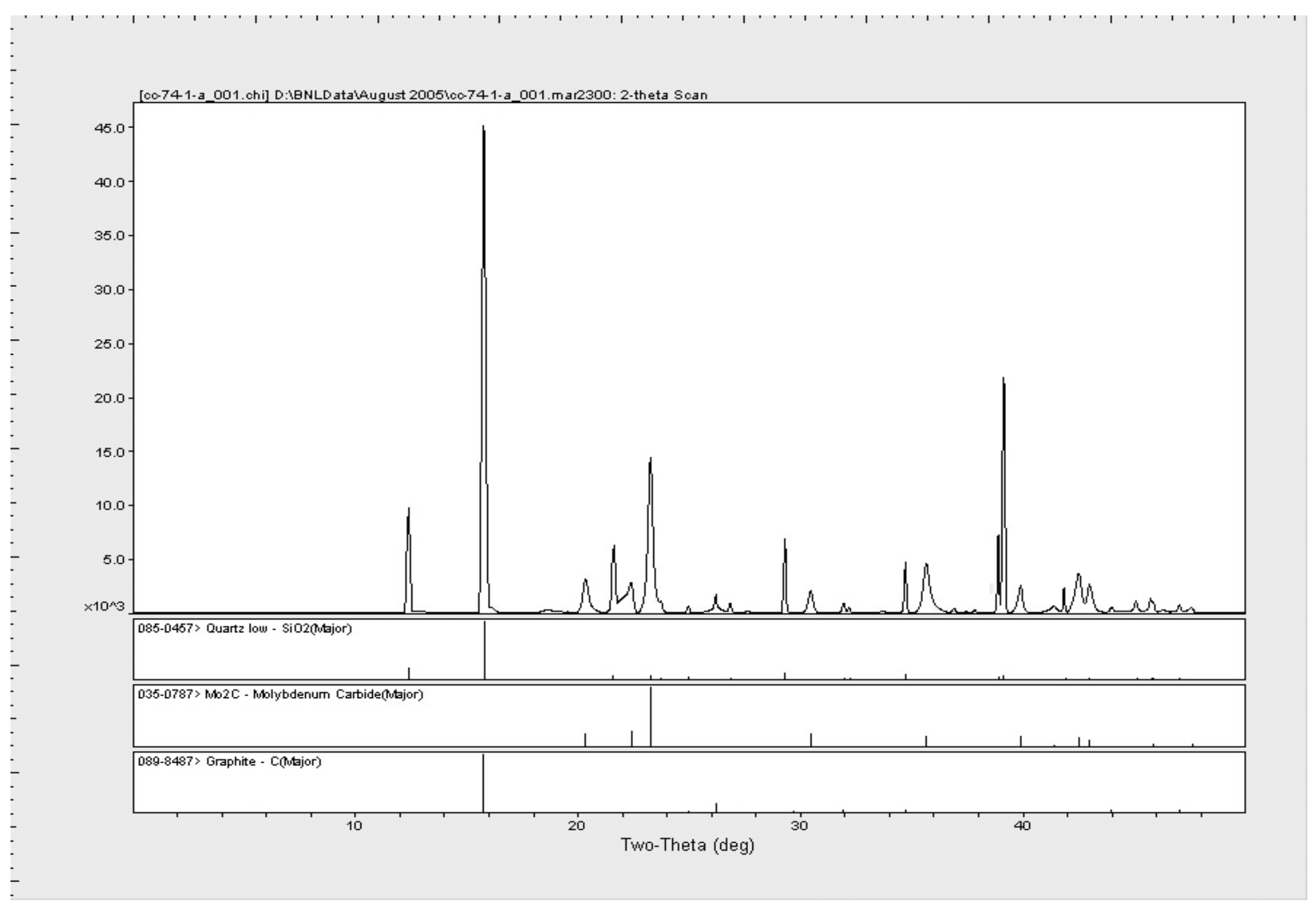

Figure 37: XRD pattern of Mo/C catalyst tested for benzene hydrogenation, catalyst was reduced at $825^{\circ} \mathrm{C}$ and held at $825^{\circ} \mathrm{C}$ for 60 minutes 


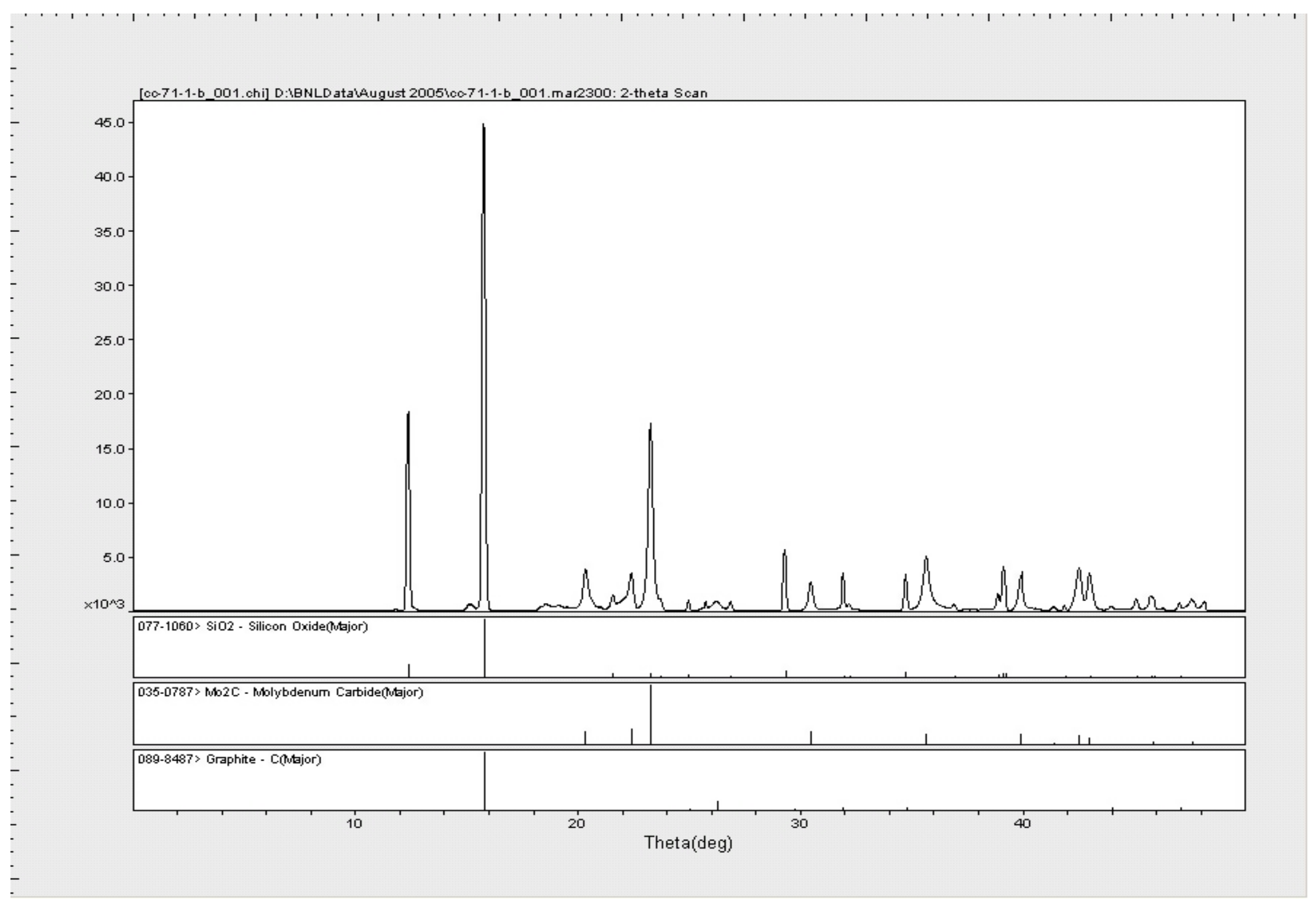

Figure 38: XRD Pattern of Mo/C catalyst tested for benzene hydrogenation, catalyst was reduced at $875^{\circ} \mathrm{C}$ and held at $875^{\circ} \mathrm{C}$ for 15 minutes 


\section{Appendix F: Reaction Equilibrium Calculations}

Detailed calculations involving the equilibrium between $\mathrm{CO}$ and $\mathrm{CO}_{2}$ during the transition from $\mathrm{MoO}_{2}$ to $\mathrm{Mo}_{2} \mathrm{C}$, described in Section 4.4.

$$
\begin{aligned}
& \mathrm{CO}_{2}+C \Leftrightarrow 2 C O \\
& \Delta G_{r}=2\left(\Delta G_{f}\right)_{\mathrm{CO}_{2}}-\left(\Delta G_{f}\right)_{C O} \\
& \Delta G_{r}=-R T \ln \left(K_{a}\right) \\
& K_{a}=\frac{\left(y_{C O}\right)^{2} P}{y_{\mathrm{CO}_{2}}}
\end{aligned}
$$

Table 12: Gibbs' Energy of Formation and Reaction from Yaws' Handbook for $\mathrm{CO}$ and $\mathrm{CO}_{2}(41)$

\begin{tabular}{|r|r|r|r|}
\hline $\mathbf{T}(\mathbf{K})$ & $\boldsymbol{\Delta G}_{\mathbf{f}, \mathbf{C O} \mathbf{( k J} / \mathbf{m o l})}$ & $\left.\boldsymbol{\Delta} \mathbf{G}_{\mathbf{f}, \mathbf{C o}} \mathbf{( k J / m o l}\right)$ & $\boldsymbol{\Delta G}_{\mathbf{r}}(\mathbf{k J} / \mathbf{m o l})$ \\
\hline 700 & -393.06 & -172.659 & 47.742 \\
\hline 800 & -392.97 & -181.573 & 29.824 \\
\hline 900 & -392.87 & -190.476 & 11.918 \\
\hline 1000 & -392.76 & -199.367 & -5.974 \\
\hline 1100 & -392.63 & -208.247 & -23.864 \\
\hline 1200 & -392.50 & -217.115 & -41.600 \\
\hline
\end{tabular}

